\title{
LA ECONOMÍA SOCIAL ARAGONESA. UN MOTOR DE DESARROLLO
}

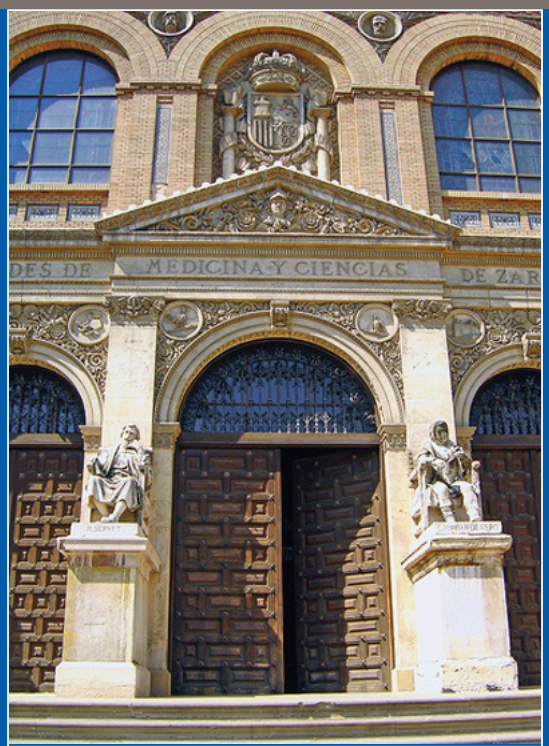

\section{Actas de las I Jornadas de la Economía Social en Aragón}

Carmen Marcuello Servós (Compiladora)

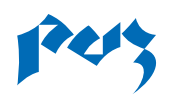

Prensas Universitarias de Zaragoza 



\section{LA ECONOMÍA SOCIAL ARAGONESA. UN MOTOR DE DESARROLLO}





\title{
LA ECONOMÍA SOCIAL ARAGONESA. UN MOTOR DE DESARROLLO
}

Actas de las I Jornadas de la Economía Social en Aragón

\author{
Carmen Marcuello Servós
}

(Compiladora)

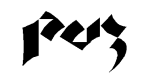

Prensas Universitarias de Zaragoza 
La ECONOMÍA social aragonesa : un motor de desarrollo : actas de las I Jornadas de la Economía Social en Aragón / Carmen Marcuello Servós (compiladora). Zaragoza : Prensas Universitarias de Zaragoza, 2009

238 p. ; $22 \mathrm{~cm}$

ISBN 978-84-92774-17-3

Economía social-Aragón-Congresos y asambleas

MARCUELLO SERVÓS, Carmen

334.012.44(460.22)(063)

Cualquier forma de reproducción, distribución, comunicación pública o transformación de esta obra solo puede ser realizada con la autorización de sus titulares, salvo excepción prevista por la ley. Diríjase a CEDRO (Centro Español de Derechos Reprográficos, www.cedro.org) si necesita fotocopiar o escanear algún fragmento de esta obra.

(C) Los autores

(C) De la presente edición, Prensas Universitarias de Zaragoza

$1 .^{\text {a }}$ edición, 2009

Prensas Universitarias de Zaragoza. Edificio de Ciencias Geológicas, c/ Pedro Cerbuna, 12 50009 Zaragoza, Espańa. Tel.: 976761 330. Fax: 976761063

puz@unizar.es http://puz.unizar.es

Prensas Universitarias de Zaragoza es la editorial de la Universidad de Zaragoza, que edita e imprime libros desde su fundación en 1542.

Impreso en España

Imprime: Servicio de Publicaciones. Universidad de Zaragoza

D. L.: Z-3054-2009 


\section{Comité Organizador}

MARISA Esteve, Asociación Aragonesa de Empresas de Inserción (AREI)

Eduardo Romero, Asociación Aragonesa de Sociedades Laborales (ASES)

Rosa Gállego, Asociación Española de Fundaciones

M. á ÁNGeles López, Comité de entidades Representantes de Personas con Discapacidad

(CERMI-Aragón)

Margarita LambÁn, Coordinadora Aragonesa de Voluntariado

Pilar Nogueras, Federación Aragonesa de Cooperativas Agrarias (FACA)

Pilar Villaverde, Federación Aragonesa de Cooperativas de Trabajo Asociado

(FACTA)

Carolina Marín, Federación Aragonesa de Cooperativas de Viviendas (FACOVI)

FERnANDo PÉrez, Federación Aragonesa de Solidaridad (FAS)

Ángel GutiÉrRez, Instituto Aragonés de Empleo (INAEM)

Javier Ortega, Red de Economía Alternativa y Solidaria-Aragón (REAS-Aragón)

MARisa EsteVe, Red Aragonesa de Entidades para la Inclusión

Pablo Herranz, Unión de Cooperativas de Enseñanza de Aragón (UCEA)

José LuIs Argudo, Universidad de Zaragoza

Millán Díaz Foncea, Universidad de Zaragoza-Grupo de investigación GESES José Antonio Domingo, Universidad de Zaragoza-Grupo de investigación GESES

CARmen Marcuello, Universidad de Zaragoza-Grupo de investigación GESES

\section{Apoyo técnico}

Ana Blanca Gracia Aldea, Universidad de Zaragoza

\section{Patrocinadores}

Instituto Aragonés de Empleo (INAEM), Dirección General de Participación Ciudadana, Gobierno de Aragón, Universidad de Zaragoza

\section{Colabora}

Caja Rural de Teruel

Zaragoza, Octubre 2008

$<$ http://geses.unizar.es/jornadaseconomiasocial> 



\section{Índice}

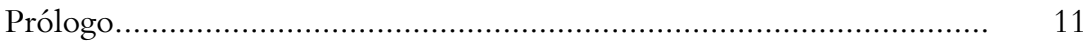

La Economía Social en Aragón. Carmen Marcuello .................................... 17

\section{MESA 1 \\ LA ECONOMÍA SOCIAL HOY. \\ UN MOTOR DE DESARROLLO}

Ámbito e identificación de los diferentes actores o grupos incluidos en el concepto de Economía Social. José Luis Monzón.

La configuración del sector empresarial de la Economía Social en España.

La Economía Social como motor de creación de empleo. Juan Antonio Pedreño

El Tercer Sector de Acción Social y la Economía Social. José Manuel Fresno

La Economía Social: dos décadas generando empleo, tejido productivo y cohesión social en Europa. Rafael Chaves.....

\section{MESA 2 \\ ANÁLISIS Y DIAGNÓSTICO \\ DE LA ECONOMÍA SOCIAL ARAGONESA}

Economía Social en Aragón (que no de Aragón). Luis Mena

Economía Social aragonesa desde la visión empresarial. Felipe Gómez de Valenzuela

Grupo 1. InSERCiÓN SOCIOLABORAL

Central de recursos para las empresas de inserción de AREI: Nuevas estructuras para la transformación social en Aragón. Asunción García Mainar

Fundación Agustín Serrate: Gestión del programa de rehabilitación de Salud Mental. Javier Borau

Modelo de formación ocupacional adaptada. M. Jesús Martínez 
Grupo 2. Desarrollo Local e INNOVACión EN LA GESTiÓn EMPRESARial

Desarrollo e Integración de Comunicaciones, SLL. Eduardo Romero Aladrén, José M. ${ }^{a}$ Andrés Navarrete y Jesús Pola

La gestión fundacional del patrimonio de Albarracín. La Fundación

Santa María de Albarracín. Antonio Jiménez Martínez

Grupo Pastores. Grupo Cooperativo. Antonio Aparicio

Tiebel Sociedad Cooperativa de Iniciativa Social. Marina Martínez, FACTA

Caja Rural de Teruel. José Antonio Pérez Cebrián

Grupo 3. PARTiCiPACión DEMOCRÁticA

Asociación Voluntariado de Geriatría: espacio propiciador de nuevas realidades participativas. María Ríos, Pilar Mesa y Mercedes Obis .........

Cooperativas de viviendas Victoria Martínez: La participación de los socios en las Cooperativas de Viviendas. Carolina Marín Andrés

COOP57 (Cooperativa de servicios financieros éticos y solidarios). Javier Ortega Díaz

Cooperativas de alumnos, UCEA-Aragón. Pablo Herranz

Grupos 2 y 3. Retos y oportunidAdes de la ECONOMÍA SOCIAL ARAGONESA

Retos y oportunidades de la Economía Social aragonesa. Marisa Esteve $y$ Ángel Gutiérrez 205

Participación democrática en las entidades de Economía Social. Chaime Marcuello

MESA 3

RETOS Y FUTURO DE LA ECONOMÍA SOCIAL

Retos y futuro de la Economía Social. Miguel Ángel Cabra de Luna........ 


\section{Prólogo}

En nombre del Instituto Aragonés de Empleo, que me honro en dirigir, deseo transmitir mi agradecimiento y felicitaciones a las entidades Aragonesas de la Economía Social, así como a las Instituciones Públicas participantes, que han hecho posible la celebración y el éxito rotundo de las Primeras Jornadas Aragonesas de Economía Social. Esperamos que esta iniciativa se siga repitiendo en años venideros, para lo cual siempre se podrá contar, como en esta ocasión, con el apoyo decidido de nuestro Instituto.

El INAEM participa directamente y tiene una importante misión en el sector de la Economía Social. De una parte, gestiona las ayudas directas a la creación de empleo, tanto para las empresas que tradicionalmente han pertenecido a este sector económico, como son las Cooperativas de Trabajo Asociado y las Sociedades Laborales, como para otras que del mismo modo participan de sus principios, entre ellas los Centros Especiales de Empleo, las Empresas de Inserción o incluso las Instituciones sin ánimo de lucro, principalmente asociaciones y fundaciones, tan necesarias en la actividad económica y social de nuestra comunidad. Anualmente, a través de los programas específicos de apoyo a las empresas y entidades de este sector, se ha venido gestionando y distribuyendo por el INAEM una cifra próxima a los once millones de euros, que suponen cerca del cuarenta por ciento de las cuantías destinadas de forma específica y concreta a la promoción del empleo. Esta cifra se verá sin duda incrementada en el año 2009, ya que este sector se considera un elemento clave a la hora de luchar contra la crisis económica en la que nos vemos inmersos.

La Economía Social se ocupa de aquella parte de la actividad económica que se centra de forma principal en las personas y en la satisfacción directa de sus necesidades, a diferencia de otros sectores económicos, en 
los que priman otros factores como el capital, que a menudo huye de la escena económica cuando intuye una época de dificultades. En este hecho diferencial estriba precisamente la importancia del sector de la Economía Social y su potencial de desarrollo en ámbitos tan diferentes, así como su capacidad de ofrecer siempre una respuesta unida y solidaria, tal y como se ha podido ver durante la celebración de estas Jornadas.

Las entidades y empresas de la Economía Social tienen mucho que decir en estos momentos. Hay que saber aprovechar el entorno desfavorable como una oportunidad que se brinda, afrontando decididamente el reto planteado. Una vez más se demostrará que nos encontramos ante un sector que es capaz de generar empleo y soluciones eficaces a partir de una base social amplia, aprovechando eficazmente los recursos que le brinda el entorno.

Ana Bermúdez Odriozola Directora Gerente del Instituto Aragonés de Empleo 
Si algo pueden aportar — como oportunidad - los tiempos de crisis, es su capacidad para desnudar los defectos del sistema y exigir tanto a los poderes públicos como a la ciudadanía que seamos capaces de recuperar las fortalezas que a lo largo de la historia han hecho de la economía la ciencia que nos ayudaba a gestionar la casa, en el caso de lo público; la de todos.

Vivimos una crisis profunda del sistema financiero, de la economía real y de los organismos reguladores, pero también y sobre todo, una crisis profunda de valores y de modelo de sociedad.

Y en este momento de urgencias y de necesidad de POLÍTICAS, la economía social nos recuerda parte de la esencia de lo que debió ser y la avaricia desmedida y el mercado iregulador? convirtió en una selva donde los ricos cada vez son más ricos y los pobres, cada vez más empobrecidos.

La economía social habla, con leguajes nuevos, de economía real y de participación en el PIB..., pero sobre todo habla de valores: habla de participación, de cooperación, de diálogo, de principios, de salarios razonables e iguales, de beneficios repartidos e invertidos, habla de responsabilidad social, de transparencia y rendición de cuentas.

Ahora, más que nunca, es el tiempo de la economía social; pegada al territorio, respetuosa con las gentes y con la tierra, generadora de desarrollo y anunciadora de un mundo más justo, solidario y sostenible.

Gracias por las Jornadas, gracias por compartir sueños, dudas y fortalezas...

Nacho Celaya

Director General de Participación Ciudadana Gobierno de Aragón 

La Economía Social Aragonesa presenta múltiples facetas y está presente en los diferentes campos económicos y sociales de nuestra comunidad. En todo el territorio aragonés hay presencia de organizaciones que buscan construir un modelo de relaciones económicas basado en las personas, con la mirada puesta en la satisfacción de las necesidades humanas a través de la cooperación y utilizando como vía primordial la consecución de los intereses y objetivos colectivos, por encima de los meramente individuales.

Desde las diferentes plataformas y entidades que hemos colaborado en la organización de estas I Jornadas de la Economía Social en Aragón, hemos visto necesario realizar estas jornadas con el objetivo de facilitar un espacio de reflexión sobre y para la Economía Social Aragonesa a partir de diferentes partícipes y dar a conocer los logros y los retos del sector con el fin de promover y fortalecer al mismo. Este objetivo global lo hemos concretado en cuatro áreas de trabajo: 1) análisis y diagnóstico de la evolución del sector; 2) presentación de buenas prácticas de gestión y desarrollo organizativo; 3) examinar los riesgos y oportunidades de la Economía Social en el contexto actual; 4) propuestas y recomendaciones de desarrollo del sector en el futuro

Consideramos que, a partir de este conjunto de factores, estas jornadas deben servir como vehículo de debate para concienciar, intercambiar experiencias, promover la reflexión, plantear recomendaciones y líneas de actuación, tanto para los responsables de las organizaciones de la Economía Social Aragonesas como para los responsables políticos. También servirán para sensibilizar y orientar a futuros investigadores y profesionales de la economía y la empresa sobre las diferentes líneas de investigación.

En el programa que se ha diseñado hemos buscado un equilibrio entre las aportaciones provenientes de la realidad de nuestra Economía Social Aragonesa y las reflexiones de personas relevantes en el sector a nivel 
estatal y de la Unión Europea. De esta forma, creemos que en las jornadas vamos a disponer de puntos de vista que nos hablarán desde los logros conseguidos y las dificultades que se presentan a partir de la práctica diaria, así como de sugerencias sobre los retos y oportunidades del futuro más global, aportadas por personas expertas y estudiosas en la materia.

Queremos agradecer a todos los que van a hacer posible estas primeras jornadas, a los que han participado en las mismas y sobre todo a los que día a día construyen la Economía Social como sector con capacidad de innovación y de respuesta a las necesidades sociales y económicas. Asimismo, queremos dar las gracias a los apoyos del INAEM, de la Dirección General de Participación Ciudadana del Gobierno Aragonés y de la Universidad de Zaragoza.

Comité organizador

Octubre, 2008 


\title{
La Economía Social en Aragón
}

\author{
Carmen Marcuello
}

GESES-Universidad de Zaragoza

La Economía Social es un sector con características propias que participa activamente en el crecimiento y en el desarrollo económico de la sociedad y que está reconocido a nivel internacional. En estas primeras Jornadas de la Economía Social en Aragón, celebradas en octubre de 2008, hemos querido destacar el papel de la Economía Social como motor de desarrollo. Esto es, los fines y el modo de actuación de las entidades que la forman tienen como principal meta la búsqueda del bienestar colectivo por encima de los intereses individuales.Y, todo esto, atendiendo a las necesidades de las personas, desde un modelo de gestión participativo y arraigado en el territorio de donde surgen.

De los debates mantenidos en las jornadas caben destacar dos asuntos. Primero, la necesidad de dar a conocer las contribuciones de las entidades empresariales de la Economía social, (cooperativas, sociedades laborales, empresas de inserción, centros especiales de empleo...) y de poner en valor la aportación económica de las entidades sociales de la Economía Social (asociaciones, fundaciones). Porque, en conjunto, se resaltaba la capacidad de crear empleo y de aportar riqueza redistribuida entre los partícipes de las entidades y la comunidad en la que tienen su actividad. Segundo, en diferentes ocasiones, se apelaba al contexto actual de crisis económica y financiera. En este contexto la forma de responder de las entidades de la Economía Social presenta diferencias con la empresa tradicional y, principalmente, con la gran empresa. Al ser entidades creadas desde proyectos enraizados en el territorio de donde surgen, tienden a proponer soluciones que buscan respuestas integradoras. Asimismo, en 
momentos de crisis las cooperativas o las sociedades laborales han sido una fórmula empresarial utilizada para fortalecer estructuras empresariales debilitadas o dar salida a situaciones difíciles que a través de la cooperativa adquieren una estructura de apoyo mutuo que les facilita el desarrollo de su actividad, mientras, las entidades sociales van a dar respuesta a las nuevas necesidades y situaciones que se producen en momentos de crisis.

Dentro de ese contexto, este libro tiene como objetivo presentar las aportaciones de estas I Jornadas de la Economía Social en Aragón, tanto de los ponentes, como de los trabajos en grupo. En este primer documento se realiza una breve descripción de la Economía Social aragonesa y se resumen las principales propuestas de las diferentes sesiones desarrolladas en las jornadas. Posteriormente, en el libro se incluyen los textos de las exposiciones que recogen las cuestiones esenciales planteadas.

\section{Sobre la Economía Social en Aragón}

En Aragón la Economía Social se estima que representa alrededor de un 4\% del PIB aragonés, aunque este sector está distribuido con diferente peso en las distintas actividades económicas. Si atendemos al número de organizaciones encontramos que según los datos del Registro de Cooperativas y el de Sociedades Laborales, en el año 2007 existen 1.934 cooperativas registradas, de las que 1.226 son de Trabajo Asociado y 1.554 Sociedades Laborales. En cuanto a las asociaciones aragonesas, el número aproximado es alrededor de 8.000, mientras que el de fundaciones aragonesas, tanto de ámbito nacional como comunitario, es más de 400. En la categoría de empresas sociales se incluye a las empresas de inserción en Aragón, actualmente en el registro constan 11 entidades, y los centros especiales de empleo, con 58 centros registrados. Esto es, alrededor de 12.000 entidades

Con respecto a las personas implicadas directamente en la Economía Social en Aragón, hay que tener en cuenta dos tipos de vinculación, la del empleo generado y la de los socios. Desde el punto de vista del empleo, entre las cooperativas y sociedades laborales el número de socios tra- 
bajadores es aproximadamente 12.000 (sumando los que se encuentran dados de alta en los regímenes general y de autónomos de la Seguridad Social). Si añadimos el número de trabajadores por cuenta ajena no socios de este tipo de entidades, incluidas aquellas cooperativas que no son de trabajo asociado, la cifra total de personas ocupadas se acerca a 25.000. Asimismo, las empresas de inserción han creado 130 puestos de trabajo mientras que los centros especiales de Empleo se aproximan a los 1.400 trabajadores. Es decir, la Economía Social en Aragón ha creado más de 27.000 empleos

Finalmente, desde el punto de vista de los socios en las cooperativas, si bien no existe una obligación legal de comunicación de este dato al registro de cooperativas, puede estimarse en una cifra próxima a 100.000 los socios integrantes de las distintas clases de cooperativas existentes y de 7.000 en las sociedades laborales, entre socios de clase general y laboral. Mientras que en tareas de voluntariado y como socios de asociaciones, la encuesta de empleo del tiempo indica que el voluntariado en Aragón es un 7,6\% de la población aragonesa (más de 90.000 personas) y en el caso del porcentaje de socios con respecto a la población en Aragón es del 26,7\% (más de 320.000 personas). Podemos considerar que aproximadamente el total de personas vinculadas como socios en las entidades de la Economía Social en Aragón es alrededor de 427.000 personas.

\section{La Economía Social hoy. Un motor de desarrollo}

La primera mesa tuvo como ponentes a José Luis Monzón, de la Universidad de Valencia y presidente de CIRIEC-España, Juan Antonio Pedreño, presidente de CEPES y COCETA, José Manuel Fresno, director de la fundación Luis Vives y Rafael Chaves, de la Universidad de Valencia y director de IUDESCOOP. Esta mesa tenía como objetivo presentar los rasgos más relevantes y actuales de la Economía Social desde una perspectiva europea y española, teniendo en cuenta qué aportaciones realiza la Economía Social al conjunto de la sociedad en materia de desarrollo y crecimiento. La primera intervención fue la de José Luis Monzón, titulada "Ámbito e Identificación de los diferentes Actores o Grupos incluidos en 
el concepto de Economía Social», a través de la cual destacó que a nivel europeo había sido aprobada recientemente la Carta de Principios de la Economía Social desde la Conferencia Europea Permanente de Cooperativas, Mutualidades, Asociaciones y Fundaciones (CEP-CMAF). Esta Carta contiene una propuesta de definición y delimitación de la Economía Social que es reconocida a nivel europeo y donde perfectamente se integra la Economía Social española. Asimismo, Monzón planteaba el avance que va a suponer el reconocimiento de la Economía Social en los sistemas de Contabilidad Nacional. En su exposición presentó también las particularidades del subsector empresarial de la Economía Social y los rasgos del subsector de no mercado y finalizó enfatizando que la Economía Social "promueve iniciativas empresariales de solidaridad recíproca entre sus promotores basadas en un sistema de valores, en el que prevalece la democracia en la toma de decisiones y la primacía de las personas sobre los capitales en la distribución de los excedentes. La Economía Social no solo contempla a las personas necesitadas como beneficiarias pasivas de la filantropía social, sino que, además, eleva a los ciudadanos a la categoría de protagonistas activos de su propio destino».

La segunda intervención fue la de Juan Antonio Pedreño, titulada «La Configuración del Sector Empresarial de la Economía Social en España. La Economía Social como Motor de Creación de Empleo». En el texto se hace un recorrido detallado sobre las aportaciones cuantitativas y cualitativas de la Economía Social, así como los retos del sector y las medidas para combatir la crisis en las Empresas de Economía Social. Así, a través de las cifras, Pedreño configura un sector empresarial de la Economía Social, que en el año 2007, a través de CEPES, representa a 51.762 entidades con 2.572.413 empleos de forma que «una de cada cuatro personas está vinculada a la Economía Social». Estos datos, además, están estrechamente ligados a valores, que son señas de identidad del sector, como la democracia, la participación y la solidaridad. En el apartado de medidas para combatir la crisis se describe un amplio número de cuestiones referidas a: 1) las políticas públicas que apoyen al sector y actualización de regulaciones como la modificación de la Ley de Cooperativas 27/1999, la Ley de Sociedades Laborales y el desarrollo reglamentario de las empresas de inserción; 2) las medidas de incentivos fiscales; 3) el acceso a la financiación; 
4) el apoyo a la creación de nuevas empresas de Economía Social;5) la estructuración del sector a través de redes; 6) los programas de desarrollo local a través de las entidades del sector; y 7) los planes de recuperación para los sectores de actividad más frágiles.

La tercera ponencia fue la de José Manuel Fresno, titulada «El Tercer Sector de Acción Social y la Economía Social». Esta intervención se centró en el Tercer Sector de Acción Social, esto es, las organizaciones que actúan «en el campo de lo social y proveen de bienes y servicios de tipo material e inmaterial a aquellas personas excluidas o en riesgo de exclusión». El autor, en la exposición y en el texto que se presenta en este libro, hace un recorrido por las señas de identidad de esta realidad atendiendo a las características de las entidades que lo conforman y a las características de su actuación, entre las que destaca la heterogeneidad, y que configuran una realidad compleja y diversa. Esta realidad ha dado respuestas a situaciones sociales también complejas y se ha enfrentado a retos constantemente. Posiblemente, a estas entidades se les exige unos resultados y responsabilidades mucho más elevados que a otras instituciones, por lo que se ven obligadas a una constante evolución y transformación. Así, el autor detalla los cambios recientes que tienen que ver con la expansión del tipo de actividades debido a su mayor influencia política y económica, la presencia en los medios de comunicación, la profesionalización creciente y la emergencia de entidades de segundo nivel estrechamente relacionadas por el trabajo en red. Asimismo, el autor destaca los problemas a los que se enfrenta el sector y establece un conjunto de retos a corto y medio plazo que van desde incrementar la autonomía, el fortalecimiento de la base social, la transparencia, la modernización de los sistemas de gestión y cualificación de los recursos humanos hasta la innovación. Finalmente, informó que desde la fundación Luis Vives en el año 2008 se ha puesto en marcha un Anuario sobre el Tercer Sector Social para contribuir al conocimiento y el reconocimiento del sector.

La cuarta y última intervención de esta mesa fue realizada por Rafael Chaves y se centró, como su propio título indica, en «La Economía Social: dos décadas generando empleo, tejido productivo y cohesión social en Europa». En el texto, tras una breve exposición sobre la evolución de la Economía Social en Europa, se describen algunas cifras globales de la Economía Social europea, las cuales muestran a un sector que agrupa a 
143 millones de socios en cooperativas que operan en sectores como la agricultura, la intermediación financiera, la distribución comercial, la vivienda, y el trabajo asociado en la industria, la construcción y los servicios. Las mutuas ofrecen asistencia y cobertura en materia de salud y protección social a más de 129 millones de personas y las asociaciones agrupan al 50\% de la ciudadanía de la Unión Europea y con más de 75.000 fundaciones. El autor profundiza en estos datos y describe a los componentes de la Economía Social en Europa, la dimensión económica y los tres modelos principales de Economía Social.

\section{Análisis y diagnóstico de la Economía Social aragonesa}

La segunda mesa tenía como objetivo realizar un análisis y diagnóstico de la Economía Social aragonesa. El análisis que se presentó fue una primera aproximación a una realidad que en Aragón no tiene una identidad pública reconocida globalmente. Hay un gran número de experiencias relevantes pero que no tiene una representación común como Economía Social. Los ponentes de esta mesa fueron Luis Mena, de la Fundación CAI-ASC, y Felipe Gómez de Valenzuela, de la Federación Aragonesa de Cooperativas Agrarias. En el primer texto, titulado «Economía Social en Aragón (que no de Aragón)", Luis Mena se centró en las entidades sociales o subsector de asociaciones y fundaciones de la Economía Social aragonesa. Comenzó aportando algunos datos generales que indican que en Aragón, en el año 2007, había unas cuatrocientas fundaciones y unas ocho mil asociaciones registradas. El autor continuó poniendo el acento en la fuerza del trabajo en red de las entidades sociales de la Economía Social aragonesa de forma que, entre las tareas desarrolladas, se ha dedicado tiempo a "compartir, debatir, consensuar, crear un lenguaje común, un discurso, un esqueleto organizativo más que en presentarse como una voz única con la contundencia de los datos». Este trabajo en red, según el autor, tiene una dimensión cualitativa muy relevante que requiere de una gran dedicación de tiempo y esfuerzo. El autor continúa en el texto "visibilizando lo que se hace», esto es, destaca la información más relevante de las plataformas analizadas y vuelve a hacer hincapié en que detrás de los datos hay un trabajo con unos principios de actuación comunes. El texto finaliza con los retos específicos propuestos desde las entidades, 
que van desde la competencia con el resto del sector, con respecto a los socios, a sus órganos de gestión y de estructuración del sector.

La segunda intervención de esta mesa fue realizada por Felipe Gómez de Valenzuela y se centró en la «Economía Social aragonesa desde la visión empresarial». El texto comienza hablando de la división de la Economía Social empresarial y la no empresarial para posteriormente mostrar los rasgos identitarios de las plataformas aragonesas analizadas: Asociación Aragonesa de Empresas de Inserción (AREI), Asociación Aragonesa de Sociedades Laborales (ASES), Federación Aragonesa de Cooperativas Agrarias (FACA), Federación Aragonesa de Cooperativas de Viviendas (FACOVI), Federación Aragonesa de Cooperativas de Trabajo Asociado (FACTA), Red de Economía Alternativa y Solidaria (REAS) y Unión de Cooperativas de Enseñanza de Aragón (UCEA). Los elementos analizados se refieren a cuestiones básicas como la misión de las entidades, su integración en redes nacionales y europeas y a los retos más próximos que han detectado las propias plataformas. Entre estos, encontramos, desde las dificultades de las empresas de inserción para asumir el sobrecoste derivado de su tarea de inserción sociolaboral de personas en riesgo de exclusión, hasta el apoyo a sus integrantes, la necesidad de incrementar el tamaño de las cooperativas agrarias o la búsqueda de herramientas efectivas de apoyo a la gestión de las cooperativas de trabajo asociado.

\section{Experiencias y buenas prácticas en la Economía Social aragonesa}

En las jornadas se vio necesario incorporar grupos de trabajo paralelos para mostrar una selección de buenas prácticas de entidades aragonesas en tres temas: 1) el papel de las entidades de Economía Social como actores activos en la inserción sociolaboral; 2) la contribución de las entidades al desarrollo local y como modelos específicos de innovación en la gestión empresarial; y 3) la participación democrática como un modelo de gestión específico de la Economía Social. Desde la perspectiva de la Economía Social, estos temas son tres asuntos relevantes en los fines de las entidades que la conforman y, a su vez, desde un enfoque de responsabilidad social, las entidades de la Economía Social son organizaciones que tienen una larga experiencia en esta materia. 


\subsection{Inserción sociolaboral}

En este grupo se presentaron cuatro buenas prácticas. La primera buena práctica, titulada «La Central de Recursos para las Empresas de Inserción de AREI: Nuevas estructuras para la transformación social de Aragón», fue presentada por Asunción García Mainar, de AREI. Esta experiencia es una forma de dar respuesta a las necesidades de las empresas de inserción aragonesas ya que facilita naves industriales, espacios de almacenaje y de servicios, de forma que ajusta los precios a las capacidades de las empresas de inserción. Esta experiencia, además de suponer un apoyo a las empresas de inserción, a cuyo servicio está, ha tenido en cuenta la capacidad de obtener financiación privada, pública y fuentes propias de la entidad para su creación y mantenimiento en el tiempo. Tal y como se describe en el texto, el diseño de la central de recursos tiene como objetivo inmediato las propias empresas de inserción, pero el objetivo final es facilitar espacios dignos y de calidad para el desarrollo de la tarea de inserción sociolaboral de los trabajadores de estas empresas. La segunda exposición se tituló «Fundación Agustín Serrate: gestión de Programa de Rehabilitación de Salud Mental», realizada por Javier Borau, desde CERMI. En esta experiencia se presenta un recorrido en el tiempo y se describen los elementos que la caracterizan. A partir de la iniciativa y el trabajo de la fundación, en colaboración con el gobierno aragonés, se plantea un servicio individualizado con el objetivo de "ofrecer a las personas con trastorno mental grave una serie de servicios orientados al acompañamiento y al apoyo individual y colectivo con el fin de lograr la recuperación personal, la autonomía y la participación social como ciudadanos/as de pleno derecho, y la integración en la comunidad». La siguiente experiencia se titula "Modelo de Formación Ocupacional Adaptada», presentado por M. Jesús Martínez, de la Red Aragonesa de Entidades Sociales para la Inclusión. En este caso de nuevo se plantea una mirada crítica a la realidad cercana y con entidades que ya tienen una larga experiencia de intervención con colectivos desfavorecidos o en riesgo de exclusión. En este sentido, la iniciativa cuenta con un modelo integral de formación adaptado de forma individual a través de itinerarios de inserción, poniendo al servicio de las personas un conjunto de servicios de formación coordinados. El valor de esta experiencia muestra una gran capacidad de gestión de recursos que dificilmente otras instituciones pueden realizar. La cuarta buena práctica fue 
«La Artesa Tienda Solidaria», presentada por Cáritas-Zaragoza, desde la Federación Aragonesa de Solidaridad. Esta tienda, con una experiencia de diez años de funcionamiento, está al servicio de los talleres ocupacionales y proyectos de cooperación internacional de Cáritas. Además de ser un lugar para comercializar los productos de estos talleres, da a conocer el trabajo que se realiza en los mismos, permite proponer otro tipo de consumo y recaudar financiación a los mismos.

\subsection{Desarrollo local e innovación en la gestión empresarial}

En este grupo de trabajo se presentaron cuatro buenas prácticas. La primera fue «Desarrollo e Integración de Comunicaciones Sociedad Laboral», por Eduardo Romero Aladrén, José M. a Andrés Navarrete y Jesús Pola, desde la Asociación Aragonesa de Sociedades Laborales. Mientras que los casos anteriores son proyectos que se ponen al servicio de los usuarios, en este caso el origen de la iniciativa son personas que desde su situación de desempleo deciden poner en marcha una actividad empresarial pero con un modelo de empresa de Economía Social. Tal y como destacan los autores, a través de una sociedad limitada laboral se podía asegurar una forma de participación e implicación de los profesionales donde prevalece el objetivo de «preservar los puestos de trabajo más allá de los avatares del mercado». La segunda intervención fue «La Gestión Fundacional del Patrimonio de Albarracín. La Fundación Santa María de Albarracín», presentada por Antonio Jiménez Martínez, desde la Asociación Española de Fundaciones. Esta fundación ha vertebrado en su patronato a diferentes niveles de la administración pública e instituciones privadas con un modelo de actuación integral sobre el patrimonio de Albarracín. En esta ocasión, estamos ante una entidad que se pone al servicio del conjunto de la sociedad entendiendo que recuperar el valor cultural a partir de un modelo sostenible propio crea valor social. La tercera buena práctica fue «Grupo Pastores. Grupo Cooperativo», presentada por Antonio Aparicio, desde la Federación Aragonesa de Cooperativas Agrarias. En palabras de los propios protagonistas, «la cooperativa y el grupo que la sustenta posibilita la realización de la actividad ganadera en numerosos pueblos de Aragón y con ello, en muchos casos, la supervivencia misma de la localidad donde se ejerce, contribuyendo de forma importante a la sostenibilidad y al mantenimiento de nuestro medio rural». Asimismo, el grupo pone en marcha procesos de innovación a partir de la investigación y de ser 
capaces de adaptarse a las necesidades de los consumidores. La cooperativa combina el espíritu y los principios cooperativos desde una gestión empresarial. La cuarta buena práctica fue «Tiebel Sociedad Cooperativa de Iniciativa Social», presentada por Marina Martínez Pardo, desde la Federación Aragonesa de Cooperativas Agrarias (FACTA). Esta experiencia abarca catorce años de trabajo y nació para ponerse al servicio de las personas como un proyecto de inserción sociolaboral que pretende "construir una empresa de rostro humano al servicio del medio social, para contribuir a su desarrollo». La actividad principal es la limpieza profesional de calidad, junto con formación ocupacional y animación sociocultural y deportiva.Y, todo esto, dirigido preferentemente para mujeres en Zaragoza y en la Comarca de Belchite. Desde la cooperativa definen el modelo de trabajo como una red integrada y conectada por la socias trabajadoras, las trabajadoras, los clientes y la red social. Este grupo de trabajo finalizó con la presentación de Caja Rural de Teruel por José Antonio Pérez Cebrián. La Caja Rural de Teruel muestra cómo una entidad financiera puede tener su razón de ser en estar al servicio del territorio desde donde surge. Asimismo, la entidad ha pasado por un proceso de cambio profundo que está claramente inspirado en los principios cooperativos integrando, a su vez, los principios de la Responsabilidad Social Corporativa y en estrecha colaboración con instituciones, entidades y empresas de la comunidad turolense.

\subsection{Participación democrática}

Sobre el tema de participación democrática en este grupo, desde la Coordinadora Aragonesa de Voluntariado, se presentó «La Asociación Voluntariado de Geriatría», a cargo de María Ríos, Pilar Mesa y Mercedes Obis. Las autoras definieron el proyecto como una muestra de que «desde pequeñas realidades y medios escasos, con implicación, dedicación, responsabilidad, participación y solidaridad se pueden alcanzar nuevas realidades y grandes metas». Esta entidad es un modelo de gestión basado en personas voluntarias combinado con profesionales al servicio de atención de personas mayores. Este servicio de atención muestra un saber hacer en la integración de la participación de los voluntarios, en la formación y el debate, de tal forma que ha sido origen de otras iniciativas consolidadas. La segunda buena práctica de este grupo de trabajo fue «Cooperativas deViviendasVictoria Martínez: La participación de los socios en las Cooperativas de Vi- 
viendas», por Carolina Marín Andrés, desde la Federación Aragonesa de Cooperativas de Viviendas (FACOVI). Esta entidad, con una experiencia de casi treinta años de trabajo, indicó que mantiene como su razón de ser «incidir en el mercado de la vivienda a través del asociacionismo cooperativo, con la finalidad de posibilitar el acceso a una vivienda digna, a precio de coste, para aquellas personas o familias que por sus recursos económicos no les es posible el acceso a una vivienda en el mercado libre». Asimismo, detalló cómo el proceso de participación requiere de elementos como la participación de los órganos de administración, la participación en la ejecución, en las decisiones sobre el coste económico y sobre el control de las decisiones. La tercera buena práctica fue «COOP57-Aragón (Cooperativa de Servicios Financieros Éticos Solidarios)», por Javier Ortega Díaz, desde la Red de Economía Alternativa y Solidaria (REAS-Aragón). Esta cooperativa de servicios financieros tiene como objetivo estar al servicio de las entidades de Economía Social y solidaria, esto es, promueven el ahorro desde unos valores y destina sus recursos para proyectos de entidades que «fomenten el cooperativismo, el asociacionismo y la solidaridad en general, promoviendo la sostenibilidad sobre la base de los principios éticos y solidarios». Asimismo, la participación de los socios es la base del desarrollo de la actividad de la entidad, que se combina con principios como la coherencia, la compatibilidad, la responsabilidad, la solidaridad y la reflexión. La última buena práctica de este grupo fue la «Cooperativa de alumnos», por Pablo Herranz, UCEA-Aragón. La experiencia se sitúa en el colegio Don Bosco, sociedad cooperativa. Esta iniciativa muestra cómo es posible «transmitir los principios cooperativos de la entidad a los alumnos» $\mathrm{y}$ «desarrollar el método cooperativo en la preparación de un intercambio con alumnos europeos». De forma que el resultado de la iniciativa es una mejora de la participación en la Comunidad Escolar de padres, alumnos y trabajadores.

\section{Retos y oportunidades de la Economía Social aragonesa}

En la segunda sesión de los grupos de trabajo el objetivo era sugerir, a partir del debate, cuáles eran los retos y oportunidades de la Economía Social aragonesa. Como resultado de esta discusión en este texto se presentan las conclusiones en dos documentos. En el primero, se realiza un conjunto de consideraciones de carácter general para el conjunto de temas 
que afectan a este sector y, en el segundo documento, se reflexiona sobre la participación democrática, una de las cuestiones esenciales de la Economía Social. Marisa Esteve y Ángel Gutiérrez son los autores del primer documento que se estructura alrededor de cinco grandes ejes: 1) la visibilidad y comunicación de las organizaciones de la Economía Social; 2) el trabajo en red; 3) la participación; 4) el papel de las entidades asociativas; 5) las relaciones con la Administración Pública. El autor del segundo documento sobre participación democrática en la Economía Social es Chaime Marcuello y explica el proceso de reflexión del grupo de trabajo en el cual se incluyeron en el debate desde los significados de la participación y la revisión de las formas de participación a los elementos que influyen en la participación.

\section{Retos y futuro de la Economía Social}

La última sesión de las Jornadas tenía como objetivo delimitar y reflexionar sobre los retos generales de la Economía Social desde una visión europea. Miguel Ángel Cabra de Luna, de la fundación ONCE y consejero del Comité Económico y Social Europeo en representación de CEPES, presentó, con el título "Retos y futuro de la Economía Social», una interesante aportación para finalizar las Jornadas. Expuso la riqueza de la Economía Social con palabras muy precisas diciendo que las características de la Economía Social la "convierten en una institución necesaria para la estabilidad y sostenibilidad del crecimiento económico (particularmente en momentos de crisis e inestabilidad como el actual), la corrección de desequilibrios en el acceso al mercado de trabajo (a través por ejemplo de la integración de grupos desfavorecidos como las mujeres, las personas con discapacidad o los emigrantes), la lucha contra la precariedad en el empleo (nuestras empresas generan empleo estable y de calidad, y no recortan plantilla cuando llegan las 'vacas flacas'), la revalorización de la actividad económica al servicio de las necesidades sociales y la profundización de la democracia económica». Aunque el enfoque de la intervención era desde el ámbito europeo, de nuevo surgieron algunos desafios comunes a la Economía Social en España y en Aragón, entre ellos destacan la falta de reconocimiento institucional de la Economía Social, la necesidad de cuentas y estadísticas nacionales y europeas, la cuestión 
terminológica, las ayudas del Estado, la inclusión de la Economía Social en las políticas públicas, así como establecer órganos en los diferentes niveles de la administración pública con competencias en Economía Social. El texto finaliza con una propuesta detallada de respuestas a estos desafios.

\section{Para seguir trabajando}

A lo largo de las ponencias, las preguntas y los debates de las jornadas se expusieron, sobre todo, experiencias, ideas y propuestas que tenían como trasfondo metas que buscan crear una sociedad más justa. Proyectos basados en las personas que trabajan para otras personas, como se reflejan en el conjunto de buenas prácticas aportadas por las diferentes entidades organizadoras. Estas «buenas prácticas» tienen un denominador común, desde la práctica y el trabajo diario se observa cómo se comparten los principios que definen la Economía Social. La bondad de estos principios se manifiesta, desde la respuesta real a necesidades sociales en Aragón, en organizaciones, al igual que en otras sociedad europeas, con modos de actuación basados en principios de participación democrática, la primacía de las personas y el objeto social sobre el capital, la aplicación de los principios de solidaridad y el beneficio o excedente como un medio para mejorar la entidad o ser reinvertido en objetivos de interés general.

Otra cuestión a destacar de los debates es el elevado nivel de exigencia entre las entidades para que las palabras tuvieran coherencia con los hechos y con los principios. Ser cooperativa, ser un centro especial de empleo, o cualquier otra de las formas jurídicas de la Economía Social no garantiza los principios anteriores. La génesis, los comienzos y el desarrollo de los proyectos de Economía Social han de demostrar que lo son. Este nivel de exigencia es muy importante, pero, en ocasiones, puede ser también un exceso de presión.

El debate de los grupos para identificar los retos y oportunidades de la Economía Social aragonesa fue también muy rico y con un número abundante de propuestas que sería interesante poner en marcha y realizar su seguimiento. Estas propuestas se dirigen especialmente al propio sector y, otras, muy concretas, a la Administración Pública aragonesa y están desarrolladas en el texto de Marisa Esteve y Ángel Gutiérrez. Uno de los 
primeros asuntos pendientes y necesarios que se destacó fue mejorar la visibilidad del sector y la comunicación de la tarea y logros de la Economía Social aragonesa a la sociedad y a las empresas, así como promover espacios de formación específicos en el sistema educativo para dar a conocer los principios de la Economía Social y facilitar la formación de profesionales. Otro asunto se refiere a la «importancia de la intercooperación» entre las entidades de la Economía Social, esto es, el trabajo en red. La intercooperación fortalece al sector y permite la creación de sinergias en muy diversos campos, como por ejemplo la $\mathrm{I}+\mathrm{D}+\mathrm{i}$. Asimismo, promover un sistema de colaboración preferencial como proveedores y clientes entre entidades de la Economía Social puede permitir entrar en nuevos sectores de actividad. En tercer lugar, las entidades asociativas del sector, plataformas o federaciones tienen un papel muy importante, porque, además de representar a sus asociados, pueden ser mecanismos muy adecuados para incorporar mejoras en la gestión y funcionamiento en las entidades asociadas. Finalmente, la participación como elemento transversal en estas entidades, tanto de socios, trabajadores, usuarios o clientes es un valor especial pero que debe disponer de mecanismos muy bien diseñados para que sean efectivos y para que realmente supongan una «riqueza de ideas a la hora de afrontar las decisiones a tomar».

Por último, es evidente que en una sola jornada no es posible abarcar toda la diversidad y riqueza del sector, por lo que se vio interesante continuar con la iniciativa de dedicar más momentos a la reflexión sobre la Economía Social aragonesa ampliando el debate a más entidades y públicos. 
$\underline{\underline{M E S A} 1}$

La Economía Social hoy.
Un motor de desarrollo 



\section{Ámbito e identificación de los diferentes actores o grupos incluidos en el concepto de Economía Social}

José LUIS Monzón

Universidad de Valencia (IUDESCOOP)

Presidente del CIRIEC-España

\section{La delimitación de la Economía Social} a partir de sus protagonistas

La identificación de la ES, tal y como ahora se conoce, tiene su punto de arranque en Francia, en la década de los 70 del siglo XX, cuando las organizaciones representativas de las cooperativas, mutuas y asociaciones crean el Comité National de Liaison des Activités Coopératives, Mutuelles et Associatives (CNLAMCA) que define la Economía Social como el conjunto de entidades no pertenecientes al sector público que, con funcionamiento y gestión democráticos e igualdad de derechos y deberes de los socios, practican un régimen especial de propiedad y distribución de las ganancias, empleando los excedentes del ejercicio para el crecimiento de la entidad y la mejora de los servicios a los socios y a la sociedad.

La más reciente delimitación conceptual de la ES, realizada por sus propios protagonistas, ha sido planteada en la Carta de Principios de la Economía Social promovida por la Conferencia Europea Permanente de Cooperativas, Mutualidades, Asociaciones y Fundaciones (CEP-CMAF), (actualmente denominado Economía Social Europea) plataforma europea representativa de las cuatro familias de entidades sobredichas. Estos principios son los siguientes: 
- Primacía de la persona y del objeto social sobre el capital.

- Adhesión voluntaria y abierta.

- Control democrático por sus miembros (excepto para las fundaciones, que no tienen socios).

- Conjunción de los intereses de los miembros usuarios y del interés general.

- Defensa y aplicación de los principios de solidaridad y responsabilidad.

- Autonomía de gestión e independencia respecto de los poderes públicos.

- Destino de la mayoría de los excedentes a la consecución de objetivos a favor del desarrollo sostenible, del interés de los servicios a los miembros y del interés general.

\section{El reconocimiento de la Economía Social en los Sistemas de Contabilidad Nacional}

Los sistemas de Contabilidad Nacional desempeñan una importantísima función para ofrecer información periódica y rigurosa sobre la actividad económica, así como para desarrollar procesos de armonización terminológica y conceptual en materia económica que permitan establecer comparaciones internacionales coherentes y homogéneas. Los dos sistemas de Contabilidad Nacional más importantes actualmente en vigor son el sistema de cuentas nacionales de las Naciones Unidas (SCN-1993) y el sistema europeo de cuentas nacionales y regionales (SEC-1995). El SCN-1993 proporciona las directrices sobre Contabilidad Nacional para todos los países del mundo, mientras que el SEC1995 es de aplicación en los Estados miembros de la Unión Europea y, más allá de pequeñas diferencias, es plenamente coherente con el SCN1993.

Recientemente la Comisión Europea ha realizado un Manual de orientación para la elaboración de una cuenta satélite de las empresas de la Economía Social (cooperativas y mutuas), lo que permitirá obtener datos homogéneos, precisos y fiables sobre una parte muy significativa de la ES constituida por cooperativas, mutuas y otras empresas similares. 


\section{Una definición de ES adecuada a los sistemas de Contabilidad Nacional}

La invisibilidad institucional de la ES a la que hemos hecho referencia también se explica por la falta de una definición clara y rigurosa del concepto y ámbito de la ES que pueda ser utilizada adecuadamente por los sistemas de Contabilidad Nacional. Esta definición debe prescindir de criterios jurídicos y administrativos, centrarse en el análisis de comportamiento de los actores de la ES e identificar las similitudes y diferencias entre los mismos y entre todos ellos y el resto de agentes económicos. Y todo ello integrando en un único concepto los principios históricos y valores propios de la ES y la metodología de los sistemas de contabilidad nacional en vigor, de modo que sea una definición operativa, que suscite un amplio consenso político y científico y que, por lo tanto, permita cuantificar y hacer visible de forma homogénea, y armonizada internacionalmente, los principales datos agregados de las entidades pertenecientes a la ES.

De conformidad con lo anterior, la definición de trabajo que aquí se propone de ES es la siguiente:

Conjunto de empresas privadas organizadas formalmente, con autonomía de decisión y libertad de adhesión, creadas para satisfacer las necesidades de sus socios a través del mercado, produciendo bienes y servicios, asegurando o financiando, y en las que la eventual distribución entre los socios de beneficios o excedentes, así como la toma de decisiones, no están ligados directamente con el capital o cotizaciones aportados por cada socio, correspondiendo un voto a cada uno de ellos. La Economía Social también agrupa a aquellas entidades privadas organizadas formalmente con autonomía de decisión y libertad de adhesión que producen servicios de no mercado a favor de las familias, de cuyos excedentes, si los hubiera, no pueden apropiarse los agentes económicos que las crean, controlan o financian.

Esta definición configura dos grandes subsectores de la Economía Social: a) el subsector de mercado o empresarial y $b$ ) el subsector de productores no de mercado.

De acuerdo con la definición anteriormente establecida las características comunes a los dos subsectores de la Economía Social son las siguientes:

1) Son privadas, es decir, no forman parte del sector público ni están controladas por el mismo; 
2) Organizadas formalmente, esto es, habitualmente están dotadas de personalidad jurídica propia;

3) Con autonomía de decisión, lo que quiere decir que tienen plena capacidad para elegir y cesar a sus órganos de gobierno, para controlar y organizar todas sus actividades;

4) Con libertad de adhesión, o sea, que no son de afiliación obligatoria;

5) La eventual distribución de beneficios o excedentes entre los socios usuarios, si se produce, no es en proporción al capital o a las cotizaciones aportadas por los mismos, sino de acuerdo con la actividad que estos realizan con la entidad;

6) Ejercen una actividad económica en sí misma considerada, para satisfacer necesidades de personas, hogares o familias;

7) Son organizaciones democráticas. A excepción de algunas entidades voluntarias productoras de servicios de no mercado en favor de las familias, de carácter social, en el proceso de toma de decisiones de las organizaciones de primer grado de la Economía Social se aplica el principio de «una persona, un voto», independientemente del capital o cotizaciones aportadas por los socios. Las entidades de otros grados están también organizadas de forma democrática. Los socios usuarios controlan mayoritaria o exclusivamente el poder de decisión de la organización.

\section{El subsector de mercado o empresarial de la ES}

El subsector de mercado de la ES está constituido, fundamentalmente, por cooperativas y mutuas, grupos empresariales controlados por cooperativas y mutuas, otras empresas similares de la ES y ciertas instituciones sin fines de lucro al servicio de las empresas de la ES.

Junto a las características comunes a todas las entidades de la ES, la definición de trabajo que hemos propuesto anteriormente, así como el Manual de la Comisión subrayan tres características esenciales de las empresas de la ES:

a) Se crean para satisfacer las necesidades de sus socios, mediante la aplicación del principio de self-help, es decir, son empresas en las que habitualmente se da la doble condición de socio y usuario de la actividad. 
El Manual de la Comisión explica con detalle el alcance y limitaciones de esta característica. El objetivo central de estas empresas es satisfacer y resolver las necesidades de sus socios, que son fundamentalmente personas o familias.

Lo anterior no impide que las empresas de Economía Social desarrollen acciones de solidaridad con entornos sociales mucho más amplios y que trascienden de su base societaria. En el caso de las cooperativas, sus reglas históricas de funcionamiento las han convertido en pioneras de la aplicación del principio de responsabilidad social de las empresas o responsabilidad corporativa, ya que dichas reglas estimulan y fomentan mecanismos de solidaridad (principio de educación y acción social, principio de «puerta abierta", creación de un patrimonio irrepartible entre los socios, etc.). Sin embargo, todo ello no desvirtúa la base mutual de la empresa de Economía Social, que compite en el mercado, se financia principalmente a través del mismo y desarrolla actividades de riesgo de cuyo resultado depende, en última instancia, la prestación de servicios a los socios.

b) Las empresas de la ES son productores de mercado, lo que significa que son empresas cuya producción se destina principalmente a la venta en el mercado a precios económicamente significativos. El SEC1995 considera que las cooperativas, mutuas, sociedades holding, otras empresas similares e instituciones sin fines de lucro al servicio de las anteriores son productores de mercado.

c) Pueden distribuir beneficios o excedentes entre los socios usuarios, pero no en proporción al capital o a las cotizaciones aportadas por los mismos, sino de acuerdo con la actividad que estos realizan con la entidad.

El hecho de que puedan distribuirse beneficios o excedentes entre los socios no significa que se haga siempre. Existen muchos casos en los que las cooperativas y mutuas, por norma o costumbre, no distribuyen beneficios o excedentes entre sus socios. Aquí solo se quiere subrayar que el principio de no distribución de beneficios entre los socios no constituye una característica esencial de las empresas de la Economía Social.

En algunos países, determinadas empresas de la Economía Social adoptan la forma de sociedad anónima o de responsabilidad limitada y 
han sido creadas por trabajadores con el propósito de crear o mantener su empleo. Estas empresas podrán ser consideradas también organizaciones democráticas con procesos de decisión democráticos siempre y cuando en ellas la mayoría del capital social sea propiedad de los socios trabajadores y esté repartido entre los mismos de forma igualitaria.

Otras empresas de la Economía Social que también adoptan formas jurídicas distintas de la cooperativa, se han creado para favorecer procesos de inserción social por el trabajo y otros fines de utilidad social. En dichas empresas también se desarrollan procesos democráticos en la toma de decisiones que, en ningún caso, se basa en la propiedad del capital.

\section{El subsector de no mercado de la Economía Social}

Este subsector está constituido, muy mayoritariamente, por asociaciones y fundaciones, aunque también pueden encontrarse entidades con otra forma jurídica. Está formado por todas aquellas entidades de la ES que, según los criterios establecidos por la contabilidad nacional, son productores de no mercado, es decir, aquellos cuya producción se suministra mayoritariamente de forma gratuita o a precios económicamente no significativos.

Como ya hemos señalado, se trata de entidades privadas organizadas formalmente, con autonomía de decisión y libertad de adhesión que producen servicios de no mercado en favor de las familias, cuyos excedentes, si los hubiera, no pueden ser apropiados por los agentes que las crean, controlan o financian. Es decir, se trata de entidades no lucrativas en sentido estricto, que aplican el principio de no distribución de beneficios (PNDB) y en las que, como en todas las entidades de la Economía Social, los individuos son los verdaderos beneficiarios de los servicios producidos.

En la contabilidad nacional existe un sector institucional, el S15, diferenciado del resto de sectores y que se denomina «instituciones sin fines de lucro al servicio de los hogares». Dicho sector es definido por el SEC1995 como el que está formado por las instituciones sin fines de lucro dotadas de personalidad jurídica que sirven a los hogares y que son otros productores de no mercado privados. Sus recursos principales, distintos de los derivados de ventas ocasionales, proceden de contribuciones vo- 
luntarias en efectivo o en especie efectuadas por los hogares en su calidad de consumidores, de pagos de las administraciones públicas y de rentas de la propiedad (SEC-1995, 2.87).

En el sector ISFLSH se incluye una variada gama de entidades, en su mayoría asociaciones, que desarrollan actividades de no mercado para sus socios (entidades de carácter mutualista) o para grupos de ciudadanos no socios (entidades de interés general). La mayoría de estas entidades tienen un funcionamiento democrático y reúnen las características propias de la ES. Se trata de asociaciones de beneficencia, de ayuda y de asistencia, de sindicatos, asociaciones profesionales o científicas, asociaciones de consumidores, partidos políticos, iglesias o asociaciones religiosas y clubs sociales, culturales, recreativos o deportivos.

Como hemos dicho antes, pueden existir determinadas entidades voluntarias no lucrativas productoras de servicios de no mercado en favor de las familias que, sin poseer una estructura democrática, están incluidas en la ES bajo la denominación de Tercer Sector de acción social, debido a que los servicios que suministran gratuitamente son bienes sociales o preferentes de indudable utilidad social.

Las ISFLSH que carecen de personalidad jurídica o que tienen poca importancia están incluidas por el SEC-1995 en el sector Hogares (S14) (SEC-1995, 2.76) y forman parte también de la ES.

Por último, pueden existir otras instituciones sin fines de lucro (ISFL) de carácter privado que están financiadas por sociedades no financieras o instituciones financieras y que producen servicios culturales, recreativos, sociales, etc. que se suministran gratuitamente a los individuos. Aunque el SEC-1995 considera (por convenio) a estas entidades al servicio de sociedades no financieras o de instituciones financieras, y por tanto incluidas en los respectivos sectores institucionales (de mercado) (SEC-1995, 2.23 y 2.40), forman parte del subsector de no mercado de la ES, siempre y cuando se verifiquen los requisitos establecidos en la definición.

Deben quedar excluidos de este grupo las ISFL que son productores de mercado dedicados a producir bienes y servicios no financieros, a la intermediación financiera o a actividades auxiliares de la intermediación financiera, así como las asociaciones empresariales financiadas por medio 
de cuotas voluntarias de carácter parafiscal aportadas por sociedades no financieras o instituciones financieras a cambio de los servicios suministrados por los mismos.

\section{La Economía Social: pluralismo y núcleo identitario común}

La ES se ha posicionado en la sociedad europea como un polo de utilidad social, entre el sector capitalista y el sector público y está constituida, ciertamente, por una gran pluralidad de actores. Viejas y nuevas necesidades sociales constituyen, todas ellas, el ámbito de intervención de la ES. Necesidades que pueden resolverse empresarialmente por los propios afectados a través del mercado, en el que casi todas las cooperativas y mutuas obtienen la mayoría de sus recursos, o mediante casi todas las asociaciones y fundaciones, que suministran servicios de no mercado a las personas, hogares o familias y que, habitualmente, consiguen sus recursos mayoritarios gracias a donaciones, cuotas de socios, subvenciones, etc.

Pero este pluralismo, que se afirma y consolida a su vez en el seno de una sociedad plural, no significa un totum revolutum carente de identidad o de valor interpretativo. Al contrario, el núcleo identitario común de la ES se afirma a partir de un amplio y diverso conjunto de entidades microeconómicas, de carácter libre y voluntario, creadas desde la sociedad civil para satisfacer y resolver las necesidades de los individuos, hogares o familias y no para retribuir o dar cobertura a inversores o a empresas capitalistas, es decir, se está hablando de entidades de finalidad no lucrativa (not-for-profit). A lo largo de los últimos 200 años, este variado espectro de organizaciones de mercado o de no mercado, de interés mutualista o de interés general, ha conformado el Tercer Sector, tal y como aquí ha sido identificado por el enfoque de la ES.

\section{Tercer Sector y enfoque Nonprofit Organization (NPO)}

Aunque la expresión «Tercer Sector» se ha utilizado, mayoritariamente en el ámbito anglosajón, para describir el sector no lucrativo privado constituido fundamentalmente por asociaciones y fundaciones, lo cierto es que también en la Europa continental y en otras regiones del 
mundo «Tercer Sector» se utiliza como sinónimo de la Economía Social, tal y como ha sido acotada en el anterior capítulo.

El Tercer Sector (TS) se ha configurado como el punto de encuentro de diferentes conceptos, fundamentalmente el de «sector no lucrativo" y el de "economía social» que, aunque describen realidades con amplios espacios comunes, no son totalmente coincidentes. Además, los enfoques teóricos que se desarrollan a partir de estos conceptos asignan al TS el desempeño de distintas funciones en las economías de nuestro tiempo.

El principal enfoque teórico que aborda el análisis delTS, junto al enfoque de la ES es, ya se ha dicho, de raíz anglosajona y ha promovido desde Estados Unidos, hace ya 30 años, la literatura del Nonprofit Sector o del Nonprofit Organization (NPO). En esencia, este enfoque solo contempla a aquellas organizaciones privadas que, en virtud de sus reglas constitutivas, no pueden distribuir beneficios a las personas que las han creado, controlan o financian.

Las raíces históricas de este concepto están vinculadas a las ideas filantrópicas y caritativas, muy arraigadas en la sociedad inglesa del siglo XIX y en los países de su ámbito de influencia. Así, resultan bien conocidas las asociaciones caritativas o filantrópicas, las charities inglesas o las entidades de filantropía en los Estados Unidos y que han dado lugar a términos como el de charitable sector y voluntary sector, que se incluyen en el más amplio concepto de Nonprofit Sector.

El moderno concepto de Nonprofit Sector ha sido definido con mayor precisión y ampliamente difundido en todo el mundo a partir de un ambicioso proyecto de investigación internacional promovido por la Johns Hopkins University de Baltimore (Estados Unidos), iniciado a comienzos de la década de los 90 con el objetivo de descubrir y acotar su tamaño y estructura, así como de analizar sus perspectivas de desarrollo y de evaluar su impacto en la sociedad.

El proyecto cubre, en diferentes fases, el análisis del sector no lucrativo en 28 países de Europa, Asia y América.

Las entidades analizadas en el proyecto son las que cumplen los cinco criterios destacados en la «definición estructural operativa» de una organización no lucrativa. Dichas entidades son: 
a) Organizaciones, es decir, poseen una presencia y una estructura institucional. Habitualmente están dotadas de personalidad jurídica.

b) Privadas, institucionalmente separadas de los poderes públicos, aunque pueden recibir financiación pública e incluir en sus órganos directivos a funcionarios públicos.

c) Autónomas, con capacidad de control sobre sus actividades y libertad para elegir y cesar a sus órganos de gobierno.

d) No reparten beneficios. Las organizaciones no lucrativas pueden tener beneficios pero deben ser reinvertidos en la misión principal de la entidad y no distribuidos entre los titulares, miembros fundadores u órganos directivos de la organización.

e) Con participación voluntaria, lo que significa dos cosas: en primer lugar, que la pertenencia a ellas no es obligatoria ni está legalmente impuesta y, en segundo lugar, que la organización debe contar con la participación de voluntariado en sus actividades u órganos de gestión.

\section{Similitudes y diferencias entre el enfoque de Economía Social y el de NPO}

Por su importancia, merece la pena detenerse en las principales similitudes y diferencias que pueden establecerse entre el enfoque y concepto de ES y el desarrollado por el enfoque NPO.

En cuanto a las similitudes, tanto en el enfoque de ES como en el de NPO cabe destacar que de cinco criterios que el enfoque NPO establece para delimitar el ámbito del TS, cuatro de ellos también son exigidos por el enfoque ES; organizaciones privadas, organizadas formalmente, con autonomía de decisión y con libertad de adhesión (participación voluntaria).

Sin embargo, existen tres criterios de delimitación del TS en los que el enfoque NPO y el enfoque de ES presentan claras diferencias:

\section{a) El criterio de la no lucratividad}

El enfoque NPO excluye del TS a todas las organizaciones que distribuyen beneficios, bajo cualquier modalidad, a las personas o entidades que las han creado, controlan o financian, es decir, que las entidades del TS deben aplicar estrictamente el principio de no distribución de bene- 
ficios (PNDB). Además de no distribuir beneficios, el enfoque NPO exige que las organizaciones del TS no tengan finalidad lucrativa (not-forprofit), es decir, que no se hayan creado con el objetivo principal de generar beneficios ni de obtener una rentabilidad financiera.

En el enfoque de ES, el criterio de no lucratividad, tal y como ha sido expuesto, no constituye un requisito imperativo para las organizaciones del TS. Por supuesto que el enfoque de ES considera como parte integrante del TS a muchas organizaciones que aplican estrictamente este criterio de no lucratividad: un amplio sector de asociaciones, fundaciones, empresas sociales y otras entidades no lucrativas al servicio de las personas y las familias que verifican el criterio NPO de no lucratividad y todas las características de las organizaciones de la ES establecidas en este Informe. No obstante, las cooperativas y mutuas, que constituyen un núcleo determinante de la ES, son excluidas del TS por el enfoque NPO al distribuir la mayoría de ellas una parte de sus excedentes entre los socios.

\section{b) El criterio democrático}

Una segunda diferencia entre el enfoque NPO y el enfoque de ES se concreta en la aplicación del criterio democrático. Entre los requisitos establecidos por el enfoque NPO para considerar a una entidad como parte integrante del TS no se encuentra un elemento tan característico del concepto de ES como es el de la organización democrática, por lo que el enfoque NPO incluye en el ámbito del TS a muchas y muy importantes organizaciones no lucrativas que no verifican el criterio democrático y que, por consiguiente, el enfoque de ES las excluye de dicho TS. En efecto, muchas instituciones no lucrativas, incluidas en el sector de sociedades no financieras y financieras, venden sus servicios a precios de mercado y no verifican el principio de funcionamiento democrático. Entre estas organizaciones no lucrativas contempladas por el enfoque NPO que son excluidas del TS por el enfoque de ES cabe citar a determinados hospitales, universidades, colegios, entidades culturales y artísticas y otras instituciones que no cumplen el criterio democrático y que venden sus servicios en el mercado, verificando todos los requisitos establecidos por el enfoque NPO.

En el enfoque de ES, en general, son excluidas del TS aquellas entidades no lucrativas que no tengan un funcionamiento democrático si bien, como ya hemos ha señalado, se acepta la inclusión en la ES de aquellas en- 
tidades voluntarias no lucrativas que proporcionan servicios de no mercado a personas o familias de forma gratuita o a precios que no son económicamente significativos. Estas instituciones no lucrativas justifican su utilidad social en el suministro gratuito de bienes o servicios preferentes a personas o familias en riesgo de exclusión social.

c) El criterio del servicio a las personas

Por último, una tercera diferencia consiste en la diversa amplitud y jerarquía que en el enfoque NPO y en el de ES tienen los destinatarios de los servicios ofrecidos por las entidades integradas en el TS. En el enfoque de ES las organizaciones tienen como objetivo principal el servicio a las personas o a otras organizaciones de ES.

En las entidades de primer grado la mayoría de los beneficiarios de la actividad de dichas entidades son personas físicas, hogares o familias, sea en tanto que consumidores o sea en tanto que empresarios o productores individuales. Muchas de estas entidades solo admiten como socios a personas fisicas. En algunas ocasiones también autorizan el ingreso de personas jurídicas de cualquier tipo pero, en todo caso, la ES sitúa en el centro de sus preocupaciones a los seres humanos, que constituyen su razón de ser, la finalidad de sus actividades.

Sin embargo, en el enfoque NPO no existe ningún criterio que sitúe el servicio a las personas como objetivo prioritario. Las entidades no lucrativas pueden crearse, tanto para proporcionar servicios a las personas, como a las sociedades que las controlan o financian. Incluso pueden existir entidades no lucrativas de primer grado exclusivamente constituidas por sociedades de capital financieras o no financieras. De este modo, el campo de análisis del enfoque NPO queda delimitado de una forma muy heterogénea.

En conclusión, las similitudes y diferencias señaladas entre el enfoque NPO y el enfoque de ES, junto a la existencia de un espacio común de organizaciones consideradas por ambos enfoques, permiten apreciar importantes divergencias conceptuales y metodológicas que no hacen posible la configuración del TS como un simple resultado de agregación de los grupos de entidades contemplados por ambos enfoques.

En cuanto a las diferencias de ambos enfoques sobre las funciones que el TS puede desempeñar en las economías avanzadas, cabe decir que para el enfoque NPO el TS se sitúa entre el Estado y el mercado y las misio- 
nes de su núcleo más característico (el tercer sector social) consisten en satisfacer una importante cantidad de necesidades sociales que no son $\mathrm{cu}-$ biertas ni por el mercado (por falta de demanda solvente y con capacidad adquisitiva) ni por el sector público (por incapacidad de las finanzas públicas), de tal manera que es preciso recurrir a un tercer tipo de recursos y motivaciones. La concepción anglosajona, que se funda en el voluntariado, las charities (en Inglaterra) y las fundaciones (Estados Unidos), insiste en los valores de la filantropía y en el criterio del non-profit.

La falta de rentabilidad de las acciones desarrolladas demostrará la pureza y rectitud de las motivaciones que hay detrás de ellas y confirmará su pertenencia al TS que se presenta, de este modo, con un carácter caritativo y asistencial, con la misión de paliar las carencias de un sistema público de protección social poco generoso y los excesos de un sistema de mercado más dinámico, pero también más implacable que ningún otro sistema con los sectores sociales más insolventes.

Para el enfoque de ES, el TS no se sitúa entre el mercado y el Estado, sino entre el sector capitalista y el sector público. En este sentido, el TS se posiciona en las sociedades avanzadas como un polo de utilidad social constituido por un amplio conjunto de organizaciones privadas que se crean para resolver necesidades sociales y no para retribuir a inversores capitalistas.

En todo caso, la concepción del TS que desarrolla la ES configura a este no como un sector residual, sino como polo institucional del sistema que, junto al sector público y al sector privado capitalista, resulta clave para consolidar el bienestar en las sociedades avanzadas, contribuyendo a resolver algunos de sus problemas más relevantes como los de la exclusión social, el paro masivo de larga duración, los desequilibrios territoriales, la autonomía de los territorios, la distribución más equitativa de la renta y la riqueza y otros.

A diferencia del enfoque NPO, que solo contempla una función caritativa y filantrópica del TS, desarrollando iniciativas de solidaridad unidireccional, la ES promueve iniciativas empresariales de solidaridad recíproca entre sus promotores, basadas en un sistema de valores, en el que prevalece la democracia en la toma de decisiones y la primacía de las personas sobre los capitales en la distribución de los excedentes. 
La ES no solo contempla a las personas necesitadas como beneficiarias pasivas de la filantropía social, sino que, además, eleva a los ciudadanos a la categoría de protagonistas activos de su propio destino.

La principal conclusión que puede establecerse a partir de las reflexiones que hemos formulado es que el ámbito de la ES está suficientemente delimitado y diferenciado del resto de agentes económicos y que, por lo tanto, puede ser identificado como un sector institucional del sistema económico a partir de los criterios elaborados por las normas internacionales de contabilidad nacional. 


\title{
La configuración del sector empresarial de la Economía Social en España. La Economía Social como motor de creación de empleo
}

\author{
Juan Antonio Pedreño \\ Presidente de CEPES y COCETA
}

La Confederación Empresarial Española de la Economía Social, constituida en 1992, es una confederación empresarial, de ámbito estatal, cuyo carácter intersectorial la convierte en la máxima y única institución representativa de la Economía Social en España, constituyéndose como una plataforma de diálogo institucional con los poderes públicos $(<$ www.cepes.es $>$ ).

CEPES, como organización aglutinadora de las diversas actuaciones económicas existentes bajo el concepto de Economía Social, integra a 26 organizaciones. Todos ellas son confederaciones nacionales o autonómicas y grupos empresariales específicos que representan los intereses de las cooperativas, sociedades laborales, mutualidades, empresas de inserción, centros especiales de empleo, cofradías de pescadores y asociaciones del sector de la discapacidad.

CEPES representa y aglutina los intereses de 51.762 empresas, con una facturación que alcanzó los 101.555 millones de euros (aprox. el 10\% del PIB). Es un sector generador de empleo estable por encima de los esquemas tradicionales, y así se desprende de los 2.572.413 empleos del pasado año que representan el 12,5\% del total de la población ocupada. Más de 11.300 .000 personas están asociadas a organizaciones de economía social. "Una de cada cuatro personas está vinculada a la economía social». 
Son empresas que poseen un potencial de crear y desarrollar empleo más allá de los diversos esquemas económicos. Su ritmo de crecimiento hace que sea considerada como una actividad económica a desarrollar y a tener en cuenta como interlocutor social. Este potencial de crecimiento ha sido reconocido y apoyado históricamente por la Comisión Europea, que envía directrices y orientaciones a los gobiernos, aconsejándoles potenciar el sector de la Economía Social. Empresas que son el motor del empleo. En los últimos cuatro años, más de 3.000 empresas netas creadas y más de 250.000 empleos dan buena prueba de ello y confirman el resultado de una realidad económica y empresarial incuestionable.

\begin{tabular}{|ccc|}
\hline & $\begin{array}{c}\text { Evolución } n^{\circ}{ }^{\circ} \text { empresas } \\
\text { de Economía Social }\end{array}$ & $\begin{array}{c}\text { Evolución del empleo } \\
\text { en la Economía Social }\end{array}$ \\
\hline Año 2004 & 48.691 & 2.257 .986 \\
Año 2005 & 50.659 & 2.320 .454 \\
Año 2006 & 51.508 & 2.497 .846 \\
Año 2007 & 51.762 & 2.572 .413 \\
\hline
\end{tabular}

FUENTE: CEPES.

Son empresas de todos los tamaños, que actúan en todos los sectores económicos y combinan la eficacia empresarial con elementos de solidaridad y cohesión social; en definitiva estamos hablando de "otra forma de emprender».

Son empresas que se caracterizan y se diferencian fundamentalmente de la empresa tradicional en que:

- Prima la persona por encima del capital.

- Suelen ser organizaciones con espíritu democrático en la toma de decisiones.

- El reparto de beneficios/resultados se hace con criterios colectivos.

- Son empresas especialmente solidarias con el entorno y provocadoras de cohesión social.

- Funcionan con criterios de responsabilidad social.

- Nacen con vocación de creación de empleo estable y de calidad. 
Además, a diferencia del resto de empresas «tradicionales», las empresas de Economía Social ${ }^{1}$ :

- Se suelen ubicar en zonas geográficas donde el inversor tradicional no actúa porque no responde a sus criterios de rentabilidad. Está, además, comprometida con lo local y lo local es su fuente de energía. Si analizamos todos los nacimientos de los pequeños y grandes movimientos empresariales de la economía social, se puede observar que todos ellos surgen de la necesidad de dar soluciones a problemas del entorno ${ }^{2}$.

- Se cimientan en núcleos de población cuyo acceso al trabajo no tiene más alternativa que la construcción de su propio proyecto empresarial, o en sectores económicos que se han desarrollado gracias a este modelo de empresas, por ejemplo, en la agricultura, donde el peso de las cooperativas ha sido determinante en su evolución (fomentan el espíritu emprendedor) ${ }^{3}$.

- Dan respuesta a la cohesión e inserción social, mediante el trabajo asociativo o cooperativo para la integración de personas y grupos en riesgo de exclusión. Tiene presencia en espacios sociales desatendidos por el sistema económico tradicional.

1 Cumbre de Presidentes Iberoamericanos, celebrada en Montevideo el año 2006, en su punto 36 de las conclusiones: "Reconocemos el papel fundamental, en el desarrollo integral de nuestras naciones, de las cooperativas y demás organizaciones de economía social, cuyos principios de productividad, competitividad, complementariedad, solidaridad y, sobre todo de responsabilidad social, fortalecen el carácter participativo de nuestras democracias, convocan la integración y cohesión social, en particular de las mujeres, jóvenes, las personas adultas y con discapacidad, generando condiciones de desarrollo».

2 Dictamen del Consejo Económico y Social Europeo: "Economía Social y Mercado Único». Diario Oficial $n .{ }^{\circ} \mathrm{C} 117$ de 26/04/2000 p.0052-0058: «La economía social está presente en todos los niveles, tanto nacionales como europeos, pero sus raíces son locales. Desempeña un importante papel en el logro de la cohesión social. La economía social local comparte con el sector público la responsabilidad en las infraestructuras de la sociedad. Al mismo tiempo, las empresas de economía social desempeñan con frecuencia un papel importante en el desarrollo rural y urbano [...]». Dictamen de 2005 del Comité Económico y Social Europeo: "Alcance y efectos de la deslocalización de empresas». Fomenta el desarrollo local y el medio rural: «[...] Las empresas de economía social dada su tendencia interrumpida a crear empleo y, además, en virtud de su estatuto, a generar puestos de trabajo que, en principio, son más difícilmente deslocalizables».

3 Libro Verde El espíritu empresarial en Europa: «Las empresas de economía social fomentan la participación de los interesados en la gestión y la prestación de [...] servicios (sanitarios, educativos y de bienestar), proporcionando la innovación y la orientación al cliente». 


\section{Reflexiones}

1. Bajo una perspectiva cuantitativa, la Economía Social hoy es una realidad incuestionable representada por más de 51.500 empresas, de todos los tamaños y que actúan en todos los sectores económicos. Con una facturación anual que representa el 10\% del PIB, empresas que tienen más de 2.500.000 trabajadores que suponen el 12,5\% del empleo sobre la población ocupada y que asocian a más de 11.200 .000 personas.

2. ${ }^{\circ}$ Bajo una perspectiva asociativa, todas las organizaciones de la Economía Social representativas de las distintas familias que la componen y definen, forman parte de una organización, CEPES, única organización representativa de todo el conjunto de la Economía Social y en donde se ha entendido que es preciso actuar de forma unitaria, que no única, que ha conseguido una consolidación organizativa y la integración de todas las familias y que le ha permitido por todo esto tener un amplio reconocimiento institucional y social.

3. ${ }^{\circ}$ Bajo una perspectiva cualitativa en la aportación de valores a la sociedad, la Economía Social aporta valores como democracia, participación, solidaridad y además compromisos como el de ser unas empresas especialmente solidarias con el entorno, que funcionan con criterios de responsabilidad social, generadoras de un empleo estable por definición y, por tanto, empleo de calidad, y a su vez generadoras de capital social y siendo además un factor de democracia que contribuye a la estabilidad y al pluralismo de los mercados económicos.

Son empresas que apuestan por un desarrollo sostenible y por un compromiso con su entorno cercano y por tanto con el desarrollo local y que actúa allí donde se precisa una solución a problemas locales de empleo, que favorecen la integración sociolaboral de colectivos en exclusión. Empresas, en definitiva, con unos valores y unos referentes de plena vigencia y actualidad.

\section{Retos del Sector de la Economía Social}

- Reconocimiento de las organizaciones de la Economía Social como agente con derecho a la presencia sistemática en el diálogo institucional tanto a nivel nacional como internacional. Considerar la Economía Social como un agente económico que actúa con personalidad propia aportando riqueza colectiva, empleo y cohesión social, y admitir 
a sus organizaciones representativas, y en particular a CEPES como organización cúpula, vertebradora del sector, en todos los niveles de las Administraciones Públicas en los que se aborden temas que afectan a los ámbitos en que actúan. La Economía Social deberá ser reconocida y admitida como miembro en los foros de decisión económica, laboral y del diálogo institucional, y en aquellos en los que se aplican las políticas de formación, de empleo, el desarrollo social y el fomento de las PYMES.

- Consolidación como organización empresarial.

- Incrementar la visibilidad de las entidades y empresas de la economía social favoreciendo el reconocimiento público de la acción de estas empresas $y$ de su repercusión social, de forma que se facilite el necesario reconocimiento social e institucional. Los medios de comunicación de titularidad pública tendrán presente la difusión y explicación de esta realidad económica y social.

- Crear una Ley de Economía Social, que identifique esta forma de hacer empresa e integre sus diversas formas de actuar. Existe y actúa en la sociedad y en el mercado de forma incuestionable, pero no es reconocida jurídicamente y como tal debe serlo en el ordenamiento jurídico actual, procurando con ello eliminar interpretaciones restrictivas que van contra su justo reconocimiento.

- Fortalecer la presencia de las empresas de Economía Social en sectores emergentes, como la dependencia o el sector de la educación de 0 a 3 años.

- Posicionar a la Economía Social en el ámbito de la responsabilidad social de las empresas.

- Emprender las reformas legislativas necesarias para que las cooperativas, sociedades laborales, empresas de inserción para que se adapten a los nuevos retos de la economía globalizada al tiempo que se mejora su capacidad competitiva, dando respuesta a las nuevas necesidades sociales. También, la adaptación de todas aquellas normas que afecten a las demás entidades del sector de la Economía Social.

- Abordar la reforma de la Ley Fiscal de las Cooperativas, sobre todo a partir del Borrador de Decisión de la Comisión Europea que amenaza a la diferenciación fiscal de las cooperativas en cuanto a ser considerada Ayudas de Estado. 
- Reforzar la idea del emprendizaje y de su traslado a todos los puntos de los ámbitos laboral y educativo; especialmente, el emprendizaje en el ámbito de la Economía Social, potenciando su presencia tanto en los planes educativos en general, como de formación profesional en particular, así como impulsando su presencia en la universidad

- Fomentar el crecimiento del sector, animando la creación de empresas mediante las fórmulas de economía social e incentivando la generación de nuevas iniciativas de construcción de democracia económica.

- Favorecer el acceso a una financiación y una fiscalidad que atiendan a su especificidad empresarial.

\section{Medidas para combatir la crisis en las Empresas de Economía Social}

En un momento como el actual, de desaceleración económica que también está produciendo una desaceleración en la constitución de empresas de Economía Social, desde CEPES consideramos que es un compromiso de la organización, ante sus socios y ante la sociedad, facilitar una reflexión profunda sobre el papel que ha de desempeñar la Economía Social como motor de creación de empleo; ayudar a comprender el impacto de la desaceleración en cada familia empresarial, y realizar un adecuado diagnóstico de la situación en función de las necesidades, partiendo de los condicionantes de la situación económica real que rodea a las empresas pero construyendo escenarios de evolución probables, aportando posibles medidas organizativas y de gestión así como legislativas que minimicen el impacto de la incertidumbre y la transformación frente al descenso del ritmo de crecimiento.

Por estas razones, CEPES ha presentado al Gobierno la siguiente batería de medidas para combatir la crisis en las empresas de Economía Social.

1. ${ }^{a}$ Fomento y potenciación del sector de la economía social.

A) Crear políticas públicas que fomenten, apoyen y desarrollen esta forma de hacer empresa. Igualmente, actualizar o renovar leyes y normativas específicas reguladoras de cada figura jurídica, especialmente la Ley de cooperativas 27/1999, la Ley de sociedades laborales 4/1997 y la Ley de 
empresas de inserción 44/2007, de forma que se adecue toda la capacidad competitiva de las empresas de economía social en el mercado actual, equilibrando su acción con el resto de las empresas.

1. Incremento de la ayuda a percibir en la incorporación de socios y trabajadores. Modificación en la Orden TAS que incide directamente en determinadas órdenes autonómicas. Proponemos que la cantidad por incorporación quedase fijada entre 12.000 y 15.000 por persona.

2. Incremento de las dotaciones presupuestarias para la Dirección General de la Economía Social, del trabajo autónomo y de la responsabilidad social de la empresa, que consecuentemente incidirán en las cantidades a percibir por cada comunidad en función, entre otras variables, de la creación de empresas de Economía Social, (actualización de la Orden de Economía Social).

3. Modificación de la Ley de Cooperativas 27/1999 de ámbito estatal y las leyes cooperativas de las Comunidades Autónomas que lo requieran, recomendando a los Gobiernos de las Comunidades Autónomas que modifiquen de forma temporal, si lo estiman oportuno, las leyes de cooperativas en los siguientes temas: reducción de 3 a 2 del número de socios e incremento del porcentaje permitido de trabajadores por cuenta ajena.

4. Reforma de la Ley de Sociedades Laborales, partiendo de la propuesta elaborada por el sector, es decir, mejora del régimen jurídico y establecimiento, en consonancia con este, de incentivos fiscales a la sociedad y al socio trabajador para facilitar el acceso de los trabajadores asalariados a la condición de socio.

5. Desarrollo reglamentario de la Ley de Empresas de Inserción 44/2007 y desarrollo legislativo de esta en las Comunidades Autónomas.

B) Generar acciones, iniciativas de mediación e incentivos fiscales que favorezcan la concentración empresarial, la creación y la continuidad de las empresas, bajo cualquier tipo de forma jurídica y titularidad, así como el ahorro y la acumulación de capital para estos fines; para las diversas formas de autoempleo, impulsar la creación de empresas de economía social y primar legal y fiscalmente la autofinanciación.

C) Facilitar el acceso a la financiación por la vía de incentivar algunas entidades financieras a reducir el exceso de garantías exigidas; promover alternati- 
vas de financiación dirigidas a las empresas de economía social, PYMES y microempresas (créditos blandos, préstamos a largo plazo, fondos de inversión empresarial, capital riesgo...) para sus proyectos de calidad, modernización y de expansión, intentando que se abran a todos los sectores y a empresas pequeñas y creando marcos de relación entre capital y emprendedores. Creación de una línea de créditos desde el ICO para las empresas de Economía Social.

1. Creación de una línea de avales específica para las empresas de Economía Social que las dote de una mayor capacidad financiera de negociación y consecuentemente de una mayor competitividad, flexibilidad en estos momentos.

2. Fomentar la capitalización de las empresas, apoyando la inversión de las empresas y de los trabajadores, mediante una línea de subvención de puntos de interés para los préstamos solicitados por estas empresas (en concreto 2 ó 3 puntos subvencionados). También la subvención de 2 ó 3 puntos de interés, al menos para las aportaciones de capital social que hayan de realizar las personas que decidan incorporarse como socios (empleo estable), y de este modo suavizar las condiciones y dificultades que están generando las entidades financieras, al tiempo que se les da más seguridad.

D) Apoyar la creación de nuevas empresas de economía social que generen empleo, mediante una política de incentivos a la inversión para empresas formadas principalmente por colectivos que presentan dificultades de acceso al mercado laboral, como son los desempleados mayores de 45 años, mujeres, jóvenes, discapacitados, inmigrantes y parados de larga duración.

E) Crear incentivos al inicio de la actividad, tales como el asesoramiento técnico y tutelaje a las iniciativas en fase de creación, elaboración de planes de viabilidad, apoyo a los procesos de planificación, ingeniería y dirección facultativa, así como ayuda a la formación empresarial. Incrementar, dentro de los programas de «viveros de empresas», o asesoramiento y tutelaje en la construcción de nuevas empresas, el afianzamiento de fórmulas empresariales relacionadas con la economía social.

F) Promover y potenciar el establecimiento de alianzas, fusiones, consorcios $y$ redes, que tiendan a dotar a las entidades y empresas de economía social de 
una dimensión de actuación adecuada. Facilitando la creación de plataformas empresariales que posibiliten la mejor intercooperación y creen sinergias que mejoren su capacidad competitiva. Impulsar redes de negocio mediante el fomento de encuentros empresariales, mecanismos de cooperación y partenariado entre empresas de Economía Social.

G) Promocionar en los programas de desarrollo local la colaboración con las empresas de economía social existentes en el territorio, así como el fomento del autoempleo colectivo como fórmula de creación de empleo estable. Impulsar el reconocimiento del papel de la economía social en las estrategias para el desarrollo local.

H) Dar apoyo y crear planes de recuperación empresarial en empresas de economía social con dificultades o que actúen en sectores en crisis, o en un mercado más tradicional y competitivo, con el fin de evitar que puedan quedar sin trabajo los emprendedores y de suavizar la sensación de fracaso, especialmente en el medio rural por sus negativas repercusiones en el desarrollo de la capacidad de emprender

2. Eliminación de las restricciones que introducen elementos distorsionadores del acceso a las ayudas por parte de las empresas de Economía Social. Se propone que el Gobierno elabore una normativa precisa que excluya las ayudas a la economía social de la regla de mínimos tal y como la propia Comisión Europea establece.

3. Admitir en el régimen especial de autónomos a los socios de trabajo o trabajadores de las cooperativas que no son de trabajo asociado (cooperativas mixtas, consumo, $2 .^{\circ}$ grado, etc.).

4. ${ }^{a}$ Ampliar hasta 3 años el plazo de permanencia como trabajadores por cuenta ajena en una cooperativa podrá tener derecho a la capitalización del desempleo.

5. ${ }^{a}$ Bonificación temporal de seguridad social a las cooperativas por la incorporación de trabajadores por cuenta ajena como socios indefinidos.

6. ${ }^{a}$ Permitir la contratación de trabajadores por las cooperativas agrarias: se propone al Gobierno la incorporación en la Ley 27/1999 de Cooperativas de la contratación de trabajadores por las cooperativas agrarias que presten labores agrarias en las explotaciones de sus socios agricultores.

7. ${ }^{a}$ Reformas fiscales y contables en las sociedades cooperativas. Se precisa conseguir un adecuado tratamiento contable y fiscal en las sociedades 
cooperativas para adaptarlas a la normativa europea. Es necesaria una firme voluntad política para que esta reforma contemple la naturaleza de este tipo de sociedades, así como una comparabilidad con el resto de empresas que actúan en el mercado, de manera que no se provoque una desmotivación en la creación y mantenimiento de este tipo de sociedades. La puesta en marcha de esta reforma legislativa otorgará la seguridad jurídica necesaria y su competitividad en el mercado.

8. ${ }^{a}$ Potenciación de la iniciativa emprendedora, estableciendo políticas y objetivos tendentes a impregnar de actitud emprendedora la orientación profesional y laboral en la enseñanza, de manera que la Economía Social y el autoempleo se inserten realmente en los planes formativos de la formación reglada y la formación profesional. La relación entre universidad, centros de formación profesional, centros de investigación y empresas debe ser de prioridad 1, para la Administración, en aras a incentivar además tecnologías adecuadas para un futuro desarrollo sostenible.

9. ${ }^{a}$ Implementar la aprobación de la estrategia global para el empleo de las personas con discapacidad. Implementación, ejecución y seguimiento de esta estrategia es una demanda importante del sector de la discapacidad que se enmarca en los objetivos estratégicos de la UE y del Gobierno español para avanzar en la creación de un entorno dinámico y competitivo en el que la igualdad de oportunidades de las personas con discapacidad sea una realidad cada vez más plena. Por tanto, la reciente aprobación de esta estrategia, acordada con el sector y con los agentes sociales, es la señal de salida para tomar iniciativas y desarrollar políticas dirigidas a incrementar la todavía escasa participación en el mercado de trabajo y asegurar un empleo de calidad. Se trata de efectuar una completa renovación de las políticas de empleo hacia nuestro colectivo.

10. ${ }^{a}$ Atender las demandas del cooperativismo de viviendas: las cooperativas de vivienda generan empleo a razón de 2,8 a 4,1 puestos de trabajo por cada vivienda que promocionan. Para generar dicho empleo es imprescindible que las administraciones públicas atiendan las demandas del cooperativismo de viviendas, especialmente en lo relativo a la política de suelo, financiación y fiscalidad. Es necesario adaptar la Ley de Cooperativas para permitir que las cooperativas de viviendas puedan construir viviendas en régimen de alquiler. 
11. Implantar medidas de impulso de la actividad económica en el sector del transporte por carretera ante la situación de desaceleración de la economía española. Entre estas medidas se demanda una nueva regulación normativa de la cooperativa de transportes en España. La no contemplación en la ley de esta figura, está impidiendo que el conductor profesional y emprendedor, que tradicionalmente enriquecía las demandas de crecimiento de este sector estratégico, pueda acceder al sector. Este estrangulamiento ha afectado al desarrollo y regeneración de las cooperativas de transportista, por la falta de cantera de nuevos emprendedores que puedan acceder al sector y que permita sustituir a los socios que se dan de baja por jubilación. La regulación que se demanda, potenciará el crecimiento del sector y el acceso de nuevos emprendedores al sector del transporte por carretera, ya que permitirá que el socio transportista de la cooperativa pueda individualizar la explotación económica del vehículo de transporte que adscribe a la cooperativa, originando una unidad económica independiente. Pese a que dicha figura se está utilizando en la práctica totalidad de la geografia española, sin embargo solo se encuentra regulado legislativamente en las leyes autonómicas de cooperativas de Castilla-La Mancha y la ComunidadValenciana, por lo que sería necesario regularlo legislativamente en la ley estatal de cooperativas y en las restantes autonomías que aún no lo han hecho.

12. ${ }^{a}$ Potenciar el papel de las empresas de Economía Social en el sector de la dependencia y en el de «0 a 3 años». Las empresas de Economía Social llevan desempeñando históricamente un papel importante en ambos sectores, ahora mismo en auge y con excelentes posibilidades de crecimiento y, por tanto, de creación de empleo. Dada la experiencia de las empresas de Economía Social en estos ámbitos, se propone al Gobierno que implante medidas que eliminen los obstáculos actuales para el desarrollo de estas actividades económicas, garantizando de esta manera la creación de empresas y por consiguiente de empleos.

13. ${ }^{a}$ Reconocimiento de las organizaciones de Economía Social como agentes con derecho a la presencia sistemática en diálogo institucional. Ley de la Economía Social. Considerar la Economía Social como un agente económico que actúa con personalidad propia aportando riqueza colectiva, empleo y cohesión social, y admitir a sus organizaciones representativas, y en particular a CEPES como organización cúpula, vertebradora del sector, en 
todos los niveles de las administraciones públicas en los que se aborden temas que afectan a los ámbitos en que actúan. La Economía Social deberá ser reconocida y admitida como miembro en los foros de decisión económica, laboral y del diálogo institucional, y en aquellos en los que se aplican las políticas de formación, de empleo, el desarrollo social y el fomento de las PYMES. Es urgente y necesaria la creación de una Ley General de la Economía Social que permita definir un marco jurídico conocido y reconocido. 


\title{
El Tercer Sector de Acción Social y la Economía Social
}

\author{
José Manuel Fresno
}

Director gerente de la Fundación Luis Vives

El desarrollo de la iniciativa social en nuestro país se ha visto reforzado por la configuración de un sistema tardío de protección social en el que se ha optado por un modelo de provisión de servicios mixto público privado en el que se han abierto grandes posibilidades para la empresa privada y, en algunos campos, también para la Economía Social y las entidades sin ánimo de lucro. Este hecho, unido a un crecimiento de la filantropía, tanto individual como empresarial, en un contexto de importante desarrollo económico y la madurez de la propia sociedad civil, ha propiciado un desarrollo importante del Tercer Sector de Acción Social, no solo en sus dimensiones sino también en las actuaciones que desarrolla y en la función social que tiene.

La Fundación Luis Vives pone en marcha una iniciativa denominada Anuario Tercer Sector Social que tiene por objeto realizar un informe periódico sobre la situación y tendencias de esta parte del Tercer Sector que no solo va adquiriendo mayor relevancia sino creciente conciencia de su identidad.

\section{El Tercer Sector de Acción Social a la búsqueda de su identidad}

Podemos convenir en que el Tercer Sector de Acción Social (TSAS) es el ámbito formado por entidades privadas de carácter voluntario, no gubernamentales $y$ sin ánimo de lucro que, surgidas de la libre iniciativa ciudadana, funcionan de forma autónoma y solidaria tratando, por medio de acciones de interés general, de impulsar 
el reconocimiento y el ejercicio de los derechos sociales, de lograr la cohesión y la inclusión social activa en todas sus dimensiones y de evitar que determinados colectivos sociales queden excluidos de unos niveles de recursos suficientes de bienestar.

Se trata, por tanto, de aquella parte del Tercer Sector que actúa en el campo de lo social y provee bienes y servicios de tipo material e inmaterial a aquellas personas excluidas o en riesgo de exclusión. El TSAS actúa en muchos casos como la última malla de la protección social y se enfrenta, en este momento, a una coyuntura actual dado que la crisis económica hace que crezca la demanda de sus servicios y corra el riesgo de reducir la oferta por la dificultad de obtener recursos económicos para mantener los mismos.

Si hemos de definir el TSAS por las características de las entidades que lo conforman, diremos que es un conjunto heterogéneo en el que además de asociaciones y fundaciones, confluyen otras formas jurídicas sin afán de lucro que persiguen fines de interés general como por ejemplo, las cooperativas sociales o entidades singulares como son ONCE, Cruz Roja y Cáritas. Algunos rasgos comunes de estas entidades son:

- Se trata de organizaciones que tienen personalidad jurídica, lo que significa que poseen una presencia y una estructura institucional; no se incluye por tanto la acción solidaria primaria o la acción solidaria organizada pero no conformada en estructuras jurídicas.

- Son entidades de carácter meramente no lucrativo también denominadas Organizaciones No Lucrativas de Acción Social (ONLAS), es decir, que se orientan al beneficio público, para satisfacer necesidades de personas, hogares y familias y no para obtener rentabilidades financieras. Pueden obtener beneficios pero estos deben ser reinvertidos en la finalidad social de la entidad y no distribuidos entre los miembros de la organización.

- Son organizaciones privadas, es decir, sin carácter gubernamental, formalmente separadas de las administraciones públicas, aunque mayoritariamente reciben financiación pública y en algunos casos incluyen en sus órganos directivos a representantes de las administraciones públicas. Con esto queremos resaltar la necesaria autonomía operativa y capacidad de control de estas entidades sobre sus actividades y libertad para elegir o cesar a sus órganos de gobierno. 
- Se trata de entidades que pretenden tener capacidad de autonomía financiera aunque estas utilicen recursos económicos ajenos que proceden por distintas vías: contraprestación a un servicio, cuotas de los miembros, donaciones y legados, ayudas y subvenciones, rendimientos de su patrimonio y activos, etc.

- Otro criterio prevalente es una adhesión y participación voluntaria. El carácter voluntario es un criterio que puede entenderse en un sentido amplio, bien porque la entidad canaliza el trabajo del voluntariado, bien porque la gestión de la misma se hace de forma voluntaria (órganos de dirección). Asimismo, significa que la pertenencia a ellas no es obligatoria, además la organización puede contar con la participación de voluntariado en sus actividades $\mathrm{y} / \mathrm{u}$ órganos de gobierno.

- Por último, el carácter democrático. Se considera también un elemento clave que suele caracterizar a estas organizaciones el hecho de contar con ciertos valores orientados a potenciar la participación activa de sus miembros.

En cuanto a las características de su actuación las entidades del TSAS muestran una realidad compleja y variada que podemos caracterizar en base a distintos aspectos:

- Si atendemos a su objeto social, estas entidades pretenden el desarrollo de actividades de utilidad social, que apuntan a la mejora de las condiciones de vida de las personas en situación social vulnerable o en riesgo de exclusión: objetivos de bienestar vinculados a temáticas de acción social y colectivos desfavorecidos. Además, estas actividades se distribuyen en diferentes ejes o campos sociales: un eje económico (empleo, ingresos...), en el cual la AS tiende a intervenir contra los efectos de la precariedad, espiral de la pobreza, principalmente a través de la prestación de servicios; un eje de relaciones sociales (aislamiento social, conflicto social...), en este caso, la AS engloba acciones de apoyo social; un eje de desarrollo personal/social (salud y sucesos vitales, dependencia, vivienda/alojamiento, convivencia), la AS engloba intervención de tipo apoyo social, autoayuda... Por último, un eje ciudadanía (participación política y social, edu- 
cación...), donde se desarrollan principalmente acciones de tipo educativo, formación y sensibilización.

- En relación a la actuación que desarrollan, el tipo de intervención puede ser directa o indirecta; el campo de acción (inserción laboral, dependencia, género...); el objeto de atención a colectivos especiales (mujeres, inmigrantes, infancia...) y los colectivos relacionados con estos (profesionales, voluntariado...).

- En cuanto a las acciones, por un lado, consta la línea de intervención directa con personas o grupos vulnerables, se materializa por diferentes actividades: información, orientación y formación, acompañamiento en búsqueda de empleo, seguimiento social en el proceso de inclusión, servicio de intermediación, asesoramiento, atención personal, proporcionar alojamiento, puesto de trabajo, etc., apoyando la vida independiente y la participación, etc. Por otro lado, el desarrollo de una acción indirecta a través de actuaciones transversales destinadas a la mejora de las condiciones de realización de las actividades directas. Formación de profesionales, campañas de información y sensibilización social para nuevos reclutamientos de recursos humanos (fomentar el voluntariado) o económicos (filantropía, donativos...). O desde programas de actuación integral (acogida, recursos de integración social, formación cultural, acceso a la vivienda digna, recursos educativos (alfabetización, formación del idioma del territorio de acogida...), protección jurídica... Conjunto de acciones que aspiran a sentar las bases de una plena participación ciudadana.

- Desde la perspectiva territorial estas entidades pueden actuar en el plano nacional, autonómico o local.

\section{Algunos datos de referencia}

Uno de los problemas fundamentales que nos encontramos a la hora de definir el Tercer Sector Social, es la falta de datos actualizados y comparables respecto a su realidad actual; magnitudes económicas, actividad que desarrolla, recursos humanos que moviliza, etc. Los distintos estudios que se han realizado presentan datos dispares y no siempre comparables. Se trata, además, de un ámbito de actuación en el que se producen eleva- 
das tasas de natalidad, dado que el ritmo de crecimiento es alto, pero también de mortalidad, o al menos de inactividad.

De acuerdo con distintos estudios podríamos considerar que elTSAS está integrado por más de 16.000 entidades, lo cual podría representar entorno al $18 \%$ de las entidades del sector. Estas organizaciones podrían estar empleando a más de 210.000 trabajadores y parece que, proporcionalmente, son más intensivas en la creación de empleo que otros subgrupos del Tercer Sector. Además movilizan cerca de un millón de personas voluntarias que colaboran con distintas tareas. El gasto anual acumulado de estas entidades podría estar en torno a 4.000 millones de euros y se considera que se podría haber duplicado en los últimos diez años.

Pero estas cifras y tendencias esconden una gran disparidad dentro de las Organizaciones No Lucrativas de Acción Social (ONLAS). Una característica importante es la fuerte concentración de recursos que se produce en algunas entidades y la atomización entre ellas. Así se considera, por ejemplo, que más del $50 \%$ de los fondos es gestionado solamente por el $5 \%$ de entidades con presupuestos superiores a tres millones de euros al año y que en torno al $70 \%$ de estas entidades cuenta con menos de cinco empleados.

\section{Tendencias y cambios recientes}

En el seno del TSAS los movimientos no solo son de orden cualitativo, sino que todo parece indicar que se está produciendo una profunda transformación de acuerdo con las tendencias que se pueden observar en los últimos años. El crecimiento en volumen viene por tanto acompañado por una expansión en el tipo de actividades y por una transformación en varios aspectos internos. Señalamos a continuación algunas de las tendencias que se observan:

- En los últimos años muchas ONLAS parecen estar desbordando el campo social en el que nacieron y comienzan a jugar de modo activo también en la arena política, especialmente a través de su influencia en la agenda política, en la arena económica, por su peso en la prestación de algunos servicios sociales a las personas y en la arena mediática, por su creciente presencia en los medios de comunicación. 
- La riqueza de estas entidades sociales se basa, precisamente, en la diversidad de sus objetivos, tamaño, presupuesto, sistemas de financiación, estilos de trabajo, etc. Si bien en el conjunto del TSAS persiste una diversidad de opciones de actuación que van desde la sensibilización a la denuncia, reivindicación, defensa de derechos, autoayuda, prestación de servicios, etc., parece que en los últimos años se produce una deriva hacia la prestación de servicios, especialmente en las entidades medianas y grandes, en detrimento de otras opciones. Este fenómeno viene determinado por el modo, lo mismo de provisión de la protección social que se está configurando en nuestro país y el sistema de financiación del sector y trae consigo importantes consecuencias en la cultura organizativa y de funcionamiento.

- La profesionalización creciente que se está produciendo en estas entidades tiene, en algunas de ellas, un tinte de profesionalismo en el que el protagonismo, poder y capacidad de decisión de los profesionales se desarrolla en detrimento de los promotores y órganos de gobierno que, a veces, quedan relegados a meras funciones ratificadoras.

- Por último, se está produciendo en el mundo de las ONLAS una emergencia de entidades de segundo nivel y de sistemas de trabajo en red, que va más allá de la clásica agrupación en federaciones y confederaciones, por colectivos de actuación, y responde a necesidades de trabajo más transversal, coordinación, creación de sinergias, etc.

\section{Problemas a los que se enfrenta}

El contexto de cambio en el que operan las entidades de acción social, unido a los elementos previamente descritos, hace que en estos momento el TSAS se encuentre en una especial coyuntura en la que se enfrenta a una serie de problemas que, depende de cómo sean abordados, determinarán su tendencia de futuro:

- El pensamiento global del sector está muy atomizado y es poco corporativo. Ello viene determinado por la falta de identidad como sector, tanto hacia fuera, por la dificultad de definir sus límites y fronteras, como hacia adentro, por la dificultad de encontrar elementos definitorios. 
- La fuerte dependencia externa es otro de los problemas determinantes de la coyuntura actual. Esta dependencia se produce, fundamentalmente, con respecto de la administración pública, dado que en torno al 50\% de los recursos económicos que gestionan estas entidades procede de la misma (40\% en las fundaciones y $60 \%$ en las asociaciones)

- Las entidades de acción social se han estructurado, históricamente, por colectivos de actuación de modo vertical; a ello se ha sumado recientemente la emergencia de redes y entidades de segundo nivel. A pesar de la emergencia reciente de redes y plataformas, hemos de afirmar que el sector, en su conjunto, sigue estando muy desestructurado.

- Las nuevas formas de organización interna de las entidades del TSAS, junto con el contexto en el que operan y sus opciones de actuación, ha conllevado recientemente, en muchas de ellas, a una transformación, más bien pérdida de buena parte de su base; una dilución del tejido social con el que contaban previamente y también cierto olvido de la cultura asociativa que les es propia. Se ha pasado a un contexto en el que el socio se transforma en cliente y el beneficiario, en usuario.

- La entidades delTSAS no solo comunican cada vez más sino que lo hacen también mejor; sin embargo, la percepción social de estas entidades es cuando menos ambigua: por una parte, de acuerdo con varios estudios, los ciudadanos se fian más de estas ONG que de otras instituciones como la Iglesia, los sindicatos o el ejército; por otra parte, existe también cierta sospecha respecto al modo en que gestionan sus fondos y la eficiencia en el uso de los mismos.

\section{Retos a corto y medio plazo}

El TSAS se enfrenta a una serie de retos a corto y medio plazo que están básicamente relacionados con su autonomía, especialmente financiera, su capacidad de interlocución social y el desarrollo de sus recursos humanos. De modo más concreto podemos desgranar estos retos en los siguientes aspectos:

- En primer lugar, es necesario lograr una mayor autonomía, especialmente financiera, que será garante de la autonomía política, 
ideológica y de actuación. Para ello habría que buscar una sostenibilidad en sus programas y actuaciones, diversificar las fuentes de financiación reduciendo la dependencia pública y avanzar hacia un nuevo sistema de financiación por parte de la administración pública, que sea más estable (conciertos en la prestación de servicios), menos cortoplacista y clientelista.

- En segundo lugar, el TSAS tienen que reforzar su base social, a la que dice representar, no olvidarse de que en su esencia está la creación de tejido social y capital relacional. Unido a ello tienen que ser más activos en la reivindicación del diálogo civil y la articulación del mismo, lo cual no excluye su posible participación en el diálogo social.

- En tercer lugar, es muy importante que estas entidades refuercen y mejoren su imagen con una mayor transparencia, fomenten la confianza de la sociedad en sus actuaciones y la credibilidad social. Las ONG ya no se legitiman hoy solo por las causas nobles que defienden y por su carácter altruista, sino por la confianza que generan, su congruencia, etc.

- En cuarto lugar, las entidades sociales tienen que buscar ser más eficientes en el uso de sus recursos y en los resultados que obtienen con sus actuaciones. Para ello es imprescindible que gestionen con mayor calidad modernizando sus sistemas de gestión, adoptando el uso de herramientas adecuadas, etc.

- En quinto lugar, el TSAS ha de trabajar por una mayor cualificación y desarrollo de sus recursos humanos; esta cualificación no solo tiene que ver con las competencias, sino también con los valores y la cultura organizativa.Y se da por entendido que cuando hablamos de los recursos humanos en este contexto, nos estamos refiriendo no solo a los profesionales sino también a los promotores y voluntarios.

- Por último, pero no por ello menos importante, las entidades sociales tienen que seguir estando atentas a la innovación, dado que una característica tradicional de las mismas ha sido su sensibilidad para estar atentas a las nuevas necesidades sociales y su capacidad para dar respuestas siendo pioneras en las mismas. 


\section{El Anuario del Tercer Sector de Acción Social en España}

La Fundación Luis Vives, como entidad privada e independiente cuya misión es el apoyo y el fortalecimiento del Tercer Sector de Acción Social, pone en marcha en el año 2008 la iniciativa de desarrollar un Anuario sobre el Tercer Sector Social. Esta iniciativa viene determinada por el hecho de que:

- Apenas existe información actualizada sobre el Tercer Sector Social en nuestro país, pues es un sector sobre el que se investiga poco.

- No existen estudios que, con carácter periódico y comparativo, analicen la realidad del mismo. Los escasos aunque importantes estudios que se han realizado, tanto con perspectiva nacional como autonómica, en los que se ha analizado la situación y tendencias de las entidades sociales, no son comparables ni periódicos.

- Se trata de un sector dinámico, que se encuentra en un fuerte proceso de crecimiento, transformación y cambio, por lo que es necesario disponer de información actualizada periódicamente.

El objetivo del Anuario sobre el Tercer Sector de Acción Social es aportar información periódica y actualizada sobre la situación, evolución y tendencias de las entidades de acción social en nuestro país. Este informe aportará datos actualizados y comparables sobre la situación y tendencias a lo largo del tiempo, lo cual será de suma utilidad no solo para el propio Tercer Sector, sino también para las administraciones y la sociedad en su conjunto.

El Anuario tendrá dos tipos de productos que se presentarán en años alternos. El primero de ellos será de carácter cuantitativo, obteniendo la información mediante la realización de una encuesta que se repetirá bienalmente, con objeto de contar con series de datos comparables sobre la realidad del sector, sus magnitudes, actividad y tendencias. El segundo podrá ser cuantitativo o cualitativo y tendrá un carácter temático, es decir, cada uno abordará una temática o situación específica de especial relevancia e interés para el Tercer Sector de Acción Social.

Para la elaboración del primero de los informes cuantitativos, es necesario comenzar por definir el concepto de Tercer Sector de Acción 
Social y acotar el tipo de entidades que pueden ser incluidas en el mismo. Un comité científico está ayudando al equipo de investigación en este cometido. Una vez consensuado el objeto de estudio se procederá a la identificación del universo a través de directorios, registros y fuentes secundarias.

En relación a la muestra, la técnica que se ha considerado más adecuada para obtener información periódica, mediante series de datos que permitan analizar la evolución y tendencias del sector, es la de panel de entidades estadísticamente representativo estratificado en función de la naturaleza jurídica, el campo de actuación, el tamaño de la entidad, el ámbito geográfico de actuación. El panel así obtenido se renovará de forma continua y sistemática, haciendo rotar un 15\% de la muestra en cada informe bienal.

En cuanto al trabajo de campo, se establecen dos etapas, una primera de contacto, actualización y captación de las unidades muestrales y una segunda de recogida de datos mediante un cuestionario adaptable a las distintas características de aquellas (entidades singulares, de segundo nivel, etc.).

En el primer año de realización se obtendrán los productos siguientes:

- Directorio de «Entidades del Tercer Sector de Acción Social en España", el cual permitirá disponer de información básica actualizada de cada entidad.

- Microdatos en soporte electrónico accesible, «Encuesta a Entidades del Tercer Sector de Acción Social en España», lo que permitirá realizar una difusión personalizada e incluso ofrecer datos «a la carta» para instituciones y profesionales, así como posibilidad de explotación y profundización por otros investigadores.

- Sumario, "Anuario sobre el Tercer Sector de Acción Social», que recogerá los principales resultados del Anuario en un formato visual para que resulte útil para presentarlo en ponencias o para medios de comunicación.

— «Anuario sobre el Tercer Sector de Acción Social». Informe descriptivo del Tercer Sector de Acción Social en España. En este informe se presentarán tablas, gráficos y comentarios sobre los 
resultados obtenidos. Los datos que se aportarán provendrán de las frecuencias, medias y porcentajes de las preguntas del cuestionario. Junto a ello se aportarán cruces de variables que son de interés para la investigación, así como datos comparativos con otras investigaciones cuando esto sea posible.

Todos estos productos serán accesibles para organizaciones no lucrativas, investigadores, administraciones públicas y otros interesados, tanto en formato físico como en formato digital, a través de la web de la fundación. 



\title{
La Economía Social: dos décadas generando empleo, tejido productivo y cohesión social en Europa ${ }^{1}$
}

\author{
RAFAEL Chaves
}

Director del Instituto Universitario de Economía Social y Cooperativa (IUDESCOOP) de la Universidad de Valencia

Aunque la ES conoce un relativo protagonismo en Europa en el primer tercio del siglo XX, el modelo de crecimiento del periodo 1945-1975 en Europa Occidental tiene como principales actores el sector privado capitalista tradicional y el sector público. Sobre dicho modelo se construye el Estado del Bienestar que, frente a los conocidos fallos del mercado, despliega un conjunto de políticas que resultan muy efectivas para corregir dichos fallos: políticas de redistribución de la renta, de asignación de recursos y de carácter anticíclico. Todas ellas basadas en el modelo keynesiano, en cuyo diseño los grandes actores sociales y económicos son, junto a los poderes públicos, la patronal y los sindicatos.

La consolidación de los sistemas de economía mixta no impidió el desarrollo de un significativo conjunto de empresas y organizaciones - cooperativas, mutualidades y asociaciones - que contribuyó a resolver problemas de importancia social y de interés general, relacionados con el desempleo

1 La presente ponencia está ampliamente basada en el estudio elaborado bajo la dirección de Rafael Chaves y José Luis Monzón para el Comité Económico y Social Europeo por el CIRIEC (Centro Internacional de Investigación e información sobre la Economía Pública, Social y Cooperativa) titulado «La Economía Social en la Unión Europea». 
cíclico, los desequilibrios territoriales y del medio rural, la descompensación de poder entre las organizaciones de distribución comercial y los consumidores y otros. Sin embargo, en este periodo, la ES prácticamente desaparece como institución significativa en el proceso de armonización del crecimiento económico con el bienestar social, correspondiendo casi todo el protagonismo al Estado.

En los países de Europa Central y Oriental, vinculados al sistema soviético y con economías centralmente planificadas, el Estado es el único protagonista de la actividad económica, sin ningún espacio de actuación para los agentes de la ES. Tan solo las cooperativas tienen una importante presencia en algunos países del bloque soviético, si bien con algunos de sus principios clásicos de comportamiento totalmente anulados, como el de "puerta abierta», «libertad de adhesión y de salida» y el de la "organización democrática».

Es a partir de la crisis del Estado del Bienestar y de los sistemas de economía mixta, en el último cuarto del siglo XX, cuando se produce en diversos países europeos un renovado interés por las organizaciones típicas de la ES, tanto por las fórmulas empresariales alternativas a las capitalistas y a las del sector público, como pueden ser las cooperativas y las mutuas, como por las entidades de no mercado, mayoritariamente constituidas por asociaciones y fundaciones. Un interés que se deriva de las dificultades que tienen las economías de mercado para encontrar soluciones satisfactorias a problemas tan relevantes como el del desempleo masivo de larga duración, la exclusión social, el bienestar en el medio rural y en zonas urbanas degradadas, la sanidad, la educación, la calidad de vida de la población jubilada, el crecimiento sostenible y otros. Se trata de necesidades sociales que no encuentran oferta suficiente o adecuada ni por los agentes privados de naturaleza capitalista ni por el sector público, ni tampoco fácil solución a través de los mecanismos autorreguladores del mercado ni de las políticas macroeconómicas tradicionales.

En los últimos decenios, a pesar de los procesos de desmutualización de importantes cooperativas y mutuas, el sector empresarial de la ES (cooperativas y mutuas) ha tenido, en su conjunto, un importante crecimiento. Importantes estudios han puesto de relieve el fuerte crecimiento experimentado en Europa por el conjunto de la ES. Uno de los más sig- 
nificativos ha sido el realizado por el CIRIEC para la Comisión Europea en el marco de la acción piloto "Tercer Sistema y Empleo» (CIRIEC, $2000)^{2}$ y en el que se subraya la creciente importancia de cooperativas, mutuas y asociaciones en la creación y mantenimiento del empleo y en la corrección de importantes desequilibrios económicos y sociales.

Tras el desmoronamiento del bloque soviético se produjo el colapso de muchas cooperativas en los países de Europa Central y del Este, que, además, conocieron un importante desprestigio entre la opinión pública. Sin embargo, en los últimos años se está produciendo un renacimiento de la iniciativa ciudadana en el desarrollo de proyectos de la ES que encuentra su reflejo en propuestas legislativas que impulsan las entidades de este sector.

Actualmente las grandes familias de Economía Social europea tienen una amplia presencia en Europa: en la Unión Europea de los 25 en el 2005 existían más de 240.000 cooperativas activas, que proporcionaban empleo directo a 4,7 millones de trabajadores y agrupaban a 143 millones de socios (Cooperatives Europe, 2006). Se hallan sólidamente implantadas en todos los sectores de actividad económica, siendo especialmente importantes en la agricultura, la intermediación financiera, la distribución comercial, la vivienda y el trabajo asociado en la industria, la construcción y los servicios. Por su parte, las mutuas de salud y protección social ofrecen asistencia y cobertura a más de 120 millones de personas. Las mutuas de seguros representan una cuota de mercado del 23,7\% (Association des coopératives et mutuelles d'assurance, AIM). Finalmente, las asociaciones representan en 2005 más del 4\% del PIB y agrupan al 50\% de la ciudadanía de la Unión Europea. En el año 2000 la UE-15 contaba con más de 75.000 fundaciones, con un fuerte crecimiento de las mismas a partir de 1980 en los 25 países miembros, incluyendo los recientemente incorporados de Europa Central y del Este (Richardson, 2003).

En las décadas recientes la Economía Social no solo ha afirmado su capacidad para contribuir eficazmente en la resolución de los nuevos problemas sociales, sino que se ha consolidado en sectores tradicionales como la agricultura, el trabajo asociado, los servicios, el consumo y las activida-

2 Disponible en <www.ulg.ac.be/ciriec>. 
des financieras y mutualistas. Es decir, la ES también se está proyectando como una institución necesaria para la estabilidad y sostenibilidad del crecimiento económico, el ajuste entre los servicios y las necesidades, la valorización de la actividad económica al servicio de las necesidades sociales, la distribución más equitativa de la renta y la riqueza, la corrección de desequilibrios en el mercado de trabajo y la profundización de la democracia económica.

La ES se ha posicionado en la sociedad europea como un polo de utilidad social, entre el sector capitalista y el sector público, que está constituido, ciertamente, por una gran pluralidad de actores. Viejas y nuevas necesidades sociales constituyen, todas ellas, el ámbito de intervención de la ES; necesidades que pueden resolverse empresarialmente por los propios afectados a través del mercado, en el que casi todas las cooperativas y mutuas obtienen la mayoría de sus recursos, o mediante casi todas las asociaciones y fundaciones, que suministran servicios de no mercado a las personas, hogares o familias y que, habitualmente, consiguen sus recursos mayoritarios gracias a donaciones, cuotas de socios, subvenciones, etc.

Pero esta ES plural, que se afirma y consolida a su vez en el seno de una sociedad plural, no significa un totum revolutum carente de identidad o de valor interpretativo. Al contrario, el núcleo identitario común de la ES se afirma a partir de un amplio y diverso conjunto de entidades microeconómicas, de carácter libre y voluntario, creadas desde la sociedad civil para satisfacer y resolver las necesidades de los individuos, hogares o familias y no para retribuir o dar cobertura a inversores o a empresas capitalistas, es decir, se está hablando de entidades de finalidad no lucrativa (not-for-profit). A lo largo de los últimos 200 años, este variado espectro de organizaciones de mercado o de no mercado, de interés mutualista o de interés general, ha conformado el Tercer Sector, tal y como aquí ha sido identificado por el enfoque de la ES.

\section{La actual Economía Social europea: componentes, dimensiones y modelos}

¿Qué formas institucionales integran el campo de la Economía Social? El resultado del estudio, consultados los expertos corresponsales nacionales, es el que aparece reflejado en la tabla 1. 
TABLA 1

Los componentes de la Economía Social en Europa

\begin{tabular}{|l|c|c|c|c|c|}
\hline \multicolumn{1}{|c|}{ Country } & Cooperative & Mutual & Association & Foundation & Others \\
\hline Belgium & $\mathrm{X}$ & $\mathrm{X}$ & $\mathrm{X}$ & $\mathrm{n} / \mathrm{a}$ & \\
France & $\mathrm{X}$ & $\mathrm{X}$ & $\mathrm{X}$ & $\mathrm{X}$ & $X 1$ \\
Ireland & $\mathrm{X}$ & $\mathrm{n} / \mathrm{a}$ & $\mathrm{n} / \mathrm{a}$ & $\mathrm{n} / \mathrm{a}$ & $\mathrm{X}$ \\
Italy & $\mathrm{X}$ & $\mathrm{X}$ & $\mathrm{X}$ & $\mathrm{X}$ & $\mathrm{X}$ \\
Portugal & $\mathrm{X}$ & $\mathrm{X}$ & $\mathrm{X}$ & $\mathrm{X}$ & $X 4$ \\
Spain & $\mathrm{X}$ & $\mathrm{X}$ & $\mathrm{X}$ & $\mathrm{X}$ & $X 5$ \\
Sweden & $\mathrm{X}$ & $\mathrm{X}$ & $\mathrm{X}$ & $\mathrm{X}$ & \\
Austria & $\mathrm{X}$ & $\mathrm{X}$ & $\mathrm{X}$ & $\mathrm{X}$ & $X 2$ \\
Denmark & $\mathrm{X}$ & $\mathrm{X}$ & $\mathrm{X}$ & $\mathrm{X}$ & $X 2$ \\
Finland & $\mathrm{X}$ & $\mathrm{n} / \mathrm{a}$ & $\mathrm{n} / \mathrm{a}$ & $\mathrm{n} / \mathrm{a}$ & $X 2$ \\
Germany & $\mathrm{X}$ & $\mathrm{X}$ & $\mathrm{X}$ & $\mathrm{X}$ & $\mathrm{X}$ \\
Greece & $\mathrm{X}$ & $\mathrm{X}$ & $\mathrm{X}$ & $\mathrm{X}$ & $X 7$ \\
Luxembourg & $\mathrm{X}$ & $\mathrm{X}$ & $\mathrm{X}$ & $\mathrm{X}$ & \\
Netherlands & $\mathrm{X}$ & $\mathrm{X}$ & $\mathrm{X}$ & $\mathrm{X}$ & \\
United Kingdom & $\mathrm{X}$ & $\mathrm{X}$ & $\mathrm{X}$ & $\mathrm{X}$ & \\
New member states & & & & & \\
Cyprus & $\mathrm{X}$ & $\mathrm{n} / \mathrm{a}$ & $\mathrm{n} / \mathrm{a}$ & $\mathrm{n} / \mathrm{a}$ & \\
Czech Republic & $\mathrm{X}$ & - & $\mathrm{n} / \mathrm{a}$ & $\mathrm{n} / \mathrm{a}$ & $X 8$ \\
Estonia & $\mathrm{X}$ & $\mathrm{n} / \mathrm{a}$ & $\mathrm{X}$ & $\mathrm{X}$ & \\
Hungary & $\mathrm{X}$ & - & $\mathrm{n} / \mathrm{a}$ & $\mathrm{X}$ & $X 9$ \\
Latvia & $\mathrm{X}$ & $\mathrm{n} / \mathrm{a}$ & $\mathrm{X}$ & $\mathrm{X}$ & \\
Lithuania & $\mathrm{X}$ & - & $\mathrm{n} / \mathrm{a}$ & $\mathrm{n} / \mathrm{a}$ & $X 10$ \\
Malta & $\mathrm{X}$ & $\mathrm{n} / \mathrm{a}$ & $\mathrm{X}$ & $\mathrm{X}$ & \\
Poland & $\mathrm{X}$ & $\mathrm{n} / \mathrm{a}$ & $\mathrm{X}$ & $\mathrm{X}$ & $X 11$ \\
Slovenia & $\mathrm{X}$ & $\mathrm{X}$ & $\mathrm{X}$ & $\mathrm{X}$ & $X 12$ \\
\hline
\end{tabular}

Note: Questionnaire question: Which of the following institutional forms do you consider to belong to the field of the "Social Economy" in your country or, if applicable, to a related concept that you consider more widely accepted?

X1: Comités d'entreprises (work councils) ; Organisations paritaires sans adhésion obligatoire (non compulsory organisations with worker's participation); Entreprises d'insertion

X2: Social enterprises

X3: Volunteering Organisations; Community Foundations; Non-Governmental Organisations; IPAB: Istituzioni di Pubblica Assistenza e Beneficenza

X4: $\quad$ Misericordias; IPSS (Instituições Particulares de Solidariedade Social);

X5: $\quad$ Sociedades Laborales, Empresas de Inserción, Centros Especiales de Empleo, specific groups such as ONCE, Sociedades Agrarias de Transformación

X6: Quangos; Social enterprises

X7: Hybrid forms between the conventional CMAF and private firms or public or professional organisations or local authorities (e.g. Development Agencies, "popular companies")

X8: Association of Common Benefits;

X9: $\quad$ Non profit companies

X10: Credit Unions / Social Enterprises

X11: Centres for Social Integration

X12: Public and Private institutions; Public enterprises 
Tres principales conclusiones pueden ser extraídas. La primera y fundamental es que los componentes varían significativamente de un país a otro, existiendo formas genuinas nacionales que los expertos han considerado ser integrantes de la Economía Social de su país (ver los X1, X2, etc.). En algunos países, como Italia y España, existen concepciones divergentes del ámbito de la Economía Social: convive una concepción empresarial de la Economía Social, integrada principalmente por las cooperativas, con una concepción de no mercado de la Economía Social, integrada principalmente por asociaciones, cooperativas sociales y otras entidades sin fines de lucro.

Una segunda conclusión a extraer es que la concepción más conocida de Economía Social, la que integra a las cooperativas, mutuas, asociaciones y fundaciones, se halla más extendida en el grupo de países donde precisamente el concepto de Economía Social presenta mayor aceptación, con la excepción de Irlanda. Cabe destacar que en dos de estos países, Francia y España, la Economía Social se halla reconocida en preceptos jurídicos.

Una tercera conclusión es el consenso generalizado en considerar a las cooperativas como componentes de la Economía Social. Este hecho viene a corroborar la creencia relativa a concebir las cooperativas como el prototipo de empresa de Economía Social. También son consideradas componentes las asociaciones, las fundaciones y las empresas sociales. La explicación de la exclusión de las mutuas del campo de la Economía Social en los nuevos países miembros de la Unión debe encontrarse en el bajo grado de reconocimiento del propio concepto de Economía Social unido a la carencia de estatuto jurídico para las mutuas en estos países.

\section{Dimensiones económicas de la Economía Social europea}

Un objetivo principal del estudio era ofrecer datos estadísticos sobre la Economía Social europea, diferenciando las tres grandes familias: cooperativas y formas asimiladas, mutuas y formas asimiladas, y finalmente el grupo de asociaciones, fundaciones y otras entidades sin fines de lucro.

La información estadística ofrecida en este estudio se ha elaborado a partir de datos secundarios suministrados por nuestros corresponsales en cada país. El periodo de referencia es 2002-2003. No obstante, por razo- 
nes de disponibilidad y de calidad de la información estadística, para algunos países la información es más reciente (2004-2005), mientras que para otros se remonta a 1995-1997, especialmente la referida a asociaciones, fundaciones y otras entidades similares. Las magnitudes estudiadas han sido el número de trabajadores, y cuando ha sido posible, el número de trabajadores equivalentes a tiempo completo, el número de socios, el número de voluntarios y el número de entidades o empresas. A efectos de poder comparar con los datos del estudio anterior de CIRIEC (2000) sobre la situación de la Economía Social en la Unión Europea se ha prestado una especial atención a la variable empleo.

\section{GRÁFICO 1}

Empleos remunerados en las cooperativas, mutuas, asociaciones y afines en la Unión Europea (2002-2003)

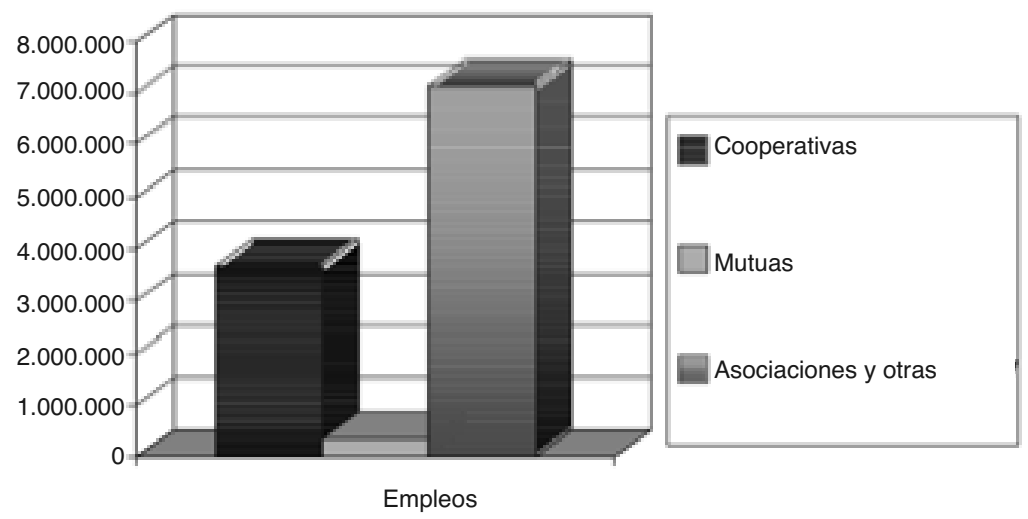

\begin{tabular}{|cccc|}
\hline Cooperativas & Mutuas & Asociaciones & Total \\
\hline 3.663 .534 & 351.291 & 7.128 .058 & 11.142 .883 \\
\hline
\end{tabular}

La principal conclusión a extraer es que la Economía Social europea constituye una realidad humana y económica muy significativa: más de 11 millones de empleos remunerados, equivalentes a aproximadamente el 6\% de la población ocupada en la Unión. Estos datos agregados subrayan el hecho de que esta realidad no puede ni debe ser ignorada por la sociedad y sus instituciones. 
La familia de las asociaciones, fundaciones y entidades afines (tercera columna de cifras) constituye globalmente el componente mayoritario de la ES europea.

\section{Modelos de Economía Social en Europa}

A la luz de esta información estadística, tres principales modelos nacionales de Economía Social pueden ser identificados.

En primer lugar, el modelo nórdico, caracterizado por altos niveles de empleo en la Economía Social en relación a la población asalariada, con países como Países Bajos (10,7\%), Irlanda $(10,6)$, Francia $(8,7 \%)$ y Reino Unido (7,0\%), donde el principal componente de la Economía Social (Tercer Sector) es la familia de las «asociaciones, fundaciones y similares». Este patrón tiene en sus específicos modelos de Estado de Bienestar su explicación.

El segundo modelo es el latino-escandinavo, caracterizado por niveles medios de empleo en la Economía Social en relación a la población asalariada: Italia $(7,5 \%)$, España $(5,9 \%)$, Suecia $(5,0 \%)$ y Finlandia $(8,5 \%)$; donde, merced a un potente movimiento cooperativo en el ámbito del trabajo asociado, el consumo y la agricultura y a activas políticas públicas de apoyo a las cooperativas, el componente más importante de la Economía Social lo conforman las cooperativas y formas asimiladas, como las sociedades laborales en España.

Finalmente, el tercer modelo es el de los nuevos países miembros de la Unión, donde las personas empleadas en la ES equivalen al 4,2\% de su población asalariada. Su rama cooperativa es aún relativamente potente, tras haber tenido que desenvolverse entre procesos de colapso económico y de renovación. La otra rama, integrada por mutuas, asociaciones y fundaciones, se encuentra todavía en estadio emergente, creciendo paralelamente al desarrollo de la sociedad civil y los movimientos sociales de estos países.

\section{Algunas referencias bibliográficas}

Chaves, R. (2002): «Politiques publiques et économie sociale en Europe: le cas de l'Espagne», Annals of Public and Cooperative Economics, vol. 73, n. ${ }^{\circ} 3$, pp. 453-480. 
CIRIEC (2000): The Enterprises and Organizations of the Third System: A strategic challenge for employment. CIRIEC-DGV European Union, Liège. (Disponible en español en <www.ciriec.es>).

Demoustier, D., R. Chaves et ál. (2006): «Débats autour de la notion d'économie sociale en Europe", Revue Internationale de l'économie sociale, ${ }^{\circ}{ }^{\circ} 300$, pp. 8-18.

MonZÓn, J. L., y R. Chaves (2008): «The European Social Economy: concept and dimensions of the third sector», Annals of Public and Cooperative Economics, vol. 79-3. (Disponible en <http://www.blackwell-synergy.com/loi/apce>).

Parlement, Commission de l'emploi et des affaires sociales (2006): Rapport sur un modèle social européen pour l'avenir. (2005/2248 /INI). 

MESA 2

Análisis y diagnóstico

de la Economía Social aragonesa 



\section{Economía Social en Aragón (que no de Aragón)}

LUIS Mena

Fundación CAI-ASC

\section{El escenario}

\subsection{Qué se presenta: qué aspectos y de qué entidades}

El escenario de partida es tan amplio y tan dinámico que no va a poder ser abordado en toda su complejidad en esta aproximación al mundo de la Economía Social desde las entidades sociales.

Los organizadores de estas jornadas, con buena lógica, han separado en dos los ámbitos de objeto de diagnóstico. Para el que nos ocupa va a ser uno de los primeros intentos en el que se sumen las potencialidades de los actores que están detrás de cada una de las realidades sobre las que se van a aportar detalles que nos van a permitir visibilizar este mundo tan relacional (lo más importante son las personas), tan colateral (tiene un carácter residual en el conjunto del desarrollo económico), tan cuestionado (tanto por parte de los propios actores como por la propia administración que, en muchos casos, lo sustenta), tan pegado a la realidad (y, sin embargo, tan desconocido al no existir una mapa integral que muestre la globalidad de las acciones, de los campos de actividad en los que interviene y del conjunto de actores que existen en todo el territorio aragonés) y tan presente (siempre ha estado ahí: con mil formas, con mil visiones y con multitud de presencias). Una de las debilidades es que no nos hayamos sentido con fuerzas para poner en valor todo lo que representa. 
Incluso en esta aproximación hemos tenido dos limitaciones: una de carácter temporal y otra referida a la calidad de la información aportada por las entidades y la elaboración de instrumentos adecuados para su tratamiento.

Hay que añadir que no están todas las que son —estaríamos hablando de unas 250 entidades - ni lógicamente se puede aportar todo lo que las mismas realizan. La realidad es mucho más amplia en tanto en cuanto no se contempla todo lo existente en el conjunto del territorio aragonés (no se tiene acceso a una buena parte de las entidades y algunas no contemplan todo el conjunto de actividad que realizan). Es importante saberlo para ubicar adecuadamente lo que pasamos a detallar. Es por eso que esta aproximación en modo alguno pretende generalizar al conjunto de actores existentes, ni pretende excluir a aquellos de los que no se pueda aportar información alguna.

\section{Los datos generales}

\subsection{De qué estamos hablando}

Un previo:

- El universo de referencia "general» lo constituyen todas las asociaciones y fundaciones de la Comunidad Autónoma de Aragón.

- En el año 2007, en Aragón, las fundaciones superaban las cuatrocientas (56\% de carácter autonómico), ubicadas mayoritariamente en la ciudad de Zaragoza (61\%), alcanzando casi el 50\% las dedicadas a «servicios sociales, cooperación internacional, promoción del voluntariado", y destacando que entre 9 (2\%) aglutinan el 65\% de la dotación patrimonial, sobre un total de 43.766.953,89 euros.

- En cuanto a las asociaciones, la dimensión del asociacionismo voluntario en nuestra comunidad suele convertirse en un problema de difícil y compleja solución para todos los estudiosos del asociacionismo, pues al tratar de fijar el universo de análisis (es decir, el volumen total de asociaciones) se topan con varias complicaciones, entre las que destacan la pluralidad legal que pueden adoptar y la debilidad de los registros oficiales. No obstante, podemos suponer que son ocho mil las entidades voluntarias activas en Aragón. Atendiendo al territorio, la densidad asociativa en España era del 5,6\% 
frente al 6,9\% en Aragón, si bien el grado de participación de los aragoneses es 3 puntos menor que en el conjunto del estado: fragmentación más elevada del asociacionismo en nuestra comunidad. El campo del asociacionismo en Aragón es plural y diverso:

- En cuanto a los ámbitos de actividad (13 principales); algunas entidades dirigen su acción a varios de ellos.

- Formas jurídicas.

- Grado de formalización.

- Antigüedad.

- Dependencia o no de ciertas ideologías o confesiones religiosas.

- Por su dimensión en cuanto al volumen de presupuesto manejado.

- Por su dimensión en cuanto al volumen de voluntarios (de cada entidad y del conjunto de voluntarios en relación con el resto del estado; incluido el número de horas dedicadas: 7,5 frente a 4,8). Menos y con menos compromiso.

- Por su pertenencia o no a algún tipo de federación, agrupación o confederación.

- Por su alcance: local, comarcal, provincial, autonómico, estatal, internacional.

\section{Los intangibles: la fuerza del trabajo en red}

Cuando se pone como punto de partida la vida de algunas plataformas de ámbito aragonés.

La credibilidad del trabajo en red ha sido y es una constante en las asociaciones y fundaciones, de tal manera que en el proceso de conformación de las mismas ha sido imprescindible contar con los esfuerzos de algunas entidades que han aportado su saber y su personal a generar espacios comunes, a construir lenguajes compartidos, a soñar con modelos de funcionamiento y organización que superaban lo peculiar y transcendían el ensimismamiento propio que caracteriza a cada entidad o, lo que es lo mismo, a darle cuerpo global a la Economía Social. Tarea que no es nada sencilla cuando la entidad pretende seguir manteniendo su cuota de actividad, si no incrementando la misma, y lo que significa crecimiento interno y mayor presencia social. 
En esta tarea se ha invertido más tiempo en compartir, en debatir, en consensuar, en crear un lenguaje común, un discurso, un esqueleto organizativo que en presentarse como una voz única con la contundencia de los datos. Muchos de los que estáis aquí sabéis de lo que estoy hablando porque habéis participado en esos procesos, en esas primeras sentadas. Es un estilo diferente, menos pragmático — seguro- pero más cercano a los intereses últimos de las entidades y del espacio social al que dirigen su acción.

Ahora es tiempo de mostrar todo lo que hasta la fecha aparece solo como un conjunto de acciones, un entramado de presencias territoriales, trabajando en eso que se ha dado en llamar mejora de la sociedad.

Es cierto que la información y los datos que nos van a permitir visibilizar algo de lo que está detrás de las entidades sociales y referido al tema que nos ocupa, nace del estudio de las memorias que han aportado las mismas.Y de ellas vamos a resaltar algunos retazos. Veamos:

\begin{tabular}{|lrrrrrr|}
\hline Red de referencia & $\begin{array}{c}\text { Compo- } \\
\text { nentes }\end{array}$ & Socios & Voluntarios & Usuarios & Trabajadores & Presupuesto \\
\hline CERMI & $(90) 19$ & & & & & \\
\hline $\begin{array}{l}\text { Federación Arago- } \\
\text { nesa de Solidaridad }\end{array}$ & 38 & 15.222 & 4.319 & & 387 & 8.943 .692 \\
\hline Red para la Inclusión & 50 & & 6.650 & 100.722 & 2.330 & 44.999 .337 \\
\hline $\begin{array}{l}\text { Coordinadora } \\
\text { de Voluntariado }\end{array}$ & 50 & 57.461 & 9.354 & 129.172 & 1.545 & 29.156 .138 \\
\hline TOTAL & 157 & 72.683 & 20.323 & 229.894 & 4.262 & 83.099 .167 \\
\hline
\end{tabular}

En un recorrido por las mismas, podemos destacar cómo las redes se van estructurando y van aportando más información y esta es cada vez más detallada conforme van pasando los años. Quiero destacar que la tarea de coordinación entre las entidades no es algo nuevo y los esfuerzos por compartir y diseñar estrategias comunes vienen de lejos, pero el construir estructura es algo novedoso y costoso. Al contrario de lo que suele ocurrir en otros ámbitos, la fuerza de la información reside en cuestiones de carácter más cualitativo. Así, por ejemplo, si tomamos como ejemplo la FAS o el CERMI podemos conocer cómo ha sido el desarrollo organizativo interno de la misma (comisiones de trabajo: educación, ayuda humanita- 
ria, comercio justo, ayuda oficial al desarrollo, difusión y campañas), quién la conforma en cada momento, quién ha participado y en qué, qué productos han generado (guías, directorios, jornadas, documentos...), qué aspectos consideran más importantes (participación en grupos de trabajo con la administración local y autonómica, de intercambio con otras coordinadoras autonómicas), y en qué momento se han producido los mismos. Y ello nos da una idea de la potencialidad del trabajo que se realiza día a día.

\section{Participaciones en comisiones}

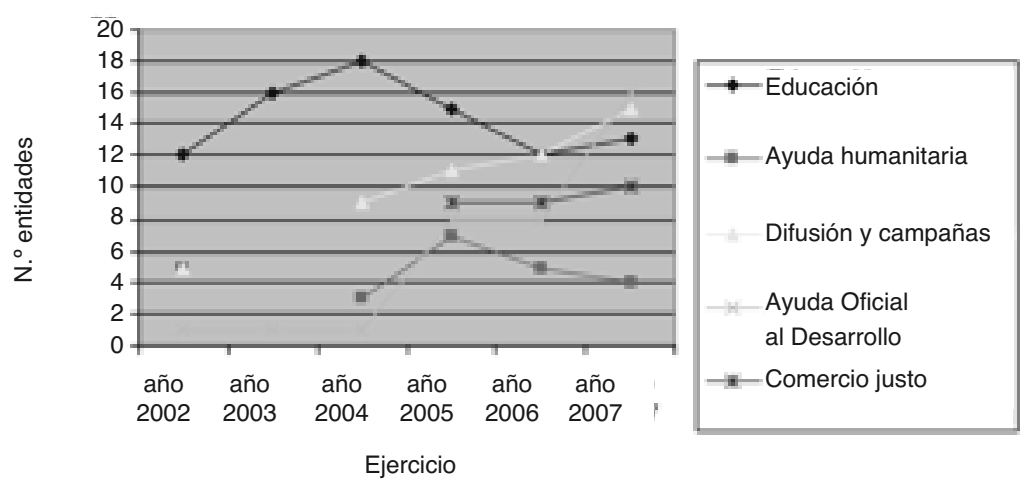

\subsection{Consolidar Estructura}

Otra de las realidades que afecta al conjunto de plataformas hace referencia al momento en el que se crea una estructura técnica que sustenta el conjunto de acciones, intencionalidades y dedicaciones. Hay que destacar que es muy significativo que a partir del momento en el que aparecen las mismas, se dedica un buen esfuerzo a explicar lo que hacen, como si hubiese que justificar la tarea que realizan para poder mantenerla. Me explico; da la sensación de que acaba de nacer otra estructura que «compite» con las que han sido sus creadoras. Como si el esfuerzo de consolidar un espacio común, tuviese entidad por sí mismo, al margen de los que lo crearon. Quiero decir, estamos hablando de personalidad jurídica propia, de personal propio, de instalaciones propias, de proyectos propios... 
Y ello, soportado con las aportaciones de las propias entidades con cuotas, que dependen de la capacidad económica de cada entidad (estableciendo tramos de aportación).

No obstante, uno de los avances más significativos es el esfuerzo que hacen las entidades por presentar con mayor detalle el público-objetivo, los servicios que prestan, la procedencia general de los recursos, en qué se gastan los mismos, los recursos humanos y si estos son hombres o mujeres. Dotando a las estructuras de coordinación de identidad propia: todo es de todos, todo salpica a todos; como diría un amigo mío: todos somos «mineritos».

\section{Visibilizar lo que se hace}

Vamos a destacar algunas características de cada una de las plataformas con el objeto de obtener una fotografia conjunta, que muestre la multitud de píxeles que son necesarios para conformar la parte de esta realidad referida a la Economía Social.

\subsection{Los miembros que las integran}

Estamos hablando de:

- Red Aragonesa de Entidades Sociales para la Inclusión;

- Federación Aragonesa de Solidaridad (FAS);

- Comité de Entidades de Representantes de Personas con Discapacidad (CERMI-Aragón);

- Coordinadora Aragonesa de Voluntariado en la Acción Social.

\begin{tabular}{|lcccccc|}
\hline Red de referencia & Componentes & Socios & Voluntarios & Usuarios & Trabajadores & Presupuesto \\
\hline CERMI & 19 & & & & & \\
\hline $\begin{array}{l}\text { Federación Arago- } \\
\text { nesa de Solidaridad }\end{array}$ & 38 & & & & & \\
\hline $\begin{array}{l}\text { Red para } \\
\text { la Inclusión }\end{array}$ & 50 & & 6.650 & 100.722 & 2.330 & 44.999 .337 \\
\hline $\begin{array}{l}\text { Coordinadora de } \\
\text { Voluntariado }\end{array}$ & 50 & 57.461 & 9.354 & 129.172 & 1.545 & 29.156 .138 \\
\hline TOTAL & 157 & 57.461 & 16.004 & 229.894 & 3.875 & 74.155 .475 \\
\hline
\end{tabular}


En los datos que se acompañan podemos descubrir cómo detrás de cada plataforma hay un importante número de entidades, algunas de las cuales aglutinan a otro buen número en su interior (por ejemplo: Fundación Adunare, Cáritas Aragón, y una buena parte de las que están en CERMI). Asimismo, hay algunas entidades que forman parte de más de una de las grandes plataformas comentadas, por lo que la interpretación de los datos no puede ser conformada como una suma, puesto que induciría a error; teniendo en cuenta que distorsionarían significativamente la información de cada uno de los apartados. No obstante, deja entrever la fuerza del sector.

Queda manifiesta, pues, la dificultad de mostrar en este momento una fotografía del montante de Economía Social que poseemos en nuestra comunidad autónoma. Sí que podemos destacar la importancia de cada una de la redes, tanto por el número de entidades que las conforman como por el número de personas que están integradas en las mismas (voluntarios y trabajadores), como por la población atendida y el presupuesto que manejan.

Al mismo tiempo, denota que estas plataformas acogen en su seno solo un trozo de la realidad de la Economía Social aragonesa (en este momento no ha sido posible obtener información detallada del conjunto de fundaciones, que complementaría y agrandaría los datos aportados).

En cuanto a la diversidad de entidades asociadas, es necesario comentar que la complejidad organizativa de las mismas y el número exigirían una mayor dedicación al objeto de obtener información sobre las tipologías, tamaños, ubicaciones, criterios organizativos... que permitirían interpretarla con mayor detalle y profundidad.

No obstante, podemos dar algunos detalles comparativos de 3 entidades diferentes, que nos mostrarán diferencias significativas en aquellos aspectos de los que hemos podido obtener información (ver cuadro de página siguiente).

Y observar una comparativa de las personas que están bajo el caparazón de las entidades (personas atendidas, profesionales y voluntarios), con el ejemplo de la fundación Federico Ozanam (gráfico de página siguiente).

Cabe destacar cómo la población atendida por el conjunto de las entidades analizadas casi se ha duplicado en dos años. 


\begin{tabular}{|l|r|r|r|}
\hline \multicolumn{1}{|c|}{ Cáritas } & 2005 & 2006 & 2007 \\
Personas Atendidas & 7.024 & 15.493 & 14.216 \\
Voluntarios & 2.774 & 2.764 & 2.661 \\
Trabajadores & 211 & 208 & 222 \\
$\quad$ Ozanam & & & \\
Personas atendidas & 5.900 & 6.253 & 10.224 \\
Voluntarios & 800 & 980 & 1.803 \\
Trabajadores & 350 & 381 & 398 \\
Ejea iniciativa social & & & 2.633 \\
Personas atendidas & 2.790 & 2.508 & 0 \\
Voluntarios & 1 & 2 & 64 \\
Trabajadores & 60 & 62 & \\
\multicolumn{1}{|c|}{ Omsida } & & & 701 \\
Personas atendidas & 668 & 404 & 11 \\
Voluntarios & 20 & 38 & 13 \\
Trabajadores & 4 & 6 & \\
\hline
\end{tabular}

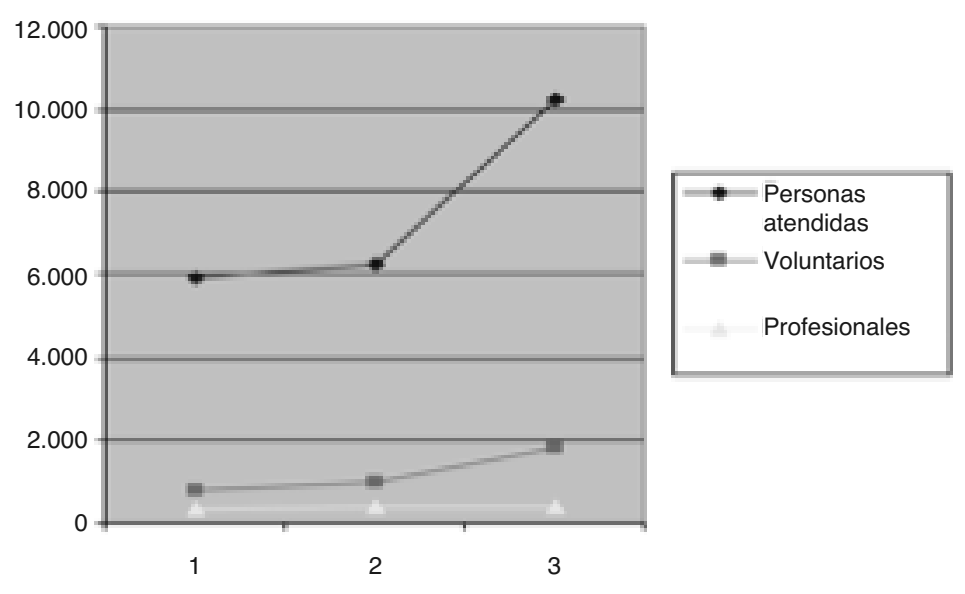

O con la globalidad de los datos aportados en cuanto al número de trabajadores y voluntarios. 


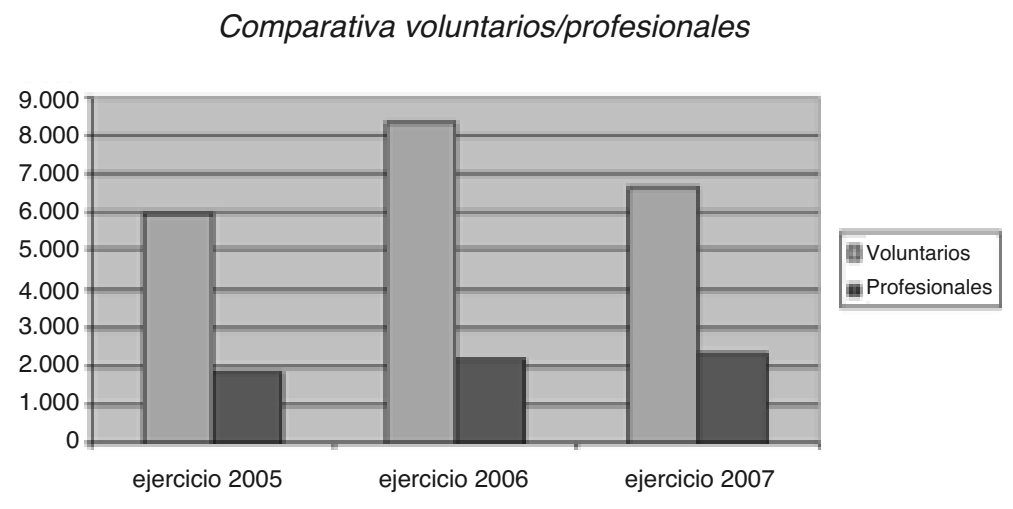

\subsection{La presencia de datos no suprime la esencia de las entidades}

Es cierto que la complejidad en la que se manejan las entidades sociales ha dificultado en estos años el conocer cuántos son, qué hacen, dónde están, con qué recursos cuentan y de dónde los perciben. Ha podido dar la sensación de que no estaban por falta de transparencia de lo que hacen, de lo que ingresan, de lo que gastan. Sin embargo, ha sido todo lo contrario, son las entidades que han dado mayor frescura a las cuentas, las que más han querido que se supiese lo que hacen y, también hay que decirlo, las más auditadas (por las instituciones financiadoras, por los entes comunitarios, por las auditorías necesarias para su gestión económica y para dar cuenta de lo que hacen, por querer cumplir con controles de determinadas normas - ISO, EFQM, SGE21 [gestión ética y de responsabilidad social], la fundación lealtad [del total de entidades transparentes 20 tienen presencia directa en Aragón y 3 tienen la sede en Aragón] los diagnósticos organizativos...-).

Los intereses de las mismas se han centrado más en saber cuál es su misión, en qué campos de actividad podían ocupar un espacio, con quién comenzar a estrechar lazos para racionalizar las intervenciones... Cada una con su velocidad, con sus posibilidades, con sus temores, con sus dudas, con sus diferencias de tamaño (en todos los sentidos), con sus dificultades para ser conocidos y reconocidos, con sus peculiaridades que las hacen diferentes. 


\section{Qué diferencia a estas entidades} de las que no están en la Economía Social

Tal y como lo definen las propias redes:

- La principal diferencia de estas entidades es la ausencia de ánimo de lucro. El objetivo no es obtener un beneficio económico sino el aprovechamiento de los recursos disponibles para ponerlos a disposición de destinatarios y usuarios. Primacía de las personas y objeto social sobre el capital.

- Vocación de gestión participativa y democrática (aquí tendríamos algo que hablar).

- Defensa y aplicación de los principios de solidaridad y responsabilidad entre sus miembros.

- Canalización de la iniciativa ciudadana.

- Acogida personal y cercana a quienes demandan ayuda.

- Denunciar y hacer visible la realidad que se atiende.

- En algunos casos, ofrecimiento de servicios sin prestación económica a cambio, o con un coste testimonial.

\section{Algunas aportaciones sobre su grado de dependencia}

Solo algunas precisiones que deberán aflorar en una segunda aproximación:

- Desde la parte económica: quienes están trabajando en este entramado son quienes nacieron para apoyar las situaciones sociales de mayor precariedad y, siendo ellos mismos, precarios. Con escasos apoyos económicos.

- Con gran autonomía en la gestión.

- Cada nueva entidad que nace lo hace igual: sin recursos, con mucha ilusión, sin mirar mucho al futuro, sin muchos visos de considerar la viabilidad económica, con una nueva necesidad que resolver y un hueco que ocupar.

- Y cuando se van todos porque ya no es novedoso, ni innovador, ni genera riqueza interna, ni se ve bien... jsiguen estando allí! (Y podríamos citar un buen número de ejemplos que así lo constatasen). 


\section{Los retos específicos}

Estas son, esquemáticamente, algunas de sus aportaciones.

\subsection{De competencia con el resto del sector}

Los principales retos que se señalan son:

- La colaboración de forma coordinada con otras entidades para paliar carencias de un mismo usuario; muchas entidades intervienen con la misma población y los intereses suelen ser coincidentes.

- Cooperación con las entidades del sector y trabajar en red para mejorar los objetivos comunes.

Las principales dificultades son:

- Solapamiento de las mismas actividades por parte de diferentes entidades, dejando descubiertas otras necesidades.

- Dificultades con el sector lucrativo.

- Dificultades en la ampliación e innovación de servicios debido a la limitación de presupuestos.

7.2. Con los socios: fidelidad, información, participación, compromiso

Los principales retos que se señalan son:

- Adaptación a la diversificación de voluntarios que se produce en los últimos años.

- Dar imagen de transparencia y fiabilidad en la gestión y calidad de los servicios.

- Mejorar la comunicación y transmisión de información entre los colaboradores.

- Mejorar el compromiso de participación de las personas implicadas en la asociación.

\subsection{De los consejos rectores}

- Tener la capacidad de demostrar transparencia, efectividad y facilitar información.

- Reforzar el compromiso de la junta directiva.

- Imagen de solvencia y confianza. 
- Captación de nuevos socios.

- Aumentar la financiación.

- Incrementar el número de beneficiarios de los servicios.

- Aumentar el conocimiento de los recursos por parte de los afectados.

\subsection{Los otros retos}

- Como no podía ser de otra manera; comenzar a trabajar en aras a crear el observatorio de Economía Social de Aragón.

- Constituir una estructura de segundo nivel, que por su ser transversal permita racionalizar los esfuerzos de las partes (como recogen cada una de las plataformas) y promueva y apoye la coordinación real entre las entidades.

- La dificultad de estar presentes en todo el territorio: territorializar las actuaciones para tener presencia en todas las comarcas.

- Aprovechar las buenas prácticas existentes y no dejarlas caer en saco roto, por ejemplo, el Pabellón de Iniciativas Ciudadanas «el Faro» (se esconde un punto de encuentro, de explosión de ideas, de gestión compartida, de préstamos de iniciativas, de personas, de objetivos y de dinero).

- El reto por excelencia es ser los protagonistas directos de un buen diagnóstico de la Economía Social que les afecta y nos afecta a todos. 


\title{
La Economía Social aragonesa desde la visión empresarial
}

\author{
Felipe Gómez de Valenzuela \\ Federación Aragonesa de Cooperativas Agrarias (FACA)
}

Acercarse a la Economía Social aragonesa resulta una tarea ilusionante a la vez que exhaustiva y complicada. Esta complejidad viene determinada y establecida por el amplio abanico de entidades que nos encontramos en el sector. La amplitud nos convierte en un grupo heterogéneo.

La primera división realizada para abordar esta mesa de análisis y diagnóstico responde al carácter o no empresarial de las entidades. Podemos hablar también, en el caso de las entidades que voy a comentar, de entidades productivas. Entiéndase esta división con muchos matices. Hablar de Economía Social productiva no significa que el resto no produzca, no sea productiva o lo haga menos. Se trata de concretar las que tienen en la producción o elaboración de bienes y servicios su principal objetivo, siempre con lo social también presente.

A la hora de abordar esta ponencia pensamos en un guión que nos acercara, bajo un prisma único, a todas las entidades de la Economía Social empresarial aragonesa. Este guión se completó de forma coordinada con los responsables de cada una de las entidades, por lo que la información recogida sale de las propias organizaciones: la Asociación Aragonesa de Empresas de Inserción (AREI); la Asociación Aragonesa de Sociedades Laborales (ASES); la Federación Aragonesa de Cooperativas Agrarias (FACA); la Federación Aragonesa de Cooperativas de Vivienda (FACOVI); la Federación Aragonesa de Cooperativas de Trabajo Asociado (FACTA); 
la Unión de Cooperativas de Enseñanza de Aragón (UCEA); y la Red de Economía Alternativa y Solidaria (REAS) componen esta parte de la Economía Social en Aragón.

Para analizar, decidimos que lo más valioso en el comienzo resulta conocer la misión de cada una de las entidades. Una de las definiciones teóricas más utilizadas, perteneciente a Jack Fleitman, define la misión como lo que pretende hacer la empresa y para quién lo va hacer. Es el motivo de su existencia, da sentido y orientación a las actividades de la empresa; es lo que se pretende realizar para lograr la satisfacción de los clientes potenciales, del personal, de la competencia y de la comunidad en general. Así, estas son las misiones de cada una de las entidades:

- AREI. La misión de la Asociación Aragonesa de Empresas de Inserción (AREI) es la defensa de los intereses colectivos de sus asociados y de sus trabajadores, así como la promoción y realización de toda clase de servicios y actividades que sirvan para la expresada defensa de intereses, con el fin de que sus integrantes logren su objeto social primordial: la integración social por lo laboral.

- ASES. La misión fundamental de ASES es la representación, defensa y asesoramiento de sus asociados ante las administraciones públicas, sindicatos y otras entidades a nivel central autonómico y local, promocionando el desarrollo de las empresas basadas en los principios de la Economía Social.

- FACA. La Federación Aragonesa de Cooperativas Agrarias tiene como misión representar, promocionar y defender a las cooperativas aragonesas y a sus intereses; promover y potenciar la generación de riqueza, la calidad de vida, la preparación profesional y la actividad de todos aquellos que integran el sistema cooperativo agroalimentario aragonés, asegurando su continuidad a largo plazo, así como su impacto positivo en la sostenibilidad y mejora del territorio aragonés.

- FACOVI. Desde su constitución, los esfuerzos de la Federación Aragonesa de Cooperativas deVivenda han estado dirigidos a fomentar la promoción y formación cooperativa en esta comunidad; asimismo, esta federación trabaja para que las cooperativas asociadas cumplan los valores cooperativos, representando a sus miembros y, en general, el cooperativismo. 
- FACTA. El objeto social de FACTA es la defensa y representación de los intereses de las cooperativas de trabajo en Aragón. FACTA se convierte en su interlocutor ante las administraciones públicas, otras organizaciones o entidades. Ante ellas interviene para contribuir a resolver los problemas que afectan al sector cooperativo en su conjunto, para expresar sus reivindicaciones, así como para plantear acciones conjuntas que impulsen esta fórmula empresarial con demostrada capacidad para contribuir al desarrollo socioeconómico.

- REAS. REAS Aragón mantiene como objetivo estratégico principal potenciar los proyectos de intercooperación.

- UCEA: entender la gestión empresarial como indispensable procurando una profesionalización de los equipos directivos, aportar soluciones a los problemas específicos de la educación, construcción del proyecto pedagógico junto al proyecto empresarial, ver que el mundo educativo necesita de alternativas válidas.

Es importante también, una vez vista la misión de cada una de las entidades, acercarse a su sector, a su representación, a su integración a nivel autonómico, nacional y europeo y a su representatividad dentro de su actividad. La mayor parte de las entidades se encuentran agrupadas en confederaciones nacionales como CONCOVI (Confederación de Cooperativas deVivienda de España) o UECoE (Unión Española de Cooperativas de Vivienda), por poner solo dos ejemplos. Detalladamente, cada una de las entidades tiene la siguiente representación:

- AREI: en el ámbito autonómico, junto con otras 52 entidades que trabajan en el campo de la inclusión, AREI forma parte de la Red Aragonesa de Entidades Sociales para la Inclusión. A través de dicha red,AREI forma parte de la red de lucha contra la pobreza y la exclusión en el ámbito estatal y europeo, con EAPN España y EAPN Europa. En el ámbito estatal, la entidad pertenece a la Federación de Asociaciones Empresariales de Empresas de Inserción (FAEDEI), integrada en la Confederación Empresarial Española de la Economía Social (CEPES) y en la Red Europea de Empresas de Inserción (ENSIE).

- ASES está confederada en el ámbito estatal en la Confederación Empresarial de Sociedades Laborales (CONFESAL), y está a su 
vez en la Confederación Empresarial Española de Economía Social (CEPES) que, con la participación activa de sus miembros, mantiene una serie de reivindicaciones para la Economía Social.

- FACA: a nivel europeo, la Federación Aragonesa de Cooperativas Agrarias está integrada en el Comité General de la Cooperación Agraria (COGECA). En el plano nacional, la Confederación de Cooperativas Agrarias de España, CCAE, es la entidad que agrupa a las 16 federaciones autonómicas dentro de España.

- FACOVI: a nivel estatal, FACOVI está integrada en la Confederación de Cooperativas de Vivienda de España (CONCOVI). La Confederación de Cooperativas de Viviendas de España es una asociación de carácter representativo de ámbito estatal, constituida para la defensa, coordinación y asesoramiento de las entidades cooperativas afiliadas; está dotada de personalidad jurídica y plena capacidad de obrar para el cumplimiento de sus fines. En el plano autonómico, la Federación renovó parcialmente su consejo rector y el presidente es Miguel A. Loriente Ariza.

- FACTA: a nivel mundial, agrupada en la Alianza Cooperativa Internacional y el Comité Internacional de Cooperativas Obreras de Producción (CICOPA); en el plano europeo, en el Comité de Coordinación de Asociaciones Cooperativas de Europa y en la Confederación Europea de Cooperativas Obreras de Producción (CECOP); a nivel nacional, en CEPES y la Confederación Española de Cooperativas de Trabajo Asociado (COCETA).

- REAS: gran aumento a nivel nacional; desde el año 2000 se han duplicado ampliamente las entidades implicadas en REAS, pasando de 104 a 226, a finales de 2006.

Forma jurídica:

$31,0 \% \ldots \ldots \ldots \ldots$. . . 70 Asociaciones

$24,3 \% \ldots \ldots \ldots \ldots \ldots$. . . . . . . . . . . . . . . . 45 Fooperativas

$19,9 \% \ldots \ldots \ldots \ldots 45$ Fundaciones

$14,6 \% \ldots \ldots \ldots \ldots$. . . . . . 33 Sociedades Limitadas

$4,9 \% \ldots \ldots \ldots \ldots \ldots \ldots$. . . . . 11 Sociedades Laborales

$5,3 \% \ldots \ldots \ldots \ldots \ldots \ldots \ldots \ldots$ 
- UCEA está integrada en la Unión Española de Cooperativas de Enseñanza (UECoE), en la que están representadas todas las autonomías. Además, UECoE pertenece como miembro de pleno derecho a todas las plataformas en donde está presente tanto el movimiento cooperativo, así CEPES, Dirección General de Fomento de la Economía Social, etc.; como en los foros educativos como en el Consejo Escolar del Estado, mesas de estudio y trabajo con diferentes departamentos del Ministerio de Educación y Cultura y manteniendo relaciones fluidas con el resto de las organizaciones empresariales.

Más allá de representación, misiones y cifras económicas, que nos pueden llevar al análisis y visión global de la Economía Social en Aragón, es importante también para realizar un correcto diagnóstico acercarse a los retos, a las dificultades y a los planes estratégicos. Hasta aquí se puede echar un vistazo al pasado y al presente, pero el sector necesita su camino hacia el futuro, hacia el progreso y la competencia empresarial con el resto de entidades no sociales que compiten en los sectores.

Muchos objetivos y visiones son compartidos entre las diferentes plataformas, como puede ser la representación de sus propios miembros o la protección y defensa de los valores del cooperativismo o la economía solidaria. Además, algunas de las entidades realizaron también un detalle de sus retos próximos, que son estos:

- AREI. Las empresas de inserción se encuentran desde su nacimiento en posición de desventaja competitiva en el mercado. El carácter social, elemento diferenciador con la empresa ordinaria, conlleva un importante sobrecoste por:

- la baja productividad por trabajador, en algunos casos hasta de un $20 \%$, y el alto absentismo entre el personal en su inicio; contratación de técnicos de acompañamiento, una figura particular que no se da en la empresa privada, cuyo trabajo es «acompañar» y orientar a los trabajadores de inserción en todo su proceso. Su productividad es solo de carácter social;

- formación de los trabajadores: mientras que en la empresa privada se trata de inversión en capital humano en la EI se trata de 
capacitar al trabajador con el objeto de que adquiera un nivel de productividad estándar para su tránsito al mercado ordinario.

Estas razones son de suficiente peso como para que una empresa de inserción sea incapaz de subsistir en el mercado si las distintas administraciones públicas no apoyan la contratación de sus trabajadores, en virtud de la situación de desventaja competitiva constante procedente de la deficiencia productiva de los trabajadores de inserción. El plantear si una empresa de inserción puede amenazar o falsear la competencia no deja de ser un absurdo, puesto que viene ya implícito en la propia concepción y objeto primordial que define a este tipo de empresas.

- ASES. Una de las dificultades con las que se enfrenta ASES es el mantenimiento de la comunicación efectiva con las empresas asociadas o vinculadas a la asociación, ya que el elevado número de las mismas dificulta el mantenimiento del feedback necesario para una óptima comunicación. Pese a esta dificultad ASES hace llegar a todas sus empresas asociadas información relevante en materia de ofertas en cursos de formación continua y de perfeccionamiento, subvenciones, convocatorias y asambleas. Uno de nuestros retos más importantes es la concienciación de los poderes públicos de la importancia de una modificación legislativa para el desarrollo del sector de la Economía Social. Así pues, ASES ha impulsado la modificación de la normativa de sociedades laborales para adaptarla a las nuevas necesidades y realidades de las empresas basadas en la autogestión.

- FACA:

- De competencia con el resto del sector: en ocasiones el tamaño de algunas de las cooperativas condiciona su puesta en el mercado del producto. Con una dimensión menor, no existe la posibilidad de acceder a economías de escala, que proporcionan menores costes unitarios, y su poder de negociación es menor, tanto frente a clientes, como a proveedores. Por este motivo, la concentración, de la que en los últimos años han surgido proyectos muy interesantes, es una buena opción para esta dificultad.

- Con los socios y consejos rectores: en un mundo tan amplio como el cooperativismo agrario, la participación es también todavía un reto asumible y mejorable. Tanto a nivel de socios 
como de consejos rectores, es importante que el núcleo cooperativo participe en la gestión, tanto de la federación, como de las propias cooperativas, para tratar de llevar a la gerencia las inquietudes y necesidades de las diferentes zonas comarcales.

- FACTA. Las cooperativas de trabajo asociado son un colectivo de pequeñas empresas (entre 10 y 50 trabajadores) y microempresas (menos de 10 trabajadores), algo superior a la media regional. En industria y construcción asumen, principalmente, funciones de subcontratista. Debilidad de los sistemas de gestión, aunque el 20\% muestran autonomía, vitalidad, dinamismo comercial y competitividad.

También cabe destacar la posición ventajosa en la política de recursos humanos, pero el limitado acceso a las ayudas públicas en formación y educación cooperativa, autofinanciación y recurso al mercado crediticio, importante potencial de creación de empleo estable y de calidad. Todo frente al escaso desarrollo de la intercooperación y el escaso grado de interrelación sectorial, pero con compromiso con el movimiento asociativo. 

GRUPOS DE TRABAJO

Experiencias de buenas prácticas en la Economía Social aragonesa

\author{
GRUPO 1 \\ «Inserción Sociolaboral»
}





\title{
Central de recursos para las empresas de inserción de AREI: Nuevas estructuras para la transformación social en Aragón
}

\author{
AsUnCión García MaInAR \\ Asociación Aragonesa de Empresas de Inserción (AREI)
}

\section{Orígenes de la entidad}

En los años 90, los cambios sociales y tecnológicos ocasionan transformaciones importantes en la organización de empresas. En el nuevo modelo socioeconómico que se define, el trabajo — cada vez más precariopasa a ser lo más deseado y va dejando fuera a los más débiles, genera exclusión si no se revisan políticas y conceptos. Hacia 1995 el Gobierno de Aragón pone en marcha el Ingreso Aragonés de Inserción. Aunque existe consenso sobre el problema de fondo - la inserción social de quienes el sistema va dejando fuera-, las organizaciones sociales aragonesas cuestionan las formas. El Consejo Económico y Social de Aragón (CESA), con la participación de unas treinta personas de distintos ámbitos de la sociedad aragonesa, revisa qué se puede hacer para la inserción efectiva de estas personas: se concluye que «la inserción pasa por lo laboral», hay que intervenir en la accesibilidad al mercado laboral de los que se quedan fuera.

En 1997, con el apoyo del CESA, se crea una asociación para la promoción de empresas de inserción, con el objeto de ser el punto de referencia de estas reflexiones. Se apuesta por la praxis, y esta pasa por abrir puertas al empleo para quienes no tenían canales de acceso.

Distintas entidades sociales, ligadas a asociaciones de vecinos, deciden convertirse en propietarias de empresas llamadas de "inserción laboral», con el único objetivo de dar salida laboral a estas personas. Estas entida- 
des no lucrativas son las que promocionan, tutelan y garantizan la función social de la empresa y la ausencia de carácter lucrativo.

Con los decretos de Fomento de Empleo entre 1999 y 2001, se amplía el número de entidades que apuestan por la inserción a través del empleo. Se promueve la creación de una asociación específica, de carácter empresarial, que responda a las nuevas necesidades, la Asociación Aragonesa de Empresas de Inserción.

En la actualidad AREI promociona y agrupa diez empresas para la inserción:

1996: MAPISER SL, promovida por Fundación Picarral y Fundación Integración y Empleo.

1996:AIVICA SL, promovida por Fundación Integración y Empleo, CAI y Parroquia del Carmen.

1998: CONSOLIDA OLIVER SL, promovida por Fundación Adunare.

1999: INSERTA SL, promovida por Fundación Ozanam

1999: REINSER SL, promovida por la Santa Hermandad del Refugio

2000: TRANVIASER SL, promovida por Fundacion el Tranvía y Asociación de Vecinos las Fuentes.

2002: ARAPACK SL, promovida por Fundación Picarral y CAI.

2006: EMFATEC SL, promovida por Fundación Picarral y Fundación Integración y Empleo.

2006: MTI SL, promovida por Fundación Picarral y Fundación Integración y Empleo.

2007:TINSER SL, promovida por Tiebel Sociedad Cooperativa.

Estas empresas tienen en común las siguientes características:

1. Están promovidas por entidades sin ánimo de lucro.

2. Están destinadas a dar trabajo a personas con grandes dificultades para acceder al mercado laboral. Se contratan personas de los programas de intervención social del Ayuntamiento de Zaragoza, de la Diputación General de Aragón y de las entidades sociales competentes. 
3. Son empresas de tránsito: cuando la persona ha superado su periodo de adecuación sociolaboral, se le promociona hacia el empleo normalizado en las empresas convencionales.

4. Son empresas protegidas, registradas y reconocidas por el Gobierno de Aragón, a través del Decreto Arinser (en la actualidad se encuentra en periodo de adaptación a la Ley 44/2007 de 13 de diciembre para la regulación del régimen de las empresas de inserción).

5. Son la alternativa económica más rentable al puro asistencialismo porque:

- La mayoría de trabajadores es perceptora del Ingreso Aragonés de Inserción u otras prestaciones de carácter subsistencial.

- Las aportaciones de las empresas de inserción a las cifras macroeconómicas contribuyen a la estabilidad, crecimiento y desarrollo socioeconómico.

En junio de 2008 las empresas de inserción de AREI están generando alrededor de 260 empleos, de los cuales 170 son empleos de inserción.

\section{Objetivos y sector de intervención}

El objetivo prioritario es la inserción social por lo laboral de las personas en situación desfavorecida, a través del empleo en las empresas de inserción que integran la asociación. Los fines que determinan los estatutos se resumen en:

a) La defensa de los intereses profesionales y colectivos de sus afiliados, así como la promoción y realización de toda clase de servicios y actividades que sirvan para la defensa expresa de intereses.

b) Promover y apoyar todas las iniciativas conducentes a la creación y consolidación de este tipo de empresas.

c) Promover y apoyar la creación de asociaciones profesionales de empresas de inserción, así como coordinarse con las existentes y las que pudieran surgir, en el resto del estado español y en la Unión Europea.

d) Promover la negociación colectiva de las empresas de inserción con la Administración, así como el establecimiento de un marco 
legal que regule aquellos aspectos jurídicos, económicos, administrativos y sociales que los miembros asociados consideren oportunos.

e) Promover la divulgación y el reconocimiento social de las empresas de inserción.

f) Prestación de servicios a los asociados.

La asociación interviene en el ámbito regional en el sector de las empresas de inserción laboral. Pueden formar parte de la asociación las Empresas de Inserción Laboral - EIL - que, cumpliendo los requisitos establecidos por la ley, soliciten su ingreso y sean admitidas conforme a los estatutos.

AREI es el referente asociativo de todos los proyectos sociales que tienen como fin asistencial el empleo, proporcionando trabajo a personas con dificultades de acceso al mercado laboral normalizado.

\section{Descripción de la buena práctica «Central de Recursos para las empresas de inserción de AREI: nuevas estructuras para la transformación social en Aragón»}

Desde que comenzaron a surgir y a funcionar las empresas para la inserción en Aragón, estas han ido creciendo y se han ido desarrollando. Aquellas empresas con carácter más industrial, que comenzaron su actividad mercantil en bajos de viviendas, necesitaban urgentemente naves donde poder trasladar la actividad mercantil que realizaban para formar en el empleo. Otras empresas, más vinculadas al desarrollo social y local de un barrio concreto, necesitaban espacios para el almacenaje de materiales diversos y productos.

Además de estas necesidades particulares de cada una de las empresas, cada vez era más necesario disponer de otros espacios de uso común, una sede social de AREI donde pudieran desarrollarse todas aquellas actividades y servicios comunes a las empresas que la asociación ofrece para satisfacer las necesidades de estas y de sus trabajadores.

Desde su creación, estas empresas han estado apoyadas por el Gobierno de Aragón, a través del decreto Arinser que registra y apoya económicamente a este tipo de empresas (en la actualidad en fase de adapta- 
ción a la nueva Ley 44/2007 de 13 de diciembre para la regulación del régimen de las empresas de inserción). Aun así, era evidente que las empresas de inserción, por sí mismas, nunca tendrían capacidad económica para acceder a espacios, ni a naves de acuerdo a sus necesidades, ni tampoco para poder mantener unos servicios centrales para la realización de las actividades comunes.

Desde AREI se cuestiona la posibilidad de llevar a cabo un proyecto que pudiera satisfacer estas necesidades, pero que solo es posible plantear y desarrollar desde intervenciones que se lleven a cabo conjuntamente con la Administración y con las entidades financieras. En la búsqueda de soluciones a esta intervención conjunta, AREI obtuvo dos respuestas positivas:

1) Caja Inmaculada, a través de su Obra Social y Cultural, decide apoyar a las empresas de inserción de Aragón a través de una dotación de 1.000.000 euros a la asociación para que esta actúe como promotora de una edificación de acuerdo a las necesidades de estas empresas.

2) Ayuntamiento de Zaragoza, a través de la cesión a título gratuito del derecho de uso de una superficie de propiedad municipal durante 75 años. AREI obtiene una parcela de $8.030,45 \mathrm{~m}^{2}$, valorada en las escrituras en 611.277,85 euros para llevar a cabo la edificación.

Este proyecto, que comienza en 2004, se plantea como la construcción de tres naves industriales para las empresas junto con la sede social e instalaciones comunes para AREI. El terreno sobre el que se construye es cedido por el Ayuntamiento de Zaragoza y Caja Inmaculada subvenciona esta construcción con 1.00.000 de euros y financia el resto del coste de la construcción, que asciende a 1.100.000 euros, mediante la concesión de un préstamo a la asociación.

Con esta construcción AREI va a poder ofrecer a sus asociadas los espacios que estas demandan a precios que pueden asumir en sus cuentas, al tiempo que dispondrá de ingresos propios, provenientes de estas rentas de alquiler, con las que podrá autofinanciarse en el tiempo.

Este es un proyecto solidario entre todas las empresas que constituyen la asociación. 
La construcción que se lleva a cabo tiene dos áreas diferenciadas:

1) Sede social AREI, para uso administrativo, con una superficie total de $938,29 \mathrm{~m}^{2}$.

2) Tres naves, para uso industrial, con los espacios específicos administrativos, por un total de $3.625,74 \mathrm{~m}^{2}$ de superficie distribuida en tres naves independientes.

Objetivo: consolidación de AREI y de sus empresas asociadas como el último paso de todas las intervenciones que finalizan en el empleo, una central de recursos de empleo para la inserción.

En la actualidad AREI dispone de una estructura estable que permite a nuestras empresas establecer un compromiso social: ofrecer un trabajo digno a toda persona que, tras haberse embarcado voluntariamente en un itinerario de inserción, los servicios sociales lo derivan hacia el empleo, dar respuesta a toda persona que, por su situación más o menos deteriorada no puede acceder a un trabajo. Es el convencimiento de que la inserción social ha de ser a través del empleo.

La inauguración de estas nuevas instalaciones ha permitido desde entonces mejorar, profesionalizar, consolidar e incluso incrementar algunas de las estructuras para el empleo protegido, y poder atender mejor todas las demandas de empleo de los servicios sociales.

Actividades: junto con las actividades que AREI venía desarrollando, a partir de la puesta en funcionamiento de las nuevas instalaciones se comienza una nueva etapa, un salto cuantitativo y cualitativo que permite profesionalizar la gestión y el funcionamiento de las empresas.

Esta profesionalización pasa por un proceso de optimización de los recursos: análisis, estudios... de las necesidades y problemáticas de las personas que pasan por nuestras empresas, búsqueda y puesta en práctica de soluciones que hagan este proceso de reinserción lo más ágil y menos costoso para las entidades sociales y lo menos traumático y más satisfactorio para los trabajadores.

En la actualidad, son tres las empresas de inserción que ocupan las tres naves industriales y otras tres empresas las que ocupan oficinas administrativas en el edificio de AREI. 
Asimismo nuestras instalaciones cuentan con espacios de trabajo adecuados para reuniones, para cursos de formación, sala de informática, zona de descanso... y la sede sociaI. AREI dispone de espacios propios para establecer servicios comunes para todas las empresas y para sus trabajadores, con las sinergias que de ello se derivan, así como la posibilidad de llevar a cabo otra serie de actividades que de otra manera sería imposible, como por ejemplo la gestión de la calidad de las áreas comunes de las empresas.

Beneficiarios: como beneficiarios directos o de primer nivel hay que referirse obligatoriamente a los trabajadores y a sus familias, como primeros beneficiarios y principal objetivo de la asociación y de las empresas de inserción. Hablamos de 260 puestos de trabajo, 170 de los cuales son puestos para trabajadores con graves dificultades de acceso al mercado laboral.

También, en un segundo nivel, podemos considerar que las instituciones públicas y privadas son beneficiarias, pues en estas empresas se da trabajo a las personas que nos derivan de sus procesos de intervención.

En un tercer nivel, como beneficiarios indirectos estaría la sociedad en su conjunto, el ámbito social en el que interactúan e intervienen estas empresas, respondiendo a las nuevas demandas de la ciudadanía, la responsabilidad y la cohesión social.

Asociación aragonesa de Empresas de Inserción (AREI)

Dirección: C/Monasterio de las Huelgas n. ${ }^{\circ} 23$

Teléfono: 976470876

E-mail:Arei@faedei.org

NIF: G-50817907

Fecha de constitución: 18 de mayo de 1999

Forma jurídica: Asociación Empresarial 



\title{
Fundación Agustín Serrate: Gestión del programa de rehabilitación de Salud Mental
}

\author{
JaVier Borau Benabarre \\ Fundación Agustín Serrate \\ (Comité Español de Representantes de Personas con Discapacidad, \\ CERMI-Aragón)
}

La Fundación Agustín Serrate es una fundación privada de asistencia social sin ánimo de lucro. Su patronato está formado por personas físicas e instituciones. Sus acciones se dirigen principalmente hacia las personas con algún tipo de discapacidad, principalmente como consecuencia de un trastorno mental grave, para que logren su plena incorporación social y laboral, tengan cubiertas sus necesidades y participen en una vida socialmente activa.

La Fundación se hace cargo del programa de rehabilitación de acuerdo con el contrato firmado con el Salud (DGA). El programa laboral ofrece al candidato un itinerario individualizado, gracias al cual puede incorporarse a un nivel de actividad, dependiendo del grado de dificultad evaluada: desde niveles de aprendizaje hasta el empleo ordinario.

Arcadia inicia su andadura en el 1987, a través de cursos de formación de jardinería y confección impartidos por el antiguo INEM e INSERSO. En el año 1989, la Diputación Provincial de Huesca crea los talleres ocupacionales, con lo que da comienzo el programa de inserción laboral de colectivos de enfermos mentales en la ciudad de Huesca, dando origen al actual Centro Especial de Empleo, «Integración Laboral Arcadia, SL», calificado por la DGA en el año 1995 y actualmente regentado por la Fundación Agustín Serrate. 


\section{Objetivo General de los programas} de rehabilitación psicosocial e inserción laboral

Ofrecer a las personas con trastorno mental grave una serie de servicios orientados al acompañamiento y el apoyo individual y colectivo con el fin de lograr la recuperación personal, la autonomía y la participación social como ciudadanos/as de pleno derecho, y la integración en la comunidad. Estos programas terapéuticos y rehabilitadores se han llevado a acabo a través de los siguientes dispositivos especializados:

\section{Programa de empleo}

Para el acompañamiento a la actividad laboral (ocupacional o protegida) y para el apoyo hacia el empleo ordinario. Incluye:

- El Centro Especial de Empleo, «Integración Laboral Arcadia, S. L.». Actividades: serrería, lavandería industrial, viveros, jardines, confección industrial, catalogación bibliográfica, servicios Internos (comedor, recepción y transportes).

— Los talleres ocupacionales «Arcadia».

- Un servicio de formación ocupacional.

Los dispositivos laborales creados en torno a la integración laboral Arcadia S. L. tienen un total de 100 plazas ocupadas. 60 en la modalidad de talleres ocupacionales y 41 plazas en la de Centro Especial de Empleo.

\section{Programa de Centro de Día}

«Agustín Serrate» (Arcadia): programas de atención básica, de gestión social, de mediación con actividades en la ciudad. Talleres artísticos y de adquisición de habilidades para la vida diaria.

\section{Programa de Pisos Supervisados}

Para ofrecer alternativas de alojamiento.

\section{Participación de Iniciativas}

Comunitarias relacionadas con la inserción social y laboral de colectivos desfavorecidos, para el refuerzo y la ampliación de los programas y servicios. 
- Horizon y Feder.

- Equal. Como miembros de la coordinadora de asociaciones para personas con discapacidad (CADIS), a través del proyecto Inserta de la agrupación de desarrollo Osca.

- Interreg IIIA. Como miembro de la CADIS y en colaboración con APAJAH 31 de l'Haute Garonne.

Por el proyecto Arcadia, desde su constitución, han pasado casi 300 personas, haciendo un recorrido completo, desde lo prelaboral al empleo ordinario.

Por su trabajo en la dificil tarea de incorporación al mundo laboral de personas con graves minusvalías mentales, recibió el Premio Nacional de Inserción por la Confederación Nacional de Centros Especiales de Empelo (CONACEE) a la integración social y laboral en el 2001. 



\title{
Modelo de formación ocupacional adaptada
}

\author{
M. a Jesús MARTínez \\ Red Aragonesa de Entidades Sociales para la Inclusión
}

\section{Presentación de la entidad}

La Red Aragonesa es un asociación sin ánimo de lucro que fue constituida en el año 2001, de carácter horizontal, plural e independiente. Surge por la necesidad de las entidades de agruparse para coordinarse y ser un interlocutor común ante la Administración. En este momento forman parte de la red 50 entidades del territorio aragonés.

Tiene como misión «ser un espacio común para mejorar la intervención de sus entidades y lograr políticas más integradoras a favor de las personas en situación de vulnerabilidad social». Son objetivos de la red:

a) Aglutinar entidades sociales diversas que se complementen y colaboren entre sí.

b) Favorecer una comunicación fluida y unos canales de información entre todas las entidades asociadas a la red.

c) Fomentar espacios de debate, reflexión y propuesta, donde se generen áreas de trabajo y nuevas herramientas de intervención y coordinación.

d) Contribuir al desarrollo de acciones de sensibilización como medio de concienciación social.

e) Ser interlocutora con las instituciones públicas, agentes sociales y la sociedad, en general.

f) Informar, asesorar y colaborar con la administración autonómica y local en la elaboración, desarrollo, aplicación y/o modificación 
de cuantas medidas puedan dictarse que afecten a las personas y colectivos excluidos.

Los servicios están orientados fundamentalmente a:

- Recepción, selección, derivación y difusión de información.

- Facilitación, promoción y apoyo a la coordinación entre entidades.

- Coordinación y dinamización de grupos de trabajo, como espacio común de trabajo para participar en la definición de las políticas sociales de inclusión de la comunidad autónoma.

- Organización de jornadas de trabajo, cursos de formación, asambleas, seminarios...

- Fomento de la vertebración de las entidades sociales aragonesas.

- Colaboraciones y coordinación con las diferentes administraciones públicas, a nivel local y regional.

- Coordinación y colaboraciones con otras entidades sociales y plataformas. También con organizaciones empresariales, sindicales, universidad...

- Desarrollo de programas de interés común.

Recursos de que dispone: el órgano de gestión está formado por la secretaría técnica, compuesta por una coordinadora y un técnico. Los recursos económicos consisten en convenios con Diputación General de Aragón, Ayuntamiento de Zaragoza y cuotas de socios.

\section{Modelo de formación ocupacional adaptada}

\subsection{Antecedentes y objetivos}

Desde la Red Aragonesa de Entidades Sociales para la Inclusión, asociación que reúne a entidades sociales sin ánimo de lucro de Aragón que trabajan con personas desfavorecidas y colectivos en riesgo de exclusión, se ha visto la necesidad de elaborar un documento de propuestas a determinados aspectos de la política de empleo, que afectan de forma más directa a las personas objeto de nuestra intervención.

Es necesario concretar y centrar la intervención que realizamos desde las diferentes entidades sociales en relación con la formación ocupacional dirigida a colectivos en situación de exclusión. Para ello debemos tener una perspectiva de la formación ocupacional más amplia, no podemos «li- 
mitarnos» a facilitar conocimientos o habilidades específicas de una profesión, sino generar unos itinerarios de desarrollo personal que puedan culminar en la integración social y laboral de los usuarios. Son individuos con unas características especiales y diferentes que, en líneas generales, carecen de unos previos imprescindibles (a nivel formativo, de hábitos sociales, de relación, etc.) y, por otro lado, no han desarrollado de forma completa las competencias claves para la ejecución y mantenimiento de un puesto de trabajo.

En la última década, diferentes organizaciones sociales aragonesas hemos gestionado proyectos de inserción sociolaboral dirigidos, tanto a discapacitados, como a población en riesgo de exclusión social, a través de las iniciativas Horizon e Integra. Podemos decir que un aspecto que ha vinculado la mayor parte de las actuaciones entre sí es el planteamiento de un itinerario de inserción sociolaboral con los beneficiarios de los mismos, entendiéndolo como un proceso que integraba diferentes acciones, a nivel de formación preocupacional, formación ocupacional, formación básica, atención social, orientación laboral, prácticas en empresa, intermediación laboral, seguimiento en el puesto de trabajo, etc., como forma de lograr mejores resultados que los que se venían obteniendo a través de acciones puntuales y aisladas.

Esta forma de trabajo es en la actualidad algo asumido como la forma más adecuada de intervenir con estos colectivos, tanto por parte de la mayoría de las entidades sociales, como por las administraciones a la hora de plantear sus políticas de empleo, y no solo el INAEM como principal entidad responsable de estas actuaciones, sino el IASS, ayuntamientos, etc. Prueba de ello son las distintas acciones enmarcadas en los proyectos Equal que se vienen desarrollando, con la participación de todos los agentes, así como actuaciones específicas del INAEM, con la Convocatoria de Acciones Especiales (CAE) o el IASS, a través de las subvenciones para proyectos de inserción laboral para colectivos en riesgo de exclusión, que tienen el planteamiento de estos itinerarios como condición para su realización.

Sin embargo, entendemos que este consenso teórico, en cuanto a la metodología adecuada para la intervención dirigida a colectivos con especiales dificultades, es necesario traducirlo en medidas concretas que permitan una mejor adaptación del propio Plan de Formación e Inserción Profesional de 
Aragón, como principal herramienta del INAEM de cara a la formación ocupacional de estos colectivos, elemento fundamental de su proceso de inserción social y laboral, junto con unos mecanismos de complementación con las medidas de acompañamiento financiadas por el IASS, a través de diferentes convocatorias, convenios y subvenciones a las entidades sociales.

Este breve reflexión nos lleva a ver la necesidad de una formación integral de las personas con una continuidad en el tiempo con una formación transversal a la de la ocupación que van a desempeñar, pero sin dejar nunca de vislumbrar el objetivo final: un puesto de trabajo.

\subsection{Personas destinatarias}

El objetivo es llegar a los grupos más afectados por la discriminación y la desigualdad en el mercado de trabajo.

Desde nuestra perspectiva, dentro de este colectivo nos encontramos con: mujeres solas con cargas familiares, inmigrantes con dificultades de integración, minorías étnicas, preceptores de IAI, personas con cargas familiares, parados de larga duración; entre otras situaciones.

Estos son grandes grupos, pero somos conscientes de que nuestros beneficiarios no se encuentran dentro de un solo grupo, son personas en las que confluyen diferentes situaciones que las caracterizan como «multiproblemáticas», lo que dificulta el desarrollo de un itinerario de inserción laboral. Su deficiencia personal, unida a una deficiencia social, es un precedente para plantearnos unas intervenciones previas para que estos itinerarios den el resultado esperado.

Teniendo en cuenta la especialización de las distintas entidades que forman la Red en actuaciones de inserción laboral con colectivos desfavorecidos, consideramos como la población objetivo del modelo las personas que se encuentren en situaciones que dificultan su integración social y laboral, entendiendo que muchas de estas personas se encontrarán en diferentes situaciones de exclusión, entre las que destacamos las siguientes:

- La población inmigrante, que en la actualidad ya ocupa la mayor parte de las plazas disponibles en los diferentes programas, haciendo especial hincapié en aquellos que carecen de cualificación profesional, los de aquellas con difícil salida en nuestro 
mercado laboral y aquellos con más dificultades de adaptación a la sociedad española, ya sea por el idioma, costumbres, aspectos culturales, etc.

- La población española gitana, cuya ocupación laboral ha sido tradicionalmente de carácter autónomo y de subsistencia, su bajo nivel formativo y la discriminación histórica de que son objeto son las principales causas del difícil acceso al empleo por cuenta ajena constituyendo un colectivo vulnerable y mayoritariamente en situación de exclusión.

- Las mujeres que quieren incorporarse o reincorporarse al mercado laboral y que carecen de cualificación y/o tienen condicionada su inserción laboral a causa de cargas familiares no compartidas.

- Los jóvenes sin cualificación, provenientes del fracaso escolar, especialmente aquellos que se desarrollan en el seno de familias invertebradas y están o han estado tutelados por la Administración o sujetos a medidas judiciales.

- Los beneficiarios del Ingreso Aragonés de Inserción u otras prestaciones sociales, como la Ayuda de Integración Familiar, que se dirigen a colectivos sociales con más riesgo de exclusión que el propio subsidio de desempleo o la renta activa de inserción.

- Los parados de larga duración, especialmente aquellos que se encuentran fuera de los circuitos de la empleabilidad.

- Las personas que sufren problemáticas específicas que afectan de forma directa a sus posibilidades de acceso al empleo: en proceso de rehabilitación de toxicomanías y otras adicciones, con problemas de salud mental, personas en tercer grado penitenciario y ex reclusos, etc.

- Colectivos que plantean diferentes situaciones reflejándose de maneras diversas en función de distintos factores: formativos, económicos, sociales, culturales, de integración, judiciales, familiares, de salud...

\subsection{Desarrollo}

El modelo que planteamos parte de una serie de premisas que son las que le dan pleno sentido, más allá de las modificaciones puntuales que se plantean. Estas premisas son las siguientes: 
- Es necesario plantear un modelo que permita una intervención integral, incorporando la formación ocupacional como un elemento de un conjunto de actuaciones. Esto exige que la formación ocupacional no puede ser un elemento aislado del resto de la intervención.

- Es necesario el desarrollo de un itinerario individualizado de inserción de cada persona, de forma que debe existir un documento en el que se planteen objetivos específicos, diseñados a partir de la situación de cada individuo, teniendo en cuenta todos los elementos que afectan a su situación de dificultad de acceso al empleo, en general, y los objetivos que se persiguen específicamente en su proceso de formación ocupacional.

- La formación ocupacional se desarrolla generalmente de forma simultánea al resto de las actuaciones y en algunos casos es el «centro de actuación", que posibilita el resto de las intervenciones.

- El modelo necesita poder poner al servicio de un usuario, de forma coordinada, distintos dispositivos, financiados por distintas administraciones públicas y/o privadas, lo que requiere de un importante esfuerzo previo de coordinación de estos elementos de cara a poder realizar una actuación eficaz.

- El número de alumnos, pudiendo ser variable en función del programa y la organización específica, debería permitir, en los casos que se viera necesario, reducirse hasta 10 personas de forma simultánea, lo que facilita la individualización del aprendizaje, aspecto básico de este planteamiento.

- Es necesario desvincular los tiempos marcados por la financiación de los dispositivos, de los procesos de las personas:

- Por un lado, es preciso el definir los tiempos de la financiación, que podrían ser anuales, si se optase por una convocatoria anual de libre concurrencia, organizada de tal forma que permitiese, tanto en cuanto hubiera financiación y un adecuado cumplimiento de objetivos, revisados año a año, un funcionamiento continuo, como sucede con otros programas.

- Por otro lado, están los tiempos de los procesos de los usuarios que deberían de ser flexibles, en función de su propio itinerario, con una entrada y una salida del dispositivo en función de 
su situación. Fijando topes máximos de tiempo, que para algunos de los colectivos de los que hablamos, y teniendo en cuenta su grado de dificultad, deberían de poder llegar a periodos de entre uno y dos años; en todo caso periodos flexibles en función de la persona y sus capacidades.

Red Aragonesa de Entidades Sociales para la Inclusión:

C) San Pablo, 70, local

Tel./fax: 976434692 / 625537682

redaragonesa@redaragonesa.org

www.redaragonesa.org 



\title{
La Artesa Tienda Solidaria
}

\author{
Mercedes TorRejón
}

Cáritas-Zaragoza (Federación Aragonesa de Solidaridad, FAS)

\section{Antecedentes}

Cáritas es la organización de la Iglesia que promueve la acción social; se ocupa de las ayudas asistenciales pero también de las promocionales, en sus más de 50 años de servicio a los más pobres. En estas tareas de promoción se enmarca la experiencia de la Artesa.

Por hacer un poco de historia: En la década de los 80 Cáritas, ante el problema del paro y sus devastadoras consecuencias en las personas que lo sufrían y en sus familias, puso en marcha un programa de estudio, reflexión y ayuda a los parados. Dentro de este, se apuesta por el trabajo con los que peor lo tienen: menos o nula cualificación laboral, enfermos, parados de larga duración...

Surgen en ese momento los talleres ocupacionales que intentan llenar un tiempo vacío haciendo algo productivo y, por otra parte, aprender unas destrezas que podrían llevar al mercado laboral.

Poco a poco se va viendo que los productos que se elaboran en los talleres tienen mercado y empieza a surgir la idea de abrir una tienda.

\section{Objetivos}

Si los objetivos de los talleres ocupacionales eran:

Estimular las habilidades y capacidades de personas adultas con problemas de comunicación, paro, ludopatía, marginación.

Fomentar su autoestima llenando su tiempo de manera útil a través de un proceso educativo y ocupacional. 
Conseguir el avance hacia su integración laboral.

Dar ocupación a estas personas que no pueden participar en un trabajo normalizado.

Los objetivos de la tienda tenían que girar alrededor de estos mismos y empezamos a trabajar con estos objetivos:

- Poner en valor el trabajo de los colectivos que trabajan en los talleres (personas marginadas que pueden realizar estupendos productos).

- Dar a conocer a la sociedad el trabajo que se realiza en los talleres (la tienda es el mejor escaparate para unos y otros. Esto hacen ellos, los usuarios; esto lo hago yo).

Son estos, pues, dos objetivos que entran de lleno en la tarea sensibilizadora de Cáritas.

Otro objetivo:

- Comercializar los productos.

Y más tarde añadimos:

- Proponer una nueva forma de consumo, un comercio solidario.

\section{Desarrollo}

El nacimiento de la tienda es muy lento, queremos montar una tienda con el mínimo gasto posible. Una tienda que no va a dar beneficios.Varios años de trabajo, sabemos qué es lo que queremos con ella, la idea está pero el camino a recorrer es largo, nadie tiene ni idea de lo que es montar una tienda. Un equipo de personas voluntarias (al frente está el técnico del programa de empleo) se ocupa de ir dando forma, lo más importante y dificil de conseguir es el local. Hace falta un sitio céntrico con un buen escaparate, con acceso fácil. Luego vendrán los permisos, las obras, todo el acondicionamiento...

CAI nos cede un local en la esquina D. Jaime, San Voto, actual ubicación.

La tienda empieza a caminar con una persona contratada y el equipo de voluntarios. Pasado un tiempo esta persona da paso a los voluntarios. 
En estos momentos, llevamos 10 años de funcionamiento, la tienda sigue prácticamente en manos de voluntarios.Yo, como técnico, coordino el trabajo. En la estructura tenemos:

- Una responsable de la tienda: se encarga de poner escaparates. Organiza los turnos de las voluntarias, repone existencias.

- Voluntarias (dependientas) hay en total unas 14, los turnos son una mañana o una tarde, una vez a la semana.

- Almacenero: responsable de recoger los materiales de los talleres, llevarlos al almacén, atender peticiones.

- Contable: lleva la contabilidad de la tienda.

Los responsables de la tienda y los responsables de los talleres trabajamos coordinadamente en cuanto a selección de productos y precios. Y una cosa muy importante es pasarte por los talleres diciéndoles a los usuarios lo bonito y lo importante que es lo que hacen.

Hace dos años dimos un paso más y se incluyeron en la tienda productos de artesanía de Palestina y Bolivia. No son productos de comercio justo, la tienda no se plantea entrar en el comercio justo en estos momentos. Se venden estos productos porque son proyectos que cooperación internacional de Cáritas desarrolla en estos países: bordados de mujeres palestinas y artesanía de Bolivia. El proyecto microempresarias pobres ayuda a la comercialización de sus productos.

\section{Conclusiones}

Nuestra tienda no da beneficios económicos, los da sociales.

Los gastos anuales son mínimos. 2007: 1.840 euros.

El importe del producto que se vende en la tienda se revierte en los talleres: pago de material y becas para los alumnos. En el caso de cooperación internacional se envía directamente a los productores. 



\title{
GRUPOS DE TRABAJO
}

\section{Experiencias de buenas prácticas en la Economía Social aragonesa}

\author{
GRUPO 2 \\ «Desarrollo local e innovación \\ en la gestión empresarial»
}





\section{Desarrollo e Integración de Comunicaciones, SLL}

Eduardo Romero Aladrén, José M.a Andrés Navarrete

Asociación Aragonesa de Sociedades Laborales (ASES)

Jesús Pola

Desarrollo e Integración de Comunicaciones SLL

\section{Presentación de ASES}

Origen y desarrollo de la entidad

Al margen de algunos antecedentes en los años 50 y 60, las sociedades laborales se configuran jurídicamente en España con la Ley 15/86 de Sociedades Anónimas Laborales (SAL), para dar una salida a empresas que entraron en procesos de crisis.

Es en la década de los 80 cuando se constituye a nivel estatal la Confederación Empresarial de Sociedades Laborales de España (CONFESAL) y la Confederación Empresarial Española de la Economía Social (CEPES) para dar apoyo y reunir a este tipo de empresas.

El año 1997 es importante por la promulgación de la Ley 4/97 de Sociedades Laborales, que, aparte de introducir algunas modificaciones, introduce también la figura de la Sociedad Limitada Laboral (SLL), mucho más flexible y con una aportación de capital social notoriamente inferior, alrededor de 3.000 euros. Esto hace que en España, a partir de esta fecha, prácticamente se duplique el número de sociedades laborales en tan solo 3 años. Siendo además la mayoría de las nuevas empresas constituidas sociedades limitadas laborales (SLL). 
El importante crecimiento del número de empresas de Economía Social constituidas en la década de los 90 y la asunción de una conciencia de diferencia social por parte de las mismas hace que surja la necesidad de una articulación organizativa del sector también a nivel regional. En Aragón, es ASES (Asociación Aragonesa de Sociedades Laborales) la organización que ejerce la función de representación del sector de las sociedades laborales.

La Asociación Aragonesa de Sociedades Laborales nace a mediados de los noventa, en concreto en el año 1996, para aglutinar a las sociedades laborales de la Comunidad Autónoma de Aragón, tanto limitadas como anónimas, y hacer frente a todas aquellas necesidades que comienzan a surgir en las sociedades laborales y que por sí mismas no pueden satisfacer.

A lo largo de su historia, ASES ha sido partícipe de multitud de actos, asambleas, jornadas, etc., de la vida social y política de nuestra comunidad.

Además, colabora y participa de forma activa con las administraciones públicas, aportando ideas y puntos de vista para la elaboración de los textos de subvenciones para sociedades laborales y en todos los debates que suscita la posible modificación de la legislación vigente.

\section{Misión y objetivos}

La misión de ASES es la representación, defensa y asesoramiento sobre la Economía Social en el beneficio de los intereses propios de las empresas asociadas ante la Administración — central, autonómica y local—, sindicatos y otras asociaciones u organizaciones de carácter y desarrollo económico y social. Asimismo, es también su objeto social la formación, atención y asesoramiento a colectivos desfavorecidos y/o en riesgo de exclusión, según los criterios marcados por el FSE.

Uno de los objetivos de la asociación, es la promoción de las sociedades laborales como nuevo estilo y forma de actividad empresarial mediante, entre otras, la gestión de programas y planes de formación, tanto ocupacional, dirigida a desempleados, como continua, enfocada a trabajadores para reforzar su capacitación profesional.

La gestión de la formación ocupacional para desempleados tiene desde ASES una doble vertiente: 
a) la de capacitar al desempleado para su incorporación al mundo del trabajo;

b) hacerlo desde la promoción del emprendimiento, desde la óptica de la Economía Social en general, y, desde la forma jurídica de la sociedad laboral, en particular.

\section{Servicios}

- Acciones IOPEA (Información y Orientación para el Empleo y el Autoempleo). Son acciones INMA, acciones grupales principalmente encaminadas a proporcionar una información general sobre autoempleo a personas desempleadas y acciones APE, acciones individuales para trabajar sobre la idea de un proyecto empresarial concreto.

- Laboralia (convenio de colaboración entre INAEM y ASES). Convenio de Colaboración con INAEM para la puesta en marcha del proyecto Laboralia, que pretende reforzar las expectativas de crecimiento de las empresas laborales, ayudando a la creación de puestos de trabajo y canalizando las iniciativas de los emprendedores hacia la creación de su propia empresa.

- Formación. ASES, como centro colaborador tanto del Gobierno de Aragón como del INEM, desarrolla periódicamente diversas acciones formativas dirigidas, en unos casos, a desempleados, para fomentar y ampliar la posibilidad de encontrar un puesto de trabajo; y a trabajadores, para reforzar y ampliar conocimientos que puedan suponer una mejora laboral. Fundamentalmente, son cursos de informática (ofimática, web, diseño gráfico, diseño de interiores, administrador de servidores, etc.) y cursos de gestión (aplicaciones de gestión, nóminas, contabilidad, etc.).

- Zaragoza Dinámica (convenio de colaboración entre el Instituto Municipal de Empleo y Fomento Empresarial del Excmo. Ayto. de Zaragoza). ASES mantiene anualmente un convenio de colaboración con el Instituto Municipal de Empleo y Fomento Empresarial del Ayuntamiento de Zaragoza, para incidir en varias áreas estratégicas de las empresas: calidad y adaptación de estas a la Ley Orgánica de Protección de Datos de Carácter Personal (LOPD). 
- Proyecto Zaragoza Social. La Asociación Aragonesa de Sociedades Laborales, con la colaboración del Ayuntamiento, ha desarrollado a lo largo del año 2007 el proyecto «Zaragoza Social», que nace como plataforma de información para dar a conocer todas las empresas zaragozanas de Economía Social.

- Proyecto Misión Posible. ASES, en colaboración con CONFESAL (Confederación Empresarial de Sociedades Anónimas Laborales de España), ha desarrollado el proyecto «Misión Posible», dirigido a la sensibilización de las PYMES sobre la importancia de la formación para mejorar la competitividad y el desarrollo de una estrategia formativa propia.

\section{Recursos}

- Recursos Humanos de ASES. Nuestra asociación cuenta con un número de profesionales de gran experiencia en sus diferentes ámbitos de trabajo.

Se dispone de un equipo de docentes con amplia experiencia acreditada para el desarrollo de los distintos planes formativos que llevamos a cabo.

Para desarrollar el resto de actividades propias de la asociación, Laboralia, IOPEA, IMEFEZ, etc., contamos con personal altamente cualificado y preparado para ello.

- Infraestructuras. Para prestar de forma adecuada sus servicios, ASES cuenta con unas instalaciones de $300 \mathrm{~m}^{2}$, con licencia definitiva de apertura como Centro de Formación y se halla homologado por el Gobierno de Aragón. Dichas instalaciones se encuentran perfectamente equipadas para la finalidad que cumplen.

El local dispone de 3 aulas climatizadas totalmente equipadas con ordenadores de última generación, conexión permanente a Internet a través de línea ADSL y otros elementos técnicos que sirven de apoyo al desarrollo de las diferentes actividades de la asociación, como cañón de proyección, televisión, vídeo y retroproyector.

Además dispone de una sala de reuniones, varios despachos para el personal y la dirección de la entidad y zonas comunes (almacén, aseos, área de descanso, etc.). 
Tanto las instalaciones como el acceso a las mismas están perfectamente adaptadas para personas con cualquier tipo de discapacidad fisica o de movilidad.

\section{Otros aspectos significativos de la Entidad}

Sistemas de Gestión. ASES está certificada en la norma UNE-EN ISO 9001:2000 desde febrero de 2002 por la empresa DEKRA, INTERTEK CERTIFICATION, obteniendo la recertificación en noviembre de 2007. Y está certificada en la norma UNE-EN ISO 14001:2004 de Sistemas de Gestión Ambiental, por la misma empresa certificadora desde noviembre de 2007.

LOPD (Ley Orgánica de protección de datos personales). Cumpliendo con la normativa vigente en materia de protección de datos (Ley Orgánica 15/1999), ASES, desde diciembre de 2007, cuenta con un contrato de cumplimiento de las exigencias de la LOPD por el que se garantiza la protección de los datos que están en poder de la asociación y la existencia de documentos de seguridad.

\section{Presentación de DEINTA \\ (Desarrollo e Integración de Comunicaciones SLL)}

\section{Origen y desarrollo de la entidad}

En el año 2001 ocho profesionales emprenden un proyecto empresarial como salida a su situación laboral. Ante la dura situación de la pérdida del puesto de trabajo y tras un intenso análisis de posibilidades, valoramos que nuestro mayor activo eran nuestras capacidades y el conocimiento que teníamos del mercado donde habíamos desarrollado nuestra actividad profesional hasta ese momento y decidimos salir al mercado con una empresa que prestara servicios y aportara valor añadido en los campos de audiovisuales, comunicaciones y seguridad.

Del análisis realizado se tomó una decisión que a la larga resultó acertada. Elaboramos un proyecto de empresa viable en dimensión, capacitación, infraestructura, etc. realizando la consiguiente valoración de las necesidades financieras que conllevaba. Siempre desde la perspectiva de ser un proyecto viable por dimensión. 
Como es obvio, el gran obstáculo que salió a nuestro paso fue la consecución de la mencionada financiación propia. En ese momento recurrimos al SACE (INAEM), sus profesionales atendieron nuestro proyecto y nos asesoraron sobre las posibilidades que nos ofrecía la creación de una sociedad laboral, asimismo nos informaron sobre ASES, como entidad que nos podía ayudar a poner en marcha nuestro proyecto empresarial.

Desde esa época nuestra colaboración con ASES ha continuado, siendo en estos momentos socios de pleno derecho y participando en la medida de nuestras posibilidades para que este modelo de empresa sea conocido, promocionado y apoyado por entidades públicas por el gran valor que tienen a la hora de crear y consolidar un tejido empresarial en cualquier ámbito geográfico, mucho más en Aragón donde la escasez de población hace aún más necesario que se creen empresas y se consoliden con una dimensión y una estructura adecuada para crecer y salir al exterior sin necesidad de deslocalizaciones.

Ante este conglomerado de datos la alternativa era bastante clara, si bien no habíamos partido de una idea preconcebida de crear una sociedad limitada laboral, esa fue la decisión final.

En un principio esta elección nos permitía estructurar la participación societaria de una forma ajustada a nuestras necesidades y situación financiera.

Pero en la decisión final tuvo una importancia primordial el aspecto social de participación e implicación que para todos los profesionales que la impulsábamos tenía.

Considerábamos, y seguimos considerando, que en una pequeña empresa tecnológica la implicación de su personal en un proyecto a medio y largo plazo es una garantía de éxito. La premisa de preservar los puestos de trabajo más allá de los avatares del mercado va implícita en esta forma de sociedad. Desde esa estabilidad los profesionales pueden desarrollar su trabajo sin las tensiones que genera la búsqueda de beneficios inmediatos.

En esta fase de creación desempeña un papel importante nuestra apuesta por ser una empresa innovadora de base tecnológica y, a caballo de esta idea, conseguimos el apoyo del CEEI Aragón para iniciar nuestras actividades en sus naves. 
Desde su puesta en marcha la empresa ha ido creciendo hasta la actualidad, en que contamos con 40 personas con un alto porcentaje de socios.

\section{Misión y objetivos}

Desde sus inicios, la empresa ha trabajado por aportar al mercado equipos y soluciones innovadoras e integradas. Desde nuestro departamento de I+D se ha trabajado intensamente, en colaboración con la Universidad de Zaragoza, en algunos casos, en el desarrollo de equipos y software que aportaran esas soluciones.

Es política de esta empresa la reinversión de lo beneficios en proyectos de desarrollo e innovación que nos permitan estar en la vanguardia del mercado.

Creemos haber conseguido ser una empresa de referencia, incluso a nivel estatal, en los mercados en los que trabajamos.

Nuestro sistema de identificación de matrículas, DEINTA CAP, con aplicaciones en control de tráfico, control de accesos, identificación de vehículos en aparcamientos, etc. tiene un reconocido prestigio.

Por otra parte, nuestra participación en la ejecución de varios proyectos en EXPO Zaragoza 2008 ha sido un hito empresarial y un espaldarazo como empresa.

Nuestros éxitos empresariales se han basado en la capacidad técnica del equipo y en su implicación con el proyecto empresarial.

Esta implicación nace de un principio muy claro: "para cualquier empresa que quiera permanecer en el mercado conseguir beneficios y crecer es innato. A la hora de su 'reparto' entran en juego los principios que la rigen».

En nuestro caso, me atrevo a afirmar que en el caso de todas las empresas de Economía Social, esos principios son el fortalecimiento de la empresa y la reinversión por encima del reparto de beneficios.

Esa opción permite una estabilidad de los puestos de trabajo y una garantía de solvencia en el mercado.

Si una empresa que tiene que innovar para ser competitiva en el mercado, y las empresas de Economía Social tienen como máxima aspiración 
esa permanencia y los fondos que generan tienen como dedicación prioritaria asegurar la permanencia, la ecuación es perfecta. Al menos en nuestro caso así ha sido.

\section{Estructura de la empresa}

La empresa se rige por un consejo de administración que aprueba la estrategia general de la empresa.

El día a día se dirige de forma colegiada desde un comité de dirección de 5 personas, de las que depende toda la organización con una estructura plana y una gestión por proyectos con un jefe de proyecto al frente del mismo.

\section{Infraestructuras}

DEINTA reinvierte año tras año sus beneficios en la mejora y actualización de su infraestructura y medios técnicos. Con un claro objetivo, mejorar la calidad y la eficiencia de nuestros servicios. Contamos con:

- Laboratorios de diseño.

- Laboratorios electrónicos.

- Laboratorios de software.

- Oficina técnica.

- Área de mecanización.

- Equipos de medición y certificación para instalaciones.

- Una importante flota de vehículos.

- Una potente aplicación que integra toda la gestión de la empresa en base a proyectos.

En pocos meses trasladaremos nuestra sede a un nuevo edificio en PLAZA en el que dispondremos de $1.500 \mathrm{~m}^{2}$. Con esta ampliación de espacio podremos contar con nuevos laboratorios de desarrollo y zonas de fabricación más amplias.

\section{Servicios y recursos de empresa}

La empresa realiza proyectos de sistemas audiovisuales, comunicaciones y seguridad desde su diseño hasta su implantación y posterior mantenimiento. Diseña, fabrica y comercializa productos propios como CAP, SIGA, etc.Además realiza proyectos de diseño técnico y software para otras empresas. 
El grupo cuenta en estos momentos con dos empresas más:

DEINTA Seguridad, para instalaciones de seguridad.

Con el objetivo de acometer el mercado de la seguridad se constituyó el 19 de mayo de 2005 la empresa DEINTA seguridad, participada $100 \%$ por DEINTA. Desde esta sociedad aportamos al mercado soluciones basadas en las tecnologías más actuales.

DEFINTA, para dar servicios de conserjería virtual.

Fruto de un acuerdo empresarial con Disminuidos Físicos de Aragón, se crea el 1 de junio de 2006 DEFINTA. Cada uno de los socios posee el $50 \%$ del capital social. Su objeto social es prestar servicios de conserjería virtual a comunidades de vecinos, urbanizaciones, polígonos industriales, etc. Aplicando las nuevas tecnologías integradas en un potente software de gestión, nos permiten prestar estos servicios por trabajadores con discapacidades, abriendo un importante mercado de trabajo para ellos.

Fondos propios 450.000 euros.

\section{Recursos humanos}

DEINTA es una empresa de alto valor añadido, basa su éxito en los profesionales que la forman. Creada como sociedad limitada laboral, su política interna tiende más hacia el bienestar de sus trabajadores, a la conciliación de la vida familiar y laboral, a mejorar su empleabilidad, etc., que al reparto de beneficios para sus socios.

Apostamos por un empleo estable y de calidad, el $80 \%$ de contratos son fijos. La mujer está integrada en todas las áreas de la empresa, desde el equipo de dirección hasta la implantación en las obras, alcanzando ya el $30 \%$ del total de la plantilla.

El grupo fundador se ha ido completando con profesionales con formación y experiencia contrastada.

Nuestro objetivo es poner al frente de cada proyecto el equipo más adecuado. Conscientes del rápido avance de la técnica en nuestras áreas de actuación, nuestro personal recibe periódicamente cursos de actualización.

Para proyectos singulares multidisciplinares establecemos acuerdos de colaboración con empresas y profesionales externos. 
La empresa está formada por 41 personas:

Director: es el coordinador del comité de dirección y desarrolla labores de representación y comerciales.

Director técnico: lidera y supervisa toda la actividad técnica de la empresa y la capacitación del personal técnico.

Directora administrativo/financiera: gestión administrativa, contable y financiera.

Director de producción: sus funciones son la gestión económica y operativa de los centros productivos.

Director técnico comercial: lidera la labor de ventas y realiza y supervisa los estudios económicos de los proyectos.

2 comerciales que desarrollan la actividad de búsqueda de proyectos y la relación con los clientes, muchos de ellos de continuidad.

2 ingenieros superiores: su actividad se desarrolla básicamente en el Dpto. de I+D.

4 ingenieros técnicos: su función es estudiar y desarrollar proyectos y gestionar su ejecución.

3 técnicos de FP II con más de 10 años de experiencia en labores de mantenimiento e instalación.

8 técnicos de FP II con más de 5 años de experiencia en labores de mantenimiento e instalación.

12 técnicos de instalación.

4 administrativos que gestionan la administración de mantenimiento, compras y proyectos, personal y calidad y medio ambiente.

1 responsable de almacén.

Disponemos de una flota de 12 vehículos.

Medios técnicos por valor de $55.000 €$.

Medios informáticos, acceso a Internet de banda ancha,VPN, accesos remotos, etc.

\section{Cultura de la empresa}

Desde sus inicios la empresa asume unos compromisos que rigen su relación con el exterior:

Con nuestros clientes:

- Comprendiendo sus necesidades.

- Aportando al proyecto un equipo capaz. 
- Realizando un buen trabajo.

- Cumpliendo los acuerdos establecidos.

Con los trabajadores:

- Integrándolos en la Empresa.

- Teniendo en cuenta sus necesidades.

- Mejorando su empleabilidad (condiciones y capacidades).

Con la calidad:

— Prácticamente desde sus inicios, la empresa apostó por un sistema de calidad.

- Estamos certificados desde el segundo año de andadura de la empresa.

Con el medio ambiente:

- Del mismo modo que con la calidad, estamos comprometidos con el medio ambiente.

- Gestión responsable de los residuos.

- Ahorro de energía.

- Certificación en medio ambiente desde el segundo año de vida de la empresa.

Con el entorno:

- Fomentando la creación de empleo estable.

- Fomentando la creación de empleo femenino.

- Colaborando con las entidades del área.

Con la innovación:

- En la ejecución de los proyectos.

- En la gestión de conocimientos.

- En los desarrollos y las soluciones. 



\section{La gestión fundacional del patrimonio de Albarracín. La Fundación Santa María de Albarracín}

Antonio Jiménez MARTíneZ

Fundación Santa María de Albarracín

(Asociación Española de Fundaciones)

\section{Presentación sintética del proyecto fundacional}

La fundación Santa María de Albarracín es un proyecto de gestión integral del patrimonio de la ciudad de Albarracín, preferentemente, que centra su acción en la recuperación patrimonial de esta localidad y en su activación cultural simultánea, así como en la creación y atención de múltiples infraestructuras culturales con las que posibilita su dinamismo cultural y el de la misma localidad cuando menos.

Este proyecto fundacional radica en la importancia patrimonial del conjunto histórico de Albarracín. Esta ciudad constituye uno de los paisajes culturales más referenciables de Europa y uno de los patrimonios rurales de mayor interés de España. Este gran valor histórico y paisajístico exige de una adecuada atención y proyección para que contribuya a la mejora social y económica de la localidad, mejorando y preservando sus valores intrínsecos. Este es el papel preferente de la Fundación Santa María de Albarracín.

Esta fundación se crea en el año 1996, como continuación del extraordinario resultado de la aplicación de dos programas de escuelas taller previos. Es en general un proyecto gradual y novedoso, que se ha ido configurando a sí mismo en función de su evolución creciente. Se caracteriza 
además por la aplicación racional de un sistema doméstico de gestión y aplicación económica de los recursos con los que cuenta, constituyendo por otra parte un adecuado sistema de colaboración interinstitucional.

\section{Antecedentes de la Fundación Santa María de Albarracín}

Como ya se ha indicado anteriormente, la Fundación Santa María de Albarracín nace después de la aplicación exitosa de dos programas sucesivos de escuelas taller. Aunque con un objetivo de mayor alcance, esta fundación se asienta adecuadamente en los programas mencionados, que vienen a constituir la fase inicial del lanzamiento de la fundación, que continúa, por otra parte, creando empleo y con la actividad de restauración preferente, iniciada con estas escuelas.

Genéricamente, las escuelas taller son programas de formación de jóvenes en oficios tradicionales, aplicados a la recuperación del patrimonio, que simultanean la creación de empleo por considerarse a la vez como jóvenes trabajadores. Son por tanto programas de formación y empleo para jóvenes desempleados, que contribuyeron, en territorios como el de Albarracín, al asentamiento de la población joven, creando alternativas laborales vinculadas con el patrimonio, y una destacable sensibilización hacia los recursos patrimoniales de la zona, muchas veces infravalorados.

Las dos escuelas taller desarrolladas, presentaron las siguientes características:

- 1. ${ }^{a}$ Escuela Taller (1988-1991). Es la primera escuela aprobada en la provincia de Teruel, cuyo promotor fue el ayuntamiento de la ciudad. Se aplicó a cincuenta jóvenes desempleados de la zona, para formarles en las clásicas materias de restauración (albañilería, cantería, forja y carpintería). La incertidumbre del inicio quedó superada con los extraordinarios logros del programa. Hay que destacar la docena de mejoras de espacios y monumentos que se abordaron, creándose a su conclusión, treinta y nueve puestos de trabajo en los oficios aprendidos, en diferentes empresas de Economía Social.

- 2. ${ }^{a}$ Escuela-Taller (1992-1995), que hubo que completar con la denominada Aula de Restauración, con la que completar otros cin- 
cuenta alumnos, en las mismas especialidades del anterior proyecto, sustituyendo únicamente cantería por pintura. Este es un proyecto de avance, que se centra, sobre todo, en la recuperación del Palacio Episcopal de Albarracín, rehabilitado como palacio de reuniones y congresos y museo diocesano. También establecerá la fundación su sede en este importante edificio del patrimonio de la ciudad. Fue inaugurado por S.M. la Reina Sofia, y un año más tarde recibió el premio Europa Nostra.

- El inició de la fundación es paralelo a un nuevo programa de Escuela Taller (1996-1998), promovido por la comunidad histórica de Albarracín, con el que se rehabilitó el batán de Tramacastilla como hospedería de calidad. El equipo de este nuevo proyecto fue prácticamente el mismo que dirigió las escuelas de Albarracín, y que prosiguió con la fundación después. El inicio de la fundación se solapó, por tanto, con el desarrollo de esta nueva escuela comarcal.

\section{La fundación y sus objetivos}

Como cualquier fundación, la de Albarracín cuenta con un patronato como ente vertebrador fundamental. Esta patronato está constituido por el Gobierno de Aragón, en quien recae la presidencia, obispado, en quien recae la vicepresidencia, Ibercaja, y el ayuntamiento de la localidad, así como otros tantos patronos electos, cuyo mandato comprende hasta cuatro años prorrogables. Lo configuran los máximos representantes de estas instituciones fundadoras y habitualmente se convoca en dos ocasiones al año: a principios del ejercicio, para la aprobación de la programación anual, y a mediados de año, para la ratificación de las cuentas anuales.

Este patronato nombró un director gerente y secretario de la fundación, como persona de extrema confianza y de amplias facultades en el desarrollo diario de la actividad del proyecto. Este cargo lo ocupa la misma persona que tuvo la responsabilidad de la dirección de los programas precedentes, de manera que es este otro de los indicadores en la continuidad del proceso fundacional. 
La fundación cuenta hasta el momento con una administración casi empresarial, evidentemente con una salvedad definitiva como es la ausencia del ánimo de lucro. Se aplica también el plan general contable, en este caso con la supervisión del protectorado de fundaciones de la administración, y de una auditoría anual a la que se someten las cuentas de esta fundación, por decisión particular de su patronato.

Las fundaciones tienen que cumplir los fines estatutarios. Los objetivos principales de estas instituciones se recogen en estos fines, que vienen a ser los principios básicos de actuación que rigen la entidad. En el caso de la fundación Santa María de Albarracín son:

- La activación social y económica de Albarracín y su comarca. En este caso, y hasta el momento, se viene utilizando el recurso preferente de la ciudad: el patrimonio histórico.

- La promoción de relaciones interinstitucionales, cuyo mejor ejemplo es el propio patronato y los numerosos convenios firmados con otros organismos (Instituto Aragonés de Fomento, Universidad, Instituto de Patrimonio Histórico Español, etc.).

- La recuperación y atención del patrimonio histórico de la zona. Esta es una de las acciones preferentes de la fundación, en la que se han logrado importantísimos resultados, preferentemente en Albarracín.

- La proyección cultural del territorio, utilizando el patrimonio como ingrediente básico. La fundación cuenta con una serie de infraestructuras culturales, en las que se apoya para esta dinamización: palacio de reuniones, auditorio, museos, salas de exposiciones, centro de restauración...

- La creación de empleo. La fundación tiene un colectivo directo de trabajadores que está en torno a los veinticinco o treinta, y que ha llegado hasta los cuarenta y dos en el caso de los periodos de máximo apogeo de la restauración. Son empleos directos a los que hay que sumar los empleos indirectos generados por la activación del patrimonio cultural de la ciudad, por ejemplo, en servicios hoteleros.

Todos estos fines se reducen, como la experiencia nos indica, a la denominada gestión integral del patrimonio, que propicia la fundación, y en la que constituye uno de los mejores ejemplos del país, que se está te- 
niendo en cuenta en otros proyectos de similares objetivos. Una adecuada gestión del patrimonio lleva implícita el resto de las tareas con las que cumplir los fines fundacionales: la restauración, el mantenimiento, la promoción del patrimonio, generación de empleo, etc.; siempre bajo una lógica de integración unitaria de esta labor genérica.

\section{El proceso de intervención fundacional. Resultados}

La actividad de la fundación, como ya se ha apuntado se centra en cuatro ámbitos diferentes y complementarios, con los que cumplir los fines estatutarios.

\subsection{Actividad de restauración arquitectónica}

Se inicia con la idea primera, que seguramente atenderá a una necesidad de recuperación de un inmueble y su uso posterior, sigue la tramitación del expediente, atendiendo los recursos necesarios para abordar la idea, y la tramitación del proyecto y permisos del mismo, y, por último, la ejecución directa de la intervención programada. En el caso de las restauraciones que recaen después en la fundación, a esta primera fase de intervención se le suma la necesidad de un equipamiento, de una dotación del personal necesario para su atención y de una lógica activación cultural. Es decir, se comienza con la idea, prosigue con la ejecución y termina con su activación final.

El proceso descrito corresponde a cada uno de los bienes inmuebles que comprenden la dotación fundacional. Ahora bien, esa dotación va creciendo anualmente, de manera que este mismo proceso se repite con cada planteamiento nuevo de restauración arquitectónica, que concluye en un incremento lógico de las infraestructuras creadas para la atención directa de la fundación, en pro siempre de un creciente Albarracín cultural. Es un proceso complejo y gradual que ha supuesto la dotación de hasta 11 infraestructuras culturales con las que la fundación desarrolla su programa cultural anual, promocionando también la vertebración cultural de la misma ciudad.

Aunque ha habido intervenciones que no dependen posteriormente de la fundación, hasta el momento, la dotación inmueble de esta institu- 
ción surge de este complejo proceso, de carácter gradual en general, como se constata, por fechas y fines de uso, en el cuadro siguiente:

\begin{tabular}{|clll|}
\hline Año & Monumento & \multicolumn{1}{c|}{ Fin cultural } & Gestión \\
\hline 1995 & Palacio Episcopal & Palacio de reuniones y congresos & Fundación \\
1995 & Palacio Episcopal & Museo diocesano & Fundación \\
1996 & Casa de Pintores & Residencia Cultural & Fundación \\
1997 & Almacén de diezmos & Albergue juvenil & Diócesis \\
1998 & Casa de Santa María & Residencia Cultural & Fundación \\
1999 & Casa de la Comunidad & Proyectos comarcales & Varios \\
2000 & Iglesia de Santa María & Iglesia Auditorio & Fundación \\
2001 & Torre Blanca & Sala de exposiciones & Fundación \\
2003 & Ermita de San Juan & Salón de actos & Fundación \\
2004 & Castillo principal & Espacio visitable & Fundación \\
2005 & Antiguo Hospital & Museo de Albarracín & Fundación \\
2006 & Antiguo Matadero & Centro de restauración & Fundación \\
2007 & Entorno del Castillo & Paseo-aparcamiento & Ayuntamiento \\
2007 & Caballerizas del palacio & Centro de información & Fundación \\
2007 & Iglesia de Santiago & Iglesia & Obispado \\
\hline
\end{tabular}

Como se puede constatar, es un proceso cíclico y creciente, que ha concluido en la dotación de suficientes infraestructuras culturales para la vertebración de Albarracín, desde su fundación, como una ciudad cultural de referencia, en sintonía con la importancia de su mismo patrimonio. Este es uno de los grandes objetivos de la fundación.

\subsection{Actividad de restauración mueble}

Además de la restauración arquitectónica, la fundación emprende un proceso de recuperación mueble, atendiendo la necesidad de la misma ciudad, en atención a su legado histórico. En Albarracín la mayoría de los monumentos tiene su equipamiento mueble: retablos, reliquias, materiales arqueológicos, libros, textiles, muebles, etc., que igualmente necesitan ser restaurados.

Para cubrir esta necesidad, se implanta una serie de cursos para especialistas en restauración, en colaboración con el INAEM y el IPCE, que lleva hasta once años de desarrollo y que ha permitido no solo su afianzamiento, sino la consideración de Albarracín como un lugar de reconocimiento en el ámbito de restauración mueble, recuperando a su vez, buena parte de su legado. También gracias a esta continuada actividad for- 
mativa, se ha ido perfeccionando y completando el método de restauración mueble de la fundación, cerrando un circuito que, si bien en principio solo contemplaba la formación aplicada, con posterioridad ha atendido la creación de empleo temporal y por último, la instalación de un centro de restauración permanente en Albarracín. Con la creación de este último centro se posibilita la restauración integral de cualquier bien arquitectónico con los bienes muebles que posea. Un buen ejemplo es la última restauración de la iglesia de Santiago.

Las repercusiones más visibles de este ámbito de acción hasta el año 2007, son las siguientes:

— Piezas restauradas ......................................... 750

— Participantes en los programas......................... 794

- Cursos impartidos...................................... 68

— Programas de promoción de empleo ................. 6

- Creación de un centro permanente de restauración.

\subsection{Actividad cultural}

Junto a la restauración arquitectónica y mueble, otra de las grandes áreas de actividad es la cultural. La actividad cultural de la fundación se desarrolla a lo largo del año, aplicando un programa genérico de humanidades y arte, con el que se dinamizan las infraestructuras de la misma fundación, pero también la ciudad de Albarracín.

Se oferta una serie de conciertos que habitualmente se desarrollan en la iglesia auditorio de Santa María y que sirven de aliciente cultural para los turistas que pasan el fin de semana en la localidad. Igualmente ocurre con las exposiciones que se instalan tanto en el museo de la ciudad, como en la Torre Blanca; algunas tan importantes como las creadas en Albarracín, aplicando el programa denominado Estancias Creativas. Con este programa la fundación invita a un determinado artista durante un periodo concreto a Albarracín, habitando el taller residencia de la Julianeta, para la creación de un trabajo original que normalmente se expone en la mencionada Torre Blanca. Solamente con este último proyecto, se potencia el carácter residencial de dicha casa de la Julianeta, donde además se crea y potencia, en definitiva, el valor artístico del conjunto histórico de Albarracín. 
Otra de las grandes acciones culturales son los seminarios que se reparten a lo largo del año. Con ellos se atiende el paisaje artística y culturalmente, así como la histórica medieval y del arte, la música y la fotografia y el diseño gráfico. Son acciones ya de referencia en Albarracín, que atraen a profesionales, expertos e interesados de cada una de las materias, activando las residencias y hospedajes, en general, de la ciudad, pero también el palacio de reuniones de la fundación. Son de gran calado y trascendencia por el especial eco cultural que tienen para la ciudad.

Por último, también se acogen diferentes eventos congresuales y de reuniones de distintos organismos, que quieren utilizar el patrimonio de Albarracín y su especial oferta hotelera y cultural, para la celebración de cualquier evento programado, siempre con la ayuda de la Fundación. Médicos, jueces, abogados, profesores, funcionarios, etc. son los colectivos varios que se acogen a esta oferta de servicios fundacionales complementarios, con los que vertebrar un Albarracín cultural distinto, e importante también desde un punto de vista económico.

Los resultados no pueden ser mejores. Durante el año 2007, ha participado en todos estos eventos un total de 2.754 personas, desarrollándose un total de 120 acciones, de las cuales, las programadas específicamente por la fundación han sido 48. Estos han sido unos resultados crecientes, especialmente a partir de las ediciones 2000-2003.

\subsection{La labor de mantenimiento, mejoras y administración}

Aunque este trabajo es mucho más callado, también es necesario para el buen funcionamiento de la fundación. La actualización de las infraestructuras de la institución (residencias, museos, etc.) es fundamental para que la calidad de los servicios no se resienta. Se atienden desde las nuevas dotaciones y equipamientos, hasta las continuas reparaciones de los inmuebles que constituyen la dotación cultural del organismo. Un claro ejemplo es el museo de Albarracín, mejorado en dos campañas sucesivas, al igual que el castillo y la Torre Blanca, y en la actualidad el museo diocesano. Las residencias no han parado de renovarse y sanearse cíclicamente.

Desde este mismo año, la fundación ha completado su servicio público de oferta patrimonial, con la apertura del denominado centro de Información. Desde este nuevo centro se ofrecen una serie de visitas guiadas por la 
ciudad, además de las entradas al complejo museístico de Albarracín, que igualmente gestiona la fundación. Con este servicio se tiende a viabilizar la misma fundación, también desde un punto de vista económico.

Aunque sin ánimo de lucro, el sistema de administración y gestión puntual de la fundación es casi el de una empresa. El tema laboral y salarial, el fiscal y contable es muy similar al de cualquier otra institución privada que realiza una función económica, aunque también sea de naturaleza cultural y social. Cada ejercicio se presenta en las cuentas anuales, supervisadas por el protectorado de fundaciones del Gobierno de Aragón, entre otros documentos solicitados, específicamente, por ser una institución sin fines lucrativos. La fundación Santa María de Albarracín también se somete a una auditoría anual, no por requerimiento legislativo, dadas las limitadas cuantías económicas que baraja, sino por su exigible claridad y limpieza administrativa. Hemos de considerar que esta institución baraja un presupuesto variable de unos 650.000 euros, con los que atender su multidisciplinar actividad, y siempre dependiendo especialmente de los programas de restauración arquitectónica comprometidos.

\section{Conclusión}

La fundación Santa María de Albarracín se ha ido configurando como un ejemplar proyecto de gestión integral del patrimonio de la ciudad de Albarracín, utilizando la restauración y mejora de dicho patrimonio, y su activación cultural, como bases de su dinámica interna, y para el cumplimiento de sus fines estatutarios. Gracias a esta labor continuada se ha vertebrado un nuevo enfoque cultural del patrimonio, atendido unitariamente y potenciado coherentemente, que ayuda a la sostenibilidad de la ciudad, garantizando su salvaguarda de futuro. Albarracín es hoy una ejemplar ciudad cultural de calidad, gracias a la labor continuada de la fundación, y en consecuencia de las instituciones que integran su patronato, aunque también de la iniciativa privada que se ha sumado a este buen hacer. 



\title{
Grupo Pastores, Grupo Cooperativo
}

\author{
Antonio Aparicio Peña. Grupo Pastores, Grupo Cooperativo \\ (Federación Aragonesa de Cooperativas Agrarias, FACA)
}

El grupo nace a partir de varios procesos de fusión e integración cooperativa, siendo carnes Oviaragón, S. Coop., la principal empresa del mismo, la mayor empresa ganadera de ovino de España, estando sus socios repartidos por toda la geografia aragonesa. Tras el correspondiente proceso de fusión de las anteriores cooperativas ganaderas existentes, se procedió a la creación de diversas estructuras empresariales para cubrir servicios como la distribución a sus clientes y consumidores, la mejora genética, o la fabricación de piensos de calidad.

La cooperativa y el grupo que la sustenta posibilita la realización de la actividad ganadera en numerosos pueblos de Aragón y con ello, en muchos casos, la supervivencia misma de la localidad donde se ejerce, contribuyendo de forma importante a la sostenibilidad y mantenimiento de nuestro medio rural. Su actividad investigadora es creciente en todos los ámbitos, desde el momento de la producción, tratando de conseguir un producto de la máxima calidad, hasta su consumo, diseñando nuevas formas de ofrecer el producto en función de las necesidades y preferencias del consumidor.

Su gestión ha sido reconocida a todos los niveles, siendo galardonada en 2006 por el Ministerio de Agricultura con el premio a la mejor empresa alimentaria española en el área de innovación e inversión tecnológica, y en 2007, por el Gobierno de Aragón con el premio a la excelencia empresarial en Aragón, en la categoría de PYMES.

Al mismo tiempo, y como empresa de Economía Social que es, su objetivo es conseguir el mayor valor y rentabilidad posible de la actividad 
ganadera y que este valor le llegue al socio y a sus trabajadores. Para ello articula las medidas necesarias para conseguir la participación, implicación y satisfacción de todas las personas intervinientes, integrando espíritu y formas de actuación cooperativa con gestión empresarial. Por otra parte, procura la integración del principio de rentabilidad con el de desarrollo sostenible. En la empresa se considera también a la formación de su personal y socios a todos los niveles, como un valor principal, siendo uno de los apartados al que más esfuerzo y recursos se destinan. 


\title{
Tiebel. Sociedad Cooperativa de Iniciativa Social
}

\author{
Marina Martínez Pardo
}

TIEBEL. Sociedad Cooperativa de Iniciativa Social

(Federación Aragonesa de Cooperativas de Trabajo Asociado, FACTA)

\section{Presentación de la entidad}

Origen y desarrollo de la entidad

La Federación Aragonesa de Cooperativas de Trabajo Asociado (FACTA) se constituyó en 1986 con el objetivo de defender y representar los intereses del cooperativismo de trabajo en Aragón. Creada como una sociedad sin ánimo de lucro, FACTA trabaja desde entonces para llevar la voz de las empresas cooperativas ante las administraciones públicas y promocionar y fomentar en la sociedad los valores y las posibilidades del cooperativismo como fórmula empresarial idónea para el acceso al mercado laboral.

A través de sus departamentos de formación y de desarrollo empresarial, FACTA acerca a socios y trabajadores la formación empresarial, técnica y societaria que les cualifica y adapta a la exigente competitividad del mercado y ofrece asesoramiento técnico, económico y legal que permite la continua actualización e innovación de las empresas.

Desde 1997, la Federación Aragonesa de Cooperativas de Trabajo Asociado dispone de un Centro de Iniciativas Empresariales de Autoempleo (CIEA) desde el que ofrece información y asesoramiento gratuito a potenciales emprendedores que optan por convertir una idea en una empresa cooperativa.

El asesoramiento económico y técnico que se ofrece desde FACTA incluye, entre otras cuestiones, la tramitación y seguimiento de créditos y 
ayudas financieras; legislación cooperativa y adaptación de estatutos; aseguramiento de calidad, medioambiente y seguridad industrial; comercio exterior y nuevas tecnologías.

\section{Misión y objetivos}

El objeto social de FACTA es la defensa y representación de los intereses de las cooperativas de trabajo en Aragón. FACTA se convierte por ello en su interlocutor ante las administraciones públicas, otras organizaciones u entidades. Ante ellas interviene para contribuir a resolver los problemas que afectan al sector cooperativo en su conjunto, para expresar sus reivindicaciones así como para plantear acciones conjuntas que impulsen esta fórmula empresarial con demostrada capacidad para contribuir al desarrollo socioeconómico.

\section{Servicios y recursos de la entidad}

Centro de Iniciativas Empresariales de Autoempleo. Creado en 1997, este servicio informa sobre las distintas fórmulas jurídicas, las ventajas laborales y fiscales de las empresas de autoempleo y asiste técnicamente a los emprendedores en el proceso de constitución y tramitación de ayudas.

Teléfono del emprendedor. 900102101 es el teléfono gratuito que FACTA pone a disposición de los emprendedores. Es un servicio de información telefónica que facilita el primer contacto con FACTA y abre el camino para que no se pierda ninguna idea que pueda convertirse en empresa.

Bolsa de autoempleo. Este servicio, gestionado desde Internet, permite ofertar proyectos empresariales, buscar socios, encontrar oportunidades sin explotar, conocer iniciativas de éxito y, por supuesto, ofertar o demandar empleo.

Asesoramiento económico y técnico. Las empresas cooperativas asociadas tienen a su disposición un servicio de asesoramiento económico y técnico sobre, entre otras, las siguientes materias: auditoria contable e intervención de cuentas; tramitación y seguimiento de créditos y ayudas financieras; legislación cooperativa y adaptación de estatutos.

Formación. A través de los programas de la fundación Tripartita para la Formación en el Empleo y del Instituto Aragonés de Empleo, FACTA ofrece cursos gratuitos para desempleados y trabajadores. 
Ayudas y subvenciones. Información, actualización y asesoramiento en tramitación de ayudas y subvenciones frente a las administraciones públicas.

Información y documentación. Las cooperativas pueden acceder a una amplia información y documentación sobre el autoempleo, la Economía Social, actualidad económica y social, a través de los estudios, informes y boletines realizados por FACTA.

\section{Experiencia a presentar. \\ Tiebel Sociedad Cooperativa de Iniciativa Social}

\section{Antecedentes}

Tiebel S. Coop., con CIF F-50569722 y número de inscripción del Registro de Cooperativas de Zaragoza ARA-RC-175, 50/Z-703, tomo II, folio 175/A, con domicilio social en Eras Altas s/n. de Azuara, Zaragoza, y fiscal en Fray Luis Urbano 1, local 2, entrada por Ignacio de Ara, 50002 Zaragoza, es una empresa cooperativa que se constituyó el 18 de octubre de 1993 e inició su actividad el 17 de diciembre del mismo año, en la comarca Tierras de Belchite. En 2005 se transformó en cooperativa de iniciativa social.

La idea motriz del proyecto es la de crear una empresa al servicio del medio social, para contribuir a su desarrollo procurando detectar la demanda de servicios latente e insatisfecha y conectándola con la oferta de trabajo potencial. La creación de puestos de trabajo, objetivo estatutario de la cooperativa, se realiza desde la potenciación y el desarrollo de formas de autoempleo colectivo, a tono con las expectativas hoy más verosímiles de generar ocupación laboral. La empresa cooperativa, por su misma identidad societaria, es un elemento idóneo para adecuar la oferta de servicios a la demanda de los mismos, adaptando a sus trabajadores, por medio de la formación continuada, a la flexibilidad necesaria en la prestación de servicios. 
En el año 1995 Tiebel recibió tanto apoyo técnico y logístico, como orientación en el diseño de los servicios de limpieza, animación y formación del grupo Sercoval, grupo de empresas de Servicios Comunitarios Valencianos, con quien comparte la filosofia profesional y socio-empresaria.

El elemento diferenciador de las cooperativas del grupo es contribuir a la calidad de vida del entorno en donde están ubicadas, afrontando las nuevas demandas sociales con la prestación innovadora de servicios específicos y la creación de puestos de trabajo cualificados.

En 1996, tras unos años de escaso trabajo en la comarca de Belchite, y coincidiendo con el inicio de actividades en Zaragoza de la fundación El Tranvía, se firma un convenio de colaboración entre ambas entidades.

Tiebel impartirá en el centro de recursos El Tranvía, ubicado en el barrio de Las Fuentes, cursos de limpieza profesional, innovadores en Zaragoza, con el objeto de dotar de formación en esta rama del sector servicios a mujeres desempleadas con dificultades para acceder al mercado laboral.

Paralelamente, se realiza un estudio en el que se comprueba que numerosas entidades no lucrativas, que en ese momento están iniciando o ampliando su actividad, demandan servicios de limpieza a empresas especializadas. Una vez consultadas, se comprueba que estarían dispuestas, en las mismas condiciones, a contratar estos servicios con empresas de Economía Social que ofrezcan trabajo a sectores socialmente desfavorecidos.

Este fue el comienzo de TIEBEL.

Hoy limpiamos:

- 190 comunidades de vecinos

- 56 centros

- 13 industrias o gabinetes profesionales

- 7 particulares.

Impartimos 11 cursos de formación profesional o animación sociocultural en Zaragoza y la comarca de Belchite.

Somos un equipo de

- 45 trabajadoras de la limpieza

- 1 almacenera-conductora 
- 2 trabajadoras sociales

- 1 administrativa

-12 monitor@s o profesor@s.

\section{Objetivos}

\section{Visión}

Participar en la transformación social a través de lo económico creando una empresa de rostro humano.

\section{Misión}

Creación de puestos de trabajo preferentemente para mujeres, ofreciendo en Zaragoza y en la comarca de Belchite servicios a la comunidad de:

- Limpieza profesional de calidad.

- Formación ocupacional.

- Animación sociocultural y deportiva.

\section{Distintivo}

- Trabajo bien hecho.

- Empresa de inserción.

- Formación ligada a la práctica real.

Objetivos

Construir una empresa de rostro humano al servicio del medio social, para contribuir a su desarrollo.

Creación de puestos de trabajo desde la potenciación y el desarrollo de formas de autoempleo colectivo.

Ser el elemento idóneo para adecuar la oferta de servicios a la demanda de los mismos, adaptando a sus trabajadores, por medio de la formación continuada, a la flexibilidad necesaria en la prestación de servicios.

\section{Principios}

- Igualdad-Equilibrio. Satisfacer de manera equilibrada los intereses respectivos de todos los protagonistas (trabajadores, empresarios, socios, clientes, proveedores, comunidad local, nacional, internacional) interesados en las actividades de la empresa o de la organización. 
- Eficiencia-Cultura de calidad. Afrontar la competitividad que impone el mercado con las miras puestas en la eficiencia, orientando la estructura al logro de la máxima calidad con la inversión de recursos y esfuerzos adecuados.

- Empleo y Diversidad. Creación de puestos de trabajo estables, en condiciones y remuneración dignas, estimulando su desarrollo personal, talento y su toma de responsabilidades.

Favorecer la inserción laboral de colectivos socialmente desfavorecidos o poco cualificados.

- Cooperación. Favorecer la cooperación en lugar de la rivalidad dentro y fuera de la organización.

- Carácter no lucrativo. Destinar los resultados positivos de sus ejercicios económicos a inversiones y reservas que consoliden el proyecto empresarial o apoyen otros proyectos solidarios.

- Compromiso con el entorno. Contribuir a la calidad de vida del entorno en donde estamos ubicados, afrontando las nuevas demandas sociales con la prestación innovadora de servicios específicos y la creación de puestos de trabajo cualificados.

\section{Organización}

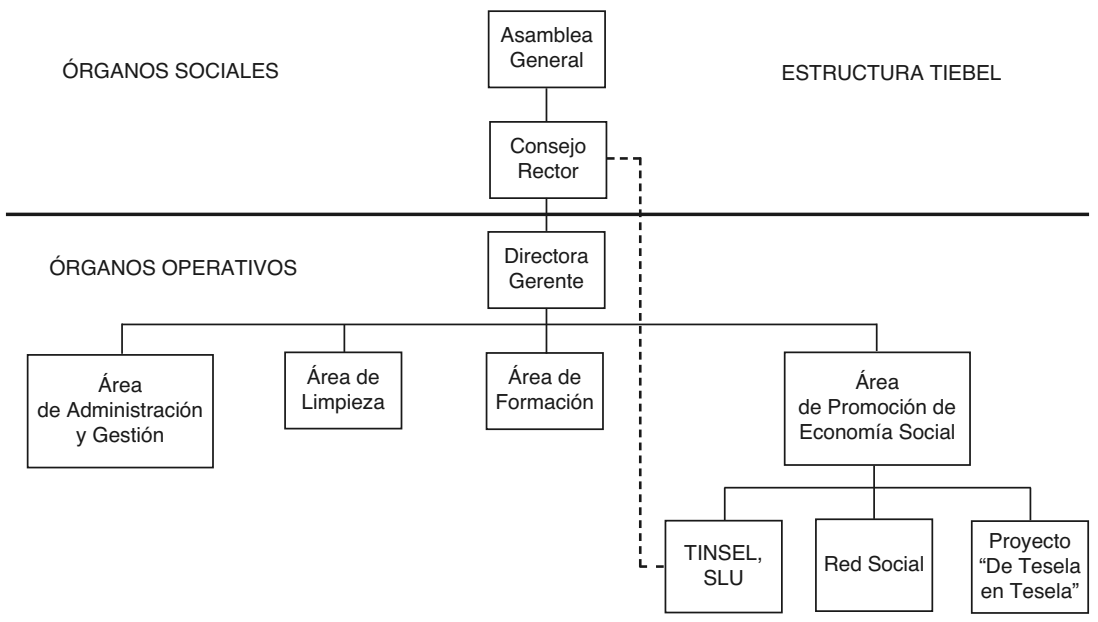




\section{Trabajamos en red}

Somos una red formada por:

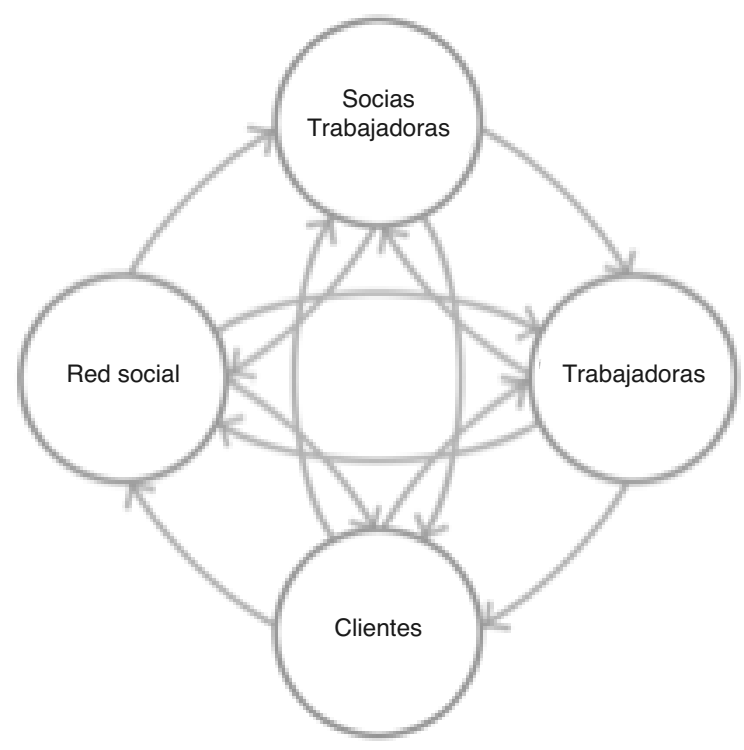

\section{Trabajadoras}

Agrupadas en equipos de trabajo donde se fomenta la participación y el desarrollo personal y profesional.

\section{Clientes}

- Pastores grupo cooperativo.

- Sociedad Municipal de Rehabilitación Urbana de Zaragoza (SMRUZ).

- Modas Escolá.

- Pequeñas empresas y despachos profesionales.

- 55 comunidades de propietarios del barrio de las Fuentes Zaragoza.

- 25 centros y despachos pertenecientes a entidades sociales. 
- Comarca de Belchite:

- Ayuntamiento de Fuendetodos

- Consorcio Goya Fuendetodos

- Ayuntamiento de Azuara

- Ayuntamiento de Lécera

- Ayuntamiento de Belchite

- Casa de la Mujer, Ayuntamiento de Zaragoza.

\section{Servicios}

Limpieza profesional

- Limpieza de mantenimiento

- Limpieza de choque

- Tratamiento de suelos

- Limpieza de garajes

- Limpieza industrial y alimentaria

- Limpieza con acompañamiento educativo.

Formación

- Formación interna

- Mejora profesional y promoción interna.

- Formación ocupacional

- Relacionada con la limpieza profesional y el aderezo doméstico. Alternativa laboral a mujeres con problemas exclusión. Sistematización de la profesión.

- Para la incorporación de la mujer rural al mundo laboral aprovechando los recursos de la zona.

- Formación en habilidades cotidianas

- Cursos de Intercambio de tareas

- Curso «cómo ser un manitas».

- Animación sociocultural

- Talleres diversos de dibujo y pintura, bolillos, teatro, etc.

Promoción Cooperativa y Economía Social

- Tiebel ha participado en diversos seminarios y jornadas para promocionar la actividad cooperativa y la Economía Social.

- Creación de Tiebel servicios de inserción SLU.

— Proyecto «De tesela en tesela, taller de mosaicos». 


\section{Economía Social: nuevos proyectos}

\section{TINSER, Tiebel Servicios de Inserción SLU}

Es una nueva iniciativa empresarial promovida y fundada por Tiebel S. Coop. Se trata de una empresa de inserción social, que basa su actividad en la prestación de servicios de limpieza profesional y la realización de itinerarios de inserción laboral. El objetivo prioritario es constituirse como un mecanismo de inserción social a través del trabajo de aquellas personas que están en situación de exclusión social, especialmente mujeres, comprometiéndose a dotarlas de los requisitos básicos que exige el mercado normalizado de trabajo. La experiencia de la empresa promotora y su valoración y buena imagen, avalada por catorce años de trabajo profesional, hace que Tiebel Servicios de Inserción SLU, pueda ser una iniciativa viable desde el punto de vista tanto social como económico.

No tenemos que olvidar que las empresas de inserción son estructuras productivas con el principal objetivo de la integración laboral, pero siempre como empresas de tránsito, donde personas con dificultades de inserción sociolaboral desarrollan las capacidades necesarias para que, tras su paso por la empresa de inserción, puedan incorporarse al mercado normalizado.

\section{Objeto social}

La sociedad tiene como objeto social la integración sociolaboral de personas en riesgo o situación de exclusión social con graves dificultades para acceder al mercado de trabajo normalizado, adquiriendo en el proceso una experiencia laboral gracias al acompañamiento individualizado de las mismas y la prestación de los siguientes servicios de limpieza profesional.

\section{Estructura}

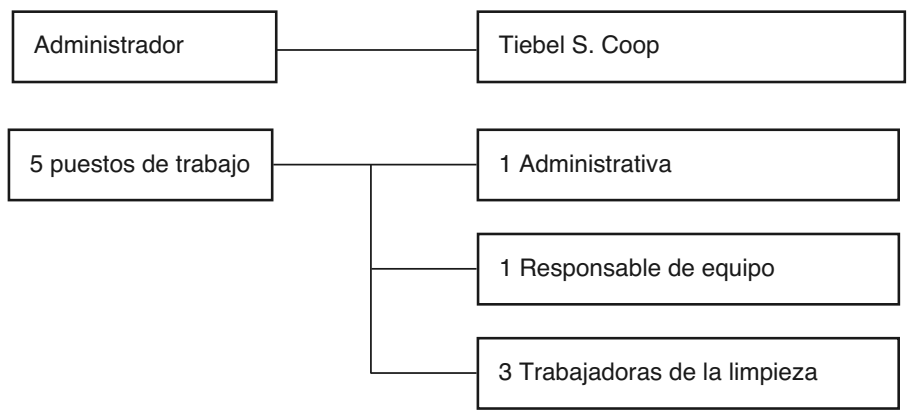




\section{Cronología}

\begin{tabular}{|c|l|}
\hline 2004 & $\begin{array}{l}\text { Análisis de la necesidad de avanzar en la Inserción Laboral a través de un proyecto vin- } \\
\text { culado a Tiebel. }\end{array}$ \\
\hline 2005 & $\begin{array}{l}\text { Estudio de viabilidad en la Cámara de Comercio de Zaragoza. Área de Fomento Empre- } \\
\text { sarial. }\end{array}$ \\
\hline 2006 & $\begin{array}{l}\text { A través del programa de Promoción de Empleo del INAEM, en colaboración con entida- } \\
\text { des no lucrativas, se concede a Tiebel una subvención para el proyecto «Estudio de via- } \\
\text { bilidad para la creación de una empresa de inserción» donde se contrata a una persona } \\
\text { para realizarlo. }\end{array}$ \\
\hline $\begin{array}{l}\text { Agos. } \\
2007\end{array}$ & Constitución de Tiebel Servicios de Inserción SL (Tiebel Servicios de Inserción SLU). \\
\hline $\begin{array}{l}\text { Sept. } \\
\mathbf{2 0 0 7}\end{array}$ & $\begin{array}{l}\text { Calificación de Tiebel Servicios de Inserción SLU como Empresa de Inserción Laboral por } \\
\text { el INAEM. N. }{ }^{\circ} \text { de inscripición EIL 18/2007. } \\
\text { Comienzo de actividad. } \\
\text { Primera contratación con itinerario de inserción. }\end{array}$ \\
\hline 2008 & $\begin{array}{l}\text { Primer objetivo cubierto: 3 trabajadoras de la limpieza, en situación de exclusión social, se } \\
\text { incorporan a la plantilla de TINSER SL. }\end{array}$ \\
\hline 2008 & $\begin{array}{l}\text { Se solicita la recalificación de Tiebel Servicios de Inserción SLU como empresa de Inser- } \\
\text { ción Laboral con respecto a la LEY 44/2007, de 13 de diciembre, para la regulación del ré- } \\
\text { gimen de las empresas de inserción (BOE 14-12-07). }\end{array}$ \\
\hline
\end{tabular}

Proyecto "de tesela en tesela», taller de mosaicos

Se trata de la puesta en marcha de un taller de mosaicos que sea capaz de promocionar el arte del mosaico como elemento artístico y cultural aprovechando las sinergias del patrimonio musivario de la localidad de Azuara (localidad origen de la cooperativa).

Su finalidad es la creación de nuevos puestos de trabajo en empresas de Economía Social, y la promoción y desarrollo de la localidad de Azuara, situada en una de las comarcas más desfavorecidas de Aragón.

En la localidad de Azuara (Zaragoza) se encuentra uno de los más importantes hallazgos patrimoniales de la cultura romana: la villa romana de la Malena, con valiosos mosaicos figurativos y geométricos.

En la localidad de Azuara se ha inaugurado un centro de Interpretación de la villa de la Malena, donde se visualiza la riqueza musivaria de la Villa.

Desde el año 2005 Tiebel S. Coop., con el objetivo de crear puestos de trabajo para mujeres del medio rural, y con la cooperación del Ayuntamiento de Azuara, ha gestionado diversos cursos de formación para el 
empleo donde1@s alumn@s han adquirido las habilidades y destrezas mínimas necesarias para la creación de mosaicos (réplicas y nuevas creaciones) en sus diversas técnicas: mármol, tesela vidriada, trencadis y piedra de canto rodado.

El periodo formativo inicial está llegando a su fin, y de todas las personas asistentes a los cursos ha surgido un grupo emprendedor dispuesto a hacer del mosaico su medio de vida.

Por otro lado, existen participantes de los cursos que por diversos motivos no quieren dedicarse profesionalmente al mosaico, quieren seguir vinculados a esta actividad y entienden y comparten que el mosaico puede reportar beneficios a corto y largo plazo en la localidad y sus habitantes.

El Ayuntamiento ha apoyado la idea promotora de Tiebel, la iniciativa de las emprendedoras y de las personas que quieren promocionar los mosaicos en Azuara y ha rehabilitado el antiguo matadero donde se ha ubicado el taller de mosaico «De tesela en tesela».

Por tanto, los agentes que intervienen en esta iniciativa son los siguientes:

- Tiebel S. Coop., promotor, idea inicial, gestor de cursos (compra de materiales, contactos con proveedores, docentes y expertos, 13 años de trayectoria profesional en gestión de empresa de Economía Social).

- Ayuntamiento de Azuara: objetivo de promocionar y apoyar formas de organizaciones colectivas y creación de puestos de trabajo y promoción de la localidad.

- Emprendedoras dispuestas a trabajar profesionalmente realizando mosaicos.

- Personas individuales: alumn@s con conocimientos del arte del mosaico que quieren apoyar a emprendedoras y promocionar el mosaico como referente de la localidad.

Para unir a todos estos agentes, sus potencialidades y necesidades se proyectó:

- Crear una asociación para la promoción del mosaico ATENEAONKA, registrada a finales de abril 2007 en la que Tiebel S.Coop. forma parte como socia fundadora. 
- Acompañar en la puesta en marcha la empresa de Economía Social compuesta por las emprendedoras analizando la forma jurídica más idónea, relaciones contractuales, etc.

- Elaboración de un convenio de colaboración entre asociación (taller de mosaico) y empresa en las que se regule:

- Técnicas y sistemas de compras.

- Técnicas y sistemas de ventas.

- Cálculo de costes y política de precios.

- Duración y condiciones del convenio.

- Amortización y dotación material del taller.

Tiebel Cooperativa seguirá apostando por mejorar la calidad de vida de las personas, especialmente de las mujeres, y del medio social en el que se encuentra.

\section{Gestión de formación}

Cursos de formación ocupacional impartidos en Azuara para la creación de empleo y empresa de Economía Social en dicha localidad y comarca de Belchite.

Esta formación está enmarcada dentro del proyecto «De tesela en tesela», taller de mosaico, en la que la cooperativa es promotor.

Cronología

\begin{tabular}{|c|l|}
\hline 2004 & $\begin{array}{l}\text { Taller de mosaicos I 100h. } \\
\text { Subvencionado por Ayuntamiento de Azuara. }\end{array}$ \\
\hline 2005 & $\begin{array}{l}\text { Taller de mosaicos II 100h. } \\
\text { Subvencionado por PRODER. }\end{array}$ \\
\hline $2005 / 06$ & $\begin{array}{l}\text { Dibujo, pintura y cromatismo aplicado a mosaicos } 75 \mathrm{~h} . \\
\text { Subvencionado por EQUAL - INAEM }\end{array}$ \\
\hline 2006 & $\begin{array}{l}\text { Ténicas de mosaico fabricado con materiales pétreos 75h. } \\
\text { Subvencionado por EQUAL - INAEM }\end{array}$ \\
\hline $2006 / 07$ & $\begin{array}{l}\text { Técnicas en albañilería y carpintería aplicadas a mosaico 60h. } \\
\text { Subvencionado por EQUAL - INAEM. }\end{array}$ \\
\hline 2007 & $\begin{array}{l}\text { Estrategias para la comercialización y venta de mosaicos 45h. } \\
\text { Subvencionado por EQUAL - INAEM }\end{array}$ \\
\hline
\end{tabular}

www.facta.es

www.tiebelcooperativa.com 


\title{
Caja Rural de Teruel
}

\author{
José Antonio Pérez Cebrián
}

Director general de Caja Rural de Teruel

\section{Origen y desarrollo de la entidad}

Caja Rural de Teruel, sociedad cooperativa de crédito, tiene sus orígenes en la federación turolense de sindicatos agrícolas católicos, que inicia sus actividades el 15 de enero de 1920.

En 1946 el Ministerio de Trabajo aprobó la adaptación de sus estatutos a la Ley de Cooperativas de 2 de enero de 1942, quedando registrada con la denominación de Caja Rural Cooperativa de Ahorro y Crédito.

En 1989 Caja Rural de Teruel se integra en el grupo Caja Rural, del que forman parte ahora 73 cajas rurales.

En 1992 se produce un intento de fusión por absorción por parte de Caja de Ahorros de la Inmaculada que finalmente no prosperó por la decisión de los socios que votaron negativamente en asamblea extraordinaria. De prosperar esta fusión-absorción, hubiera desaparecido la entidad, y con ella la única entidad de crédito propiamente de la provincia de Teruel.

Tras el intento de fusión frustrado, se hizo cargo de la entidad el actual director general José Antonio Pérez Cebrián, con quien la caja comenzó un periodo en el que se han alcanzado cotas y éxitos impensables en ese momento.

En este periodo, desde 1992, Caja Rural se ha modernizado tecnológicamente, se ha incrementado su papel en el grupo Caja Rural, se ha incrementado el volumen de balance, recursos gestionados y las cuotas de mercado en niveles muy elevados, y se ha incrementado el número de 
empleados dando trabajo a muchos jóvenes turolenses. También la caja pasó de tener ámbito únicamente provincial, a tener ámbito de actuación nacional, con cuatro oficinas en la actualidad fuera de la provincia de Teruel. Con lo que su denominación pasó a la actual Caja Rural de Teruel, Sociedad Cooperativa de Crédito.

Toda esta gestión, desde hace 16 años, ha supuesto un hito histórico en la entidad, y ha contribuido a que la caja sea actualmente la segunda entidad de la provincia de Teruel, tanto en volumen de negocio, cuota de mercado y número de oficinas.Y según la revista Ausbanc, en su informe sobre las cooperativas de crédito en España, la caja rural española con mayor índice de penetración en su provincia.

Algunos datos: 75 oficinas, 186 empleados, 16.900 socios, 45.000 clientes, 1.500 millones de euros de negocio, 7 millones de beneficios, $22 \%$ de negocio en la provincia frente al $8 \%$ en $1992,50 \%$ ratio de eficiencia excelencia.

Caja Rural es líder en el sector agropecuario 50\%, en el cooperativismo $80 \%$, en el sector empresarial 60\%, en promociones de vivienda 60\%. Líderes en seguros generales, primera aseguradora RGA y tiene suscritos múltiples convenios con asociaciones y entidades. Además de presencia en numerosas fundaciones provinciales y regionales.

\section{Principios y valores de Caja Rural de Teruel}

— En Caja Rural de Teruel lo más importantes son las personas, las buenas personas.

- La deslealtad es el peor pecado en la empresa.

- Es fundamental la participación en las necesidades del entorno próximo.

- Apoyo a los más débiles.

- Solidaridad con los sectores en dificultades.

- Ver los problemas como oportunidades.

- Comunicación franca y sincera dentro y fuera.

- Vivir en el cambio permanente. Pasión por el cambio.

- Pasión por la excelencia y las cosas bien hechas.

- Autocrítica permanente desde la autoestima. 
- Cumplir los compromisos y la palabra dada. Cumplimiento de la legalidad al máximo.

\section{Visión}

- Tendencia de la caja a ser la primera entidad financiera en la provincia de Teruel con acuerdos con todos los colectivos de la provincia, y participando en los grandes hitos económicos del futuro que acontezcan, desde la confianza, compromiso, lealtad y creatividad de los empleados, entendiendo que estos son el único motor de cambio posible.

- Orientación al cliente.

- Servicio de primer nivel.

- Mejora continua. Pasión por la calidad.

- Innovación e imaginación.

- Participación de trabajadores y socios. Sociedad de personas.

- Responsabilidad social y ética.

- Trabajar por Teruel de forma rentable.

\section{Objetivos}

- Balance de 1.600 millones de euros.

- Apertura de 15 oficinas, con 40 empleados más.

— 22.000.000 euros de margen de explotación.

- 15.000.000 euros de beneficios en 2011.

- Morosidad inferior al 1\%.

- 120.000.000 fondos propios fundamentalmente vía reservas prevaleciendo sobre las ampliaciones de capital.

- 26\% cuota de créditos y $26 \%$ de depósitos. $1 \%$ anual en cada epígrafe.

- Incrementar un 25\% el número de clientes activos.

- Incrementar 70\% seguros.

- Incrementar 100\% bolsa y fondos de inversión.

- Ídem medios de pago.

- Triplicar el negocio on line.

- Reducir los errores al 50\%. 
- Reducir las quejas y reclamaciones al 50\%.

- Mejorar la formación de los empleados con medición de la mejora.

La Caja Rural de Teruel es una cooperativa de crédito que procura centrar su actividad al servicio del mismo ámbito y territorio en el que nació, la provincia de Teruel, en el que contribuye de manera importante al desarrollo y sostenibilidad de su economía y su población. Su filosofía y métodos de actuación se definen bajo los principios de la responsabilidad social corporativa, asumiendo los principios y objetivos que de ella se derivan.

Como entidad firmemente asentada en el territorio al que sirve, se encuentra presente y colabora en la actividad de numerosos colectivos e instancias que contribuyen a su desarrollo y dinamización social y económica. También apoya a numerosas asociaciones y entidades presentes en el territorio turolense, teniendo como meta que ningún colectivo quede al margen de su colaboración. Además es una empresa que desde hace muchos años ha venido aplicando el destino del $0,7 \%$ de su volumen económico al desarrollo del Tercer Mundo. Asimismo, participa en el capital de 25 empresas turolenses, que constituyen piezas importantes del desarrollo económico de la provincia y ha firmado diversos acuerdos de colaboración con universidades y centros educativos para el desarrollo de la formación.

Una de sus principales líneas de actuación se dirige también hacia los empleados de la propia entidad. El capital humano se considera uno de los principales activos de la empresa y entre ellos se fomenta la colaboración y el trabajo en equipo. Se motiva su identificación y compromiso con los objetivos y manera de ser y actuar de la caja. También el espíritu de servicio hacia el ámbito al que sirven y la coherencia con ello en todas las facetas de su comportamiento. Igualmente, se les induce a que sean transmisores de cultura empresarial y a la mejora y optimización constante en el desempeño de las tareas que desarrollan.

Por último, se recalca que la Caja Rural de Teruel nunca ha perdido de vista que es una entidad financiera de naturaleza cooperativa. Por ello, uno de los aspectos más cuidados es el que se refiere a la participación de sus socios en la vida y decisiones de la misma, que es real y cercana, para lo que se han articulado los mecanismos necesarios. Al mismo tiempo, en su actividad y operaciones atiende especialmente al sector cooperativo de su territorio y a las empresas que lo integran. 
GRUPOS DE TRABAJO

Experiencias de buenas prácticas en la Economía Social aragonesa

\author{
GRUPO 3 \\ «Participación Democrática»
}





\title{
Asociación Voluntariado de Geriatría: espacio propiciador de nuevas realidades participativas
}

\author{
María Ríos, Pilar Mesa, Mercedes Obis \\ Asociación Voluntariado de Geriatría \\ (Coordinadora Aragonesa de Voluntariado)
}

\section{Presentación de la entidad}

La entidad surge en 1981 por iniciativa de un grupo preocupado por el bienestar de las personas mayores, la promoción del voluntariado para la atención del colectivo y el conocimiento y desarrollo de la geriatría como especialidad médica y pilar de su atención.

Ha sido pionero en el desarrollo de programas que, al ser asumidos desde otras entidades, han desaparecido:

- Valoración y asesoramiento de enfermería a domicilio para personas dependientes y familiares, que desapareció con la implantación del actual sistema de salud.

- Un centro de día, pionero en la comunidad, con transporte, actividades formativas y de ocio, rehabilitación y programas de estimulación cognitiva para personas con demencia. La asistencia era gratuita y el funcionamiento estaba sustentado en voluntarios pero el mantenimiento era muy costoso y sin garantía de financiación ni medios económicos propios de la entidad por lo que hubo que cerrarlo.

- Un equipo médico de asesoramiento a familiares de enfermos de Alzheimer sobre la enfermedad y sus implicaciones, que funcionó hasta la implantación y consolidación de la asociación de familia- 
res y la toma de conciencia por parte de la sociedad de la problemática que la enfermedad conlleva.

A lo largo de toda su historia ha desarrollado y permanecen activos los siguientes servicios:

- Acogida, información y asesoramiento.

- Valoración médico-social.

- Atención domiciliaria.

- Acompañamiento.

- Estructuras de información, comunicación y coordinación con otras entidades.

- Servicios residenciales, con la inauguración en 1984 de un centro con 40 plazas asistidas para personas mayores dependientes y la incorporación en 1990 de una unidad de atención a personas con demencia.

La entidad desarrolla todas las actividades encaminadas a la atención, cuidado y protección de las personas mayores dependientes que, por su situación, estén o puedan llegar a estar en riesgo de exclusión.

Apoyada en valores de solidaridad, participación, independencia y responsabilidad, incorpora voluntarios para el desarrollo de sus actividades siendo la implicación de la sociedad civil en el cuidado de este colectivo uno de sus objetivos.

La calidad de los servicios y la reivindicación de un cuidado y atención igual para todos los ciudadanos, con independencia de su edad y capacidades, son valores en los que se apoyan las actuaciones de la entidad y la avalan para ser un referente en la atención de este colectivo.

La transparencia en la información, el interés por mantener contacto con otras realidades y la coordinación con las mismas ha posibilitado la aparición de nuevas estructuras de participación.

La asociación Voluntariado de Geriatría es una agrupación de personas voluntarias. Su órgano de decisión es la asamblea, compuesta por todos los voluntarios, donde se toman las decisiones que desarrolla y ejecuta la junta directiva. Tiene su sede en Zaragoza y cuenta con dos centros residenciales con un total de 62 plazas asistidas, de las cuales 22 son para personas con demencia. Mantiene servicios y recursos preventivos, asistenciales y formativos: 
- Servicio de acogida, información y apoyo en la gestión.

- Valoración y propuesta de alternativas de cuidado.

- Atención domiciliaria.

- Acompañamiento.

- Unidades residenciales.

- Animación en centros.

- Apoyo a familiares.

Cuenta con una media de 125 voluntarios y 35 personas contratadas, en su mayoría personal de atención de las unidades residenciales, que con las instalaciones de la sede social, las dos residencias y el soporte económico necesario procedente de cuotas de residentes, donativos, apoyo de entidades privadas y públicas, desarrollan la labor necesaria para la consecución de los objetivos.

\section{Espacio propiciador de nuevas realidades participativas}

La asociación Voluntariado en Geriatría es una entidad que, desde sus inicios y a lo largo de su historia, ha mantenido sistemas de trabajo que han favorecido:

- La participación de sus voluntarios en foros de formación y debate.

- El fomento de las iniciativas individuales y colectivas.

- La interiorización y aprovechamiento de otras realidades asociativas.

- El apoyo a colectivos de familiares con una problemática común.

La asociación ha participado en la gestación de varias entidades de reconocido prestigio en la actualidad que surgen del trabajo desarrollado, principalmente, en dos áreas:

\section{A) De formación y participación}

En 1989 se inician ciclos de charlas para la prejubilación y durante cuatro años se trabaja fomentando el voluntariado y la participación entre y con personas mayores concretándose este trabajo con el nacimiento de Conex, cuyos estatutos se legalizan el 15 de junio de 1993.

En 1990 se pone en marcha la unidad psicogeriátrica Torremedina, de atención a personas con demencia. Previamente se ha tenido contacto 
con asociaciones de ayuda mutua y el conocimiento de las necesidades de los familiares así como el de los beneficios que pueden aportarles estas asociaciones propician que la entidad inicie una serie de cursos formativos dirigidos a familiares de pacientes con enfermedad de Alzheimer. Son los participantes en estos cursos y familiares de los pacientes atendidos en la unidad psicogeriátrica quienes, con el apoyo técnico y material de la asociación Voluntariado de Geriatría, constituyen un grupo de trabajo que constituye en 1992 AFEDA.

\section{B) De trabajo en red}

La asociación participa en un grupo de trabajo sobre voluntariado que se reúne a nivel nacional y de forma consensuada consigue llegar a un acuerdo sobre los contenidos de un posible centro de voluntariado y redactar unos estatutos que se aprueban en asamblea general en marzo de 1986 y dan lugar a la Plataforma del Voluntariado de España, que agrupa a entidades en cuyos programas participan voluntarios.

Paralelamente, representantes de las entidades participantes en este grupo con presencia en Aragón empiezan a reunirse en Zaragoza concretándose su trabajo en la firma de una declaración de principios el 5 de diciembre de 1988. Durante el año siguiente se procede a la elaboración de estatutos, incorporación de nuevos grupos y celebración del Día internacional del voluntario, el 5 de diciembre de 1989, acto en el que se presentó oficialmente la coordinadora aragonesa de voluntariado.

Estas iniciativas, unidas al apoyo humano, material y económico y, en algunos casos, al acogimiento y cesión de instalaciones durante el tiempo necesario para su organización, normalización y consolidación, han favorecido el crecimiento de nuevas realidades, en la actualidad asociaciones con entidad propia completamente consolidadas:

La Plataforma delVoluntariado de España está formada por 31 entidades, 22 plataformas, 12 federaciones, 5 fundaciones, 2 confederaciones y 1 coordinadora y actualmente es el referente nacional del voluntariado.

La coordinadora aragonesa de voluntariado engloba a 50 entidades de voluntariado que trabajan en el campo de la acción social y cuentan con 57.461 socios, 9.354 voluntarios, 1.545 trabajadores y atienden a 129.172 usuarios pertenecientes a colectivos desfavorecidos. 
Conex es una asociación integrada por un grupo de socios voluntarios mayores de cincuenta años y un grupo de colaboradores de menor edad. Todos ellos están dispuestos a ofrecer sus conocimientos y experiencias. Actualmente apoyan a personas necesitadas, distribuyen alimentos dos días por semana con una media de 70 familias a la semana sin interrupción durante todo el año y ropa un día por semana, principalmente de abrigo y para niños. También adelantan ayudas de urgencia municipales.

La Asociación de Familiares de Enfermos de Alzheimer (AFEDAZ) fue creada por y para los propios familiares en el año 1992, teniendo como misión ser un instrumento válido para atender las necesidades de los cuidadores de enfermos de Alzheimer y/u otras demencias. Proporciona, para ello, una serie de servicios que han beneficiado, hasta el momento, a más de 5.000 familias y sus enfermos.

Nuestra experiencia en participación nos permite afirmar que:

1. Ofrecer un espacio de participación activo, implicado y que trascienda nuestra realidad favorece la aparición y crecimiento de otras realidades asociativas.

2. Establecer y mantener canales de comunicación y coordinación permanentes intra y extrainstitucionales posibilita el conocimiento, profundización, trasmisión e interiorización de los valores individuales e institucionales.

3. Impregnar con este sistema todas nuestras áreas de trabajo contagia a otros sistemas organizativos.

4. Desde pequeñas realidades y medios escasos, con implicación, dedicación, responsabilidad, participación y solidaridad se pueden alcanzar nuevas realidades y grandes metas. 



\title{
Cooperativas de viviendas Victoria Martínez: La participación de los socios en las Cooperativas de Vivienda
}

\author{
Carolina Marín Andrés
}

Secretaria Consejo Rector FACOVI

Cooperativa de viviendas Victoria Martínez

(Federación Aragonesa de Cooperativas de Vivienda, FACOVI)

\section{Presentación de la cooperativa de viviendas Victoria Martínez}

La Cooperativa se constituyó en el año 1979, tomando el nombre de «Victoria Martínez» en recuerdo de la compañera de Antonio Rosell, que fue presidente del Partido Comunista de España en Aragón después de la Guerra Civil.

Era a finales de los años 70, con una democracia recién estrenada, siendo años caracterizados por profundos cambios políticos, culturales y sociales, lo que favorecía un mayor espíritu colectivo, y que unido a una importante crisis, con gran incidencia en el sector inmobiliario, permitió un comienzo muy positivo y de gran actividad en el cooperativismo de viviendas.

Sin embargo, aquellos inicios no fueron fáciles, confluyeron graves problemas en los dos aspectos fundamentales de una promoción inmobiliaria: la financiación y la construcción, ya que al tratarse de un proyecto cooperativo recién constituido, sin un referente similar en Zaragoza, y con una base social progresista, originaba recelos sobre su viabilidad en las entidades financieras, lo que originó dificultades para poder financiar dichas promociones, teniendo que soportar, durante una fase importante de la 
promoción, la financiación con los recursos propios de las aportaciones de los socios o con créditos puentes con avales personales.

En toda su trayectoria, aunque el aspecto económico siempre ha estado presente, en aras de conseguir un producto final sustancialmente inferior al del mercado, no por ello se ha descuidado el aspecto arquitectónico, destacando todos los edificios construidos por su personalidad propia, el cuidado diseño y el respeto al entorno. Prueba de ello es que el primer premio de arquitectura «García Mercadal», concedido en el año 1986, fuera para una de nuestras promociones, de 146 viviendas, entregadas en el año 1985, en el zaragozano barrio de las Fuentes, junto al parque Torre Ramona.

A finales de los 80 y principios de los 90 , se produjo un boom inmobiliario, lo que conllevó un incremento de los costes en la construcción, derivado también de las grandes obras de entonces, como las Olimpiadas y la Expo de Sevilla. La escasez y acaparamiento de suelo urbano que se produjo provocó un retroceso en la producción de viviendas protegidas, haciéndose imposible en los últimos años adquirir suelos privados de intervención inmediata donde desarrollarVPO.

Estas circunstancias han sido paliadas ya en la actualidad, por actuaciones promovidas por las administraciones autonómica y local, mediante el desarrollo de suelos públicos, enajenados posteriormente a cooperativas y promotores para el desarrollo de VPO, como es el caso de Parque Goya,Valdespartera y otras actuaciones, y, en un futuro próximo, Arcosur, lo que revela un éxito en el impulso de la promoción de vivienda protegida por parte de Aragón, siendo ejemplo para otras CCAA.

Así, en la actualidad, se han construido y adjudicado un total de 2.931 viviendas en todo Aragón, 311 actualmente en proceso de construcción en Zaragoza y Teruel.

Y a pesar de los casi 30 años transcurridos, la cooperativa sigue viva y siguen siendo hoy válidos los motivos y objetivos que llevaron a la constitución de la cooperativa, y que fundamentalmente no eran ni son otros que el incidir en el mercado de la vivienda a través del asociacionismo cooperativo, con la finalidad de posibilitar el acceso a una vivienda de digna, a precio de coste, para aquellas personas o familias que por sus recursos económicos no les es posible el acceso a una vivienda en el mercado libre. 


\section{VICTORIA MARTINEZ}

\section{PROMOCIONES EJECUTADAS}

\begin{tabular}{|c|c|c|c|c|c|}
\hline & LOCALIDAD & PRTOMO'OTRA & PROWOCION & N VIV. & FECAA \\
\hline \multirow{32}{*}{ ARAGÓN } & ZARAGOZA & COOP VICTORU MURTINEZ & POL MONSNLUD & 64 & 1984 \\
\hline & ZARAGOZA & COOP VICTORИ MKRTINEZ & POL ACTURIIJ Fases] & 368 & 1904 \\
\hline & ZARAGOZA & COOP VCTORM MHATINEZ & BOCER DE ROR & 72 & 1964 \\
\hline & LAZADA & COOP VICTORLA MARTINE? & LAZANDA & $t 1$ & 1984 \\
\hline & ZARABOZA & COOP VICTORLA MARTINEZ & TOARE RAMONA & 148 & 1285 \\
\hline & HUESCA & COOP VICTORU MWRTINEZ HUESCA & POL 13 & 45 & 1985 \\
\hline & ATECA & COOP. VICTORM MMRTINEZ & ATECA & 12 & 1985 \\
\hline & ZARAGOZA & COOP VICTORM MURTINEZ & POL ACTUR A & 134 & 1906 \\
\hline & ALTORICCON & COOP VCTORH MARTINEZ-HUESCA & AL.TOPOACON & 40 & 1966 \\
\hline & ZARACOZA & COOP. VICTORLA MURTINEZ & POL ACTUR III (2 Ficous) & $23 \mathrm{~A}$ & 1287 \\
\hline & ZARABOZA & COOP VICTORU MURTINEZ & POL UNIVERSIDADI & 56 & 1987 \\
\hline & ZARAGOZA & COOP VCTORM MURTINEZ & POL UNGEASIDAD I & 48 & 1988 \\
\hline & ZARAGOZA & COOP VCTORK MMRTINEZ & POL PUERTA SANCIO & 96 & 1908 \\
\hline & ZARAGOZA & COOP VICTORH MARTINEZ & POL ACTUR W Q Fanses: & 104 & 1968 \\
\hline & ZARACOZA & COOP VICTORLA MARTINEZ & ZALFCNADA & 48 & 1991 \\
\hline & ZARABOZA & COOP. VICTORLA MARTINEZ & POL LAPAZI & 98 & 1992 \\
\hline & TARAZONA & COOP VICTORU MURTINEZ & ESTACION & 50 & 1983 \\
\hline & ZARAGOZA & COOP VICTORK MKRTINEZ & POL LAPAZ II & 88 & 1984 \\
\hline & ZARAGOZA & COOP VICTORM MHPTINEZ & SANTA OROSK & 23 & 1994 \\
\hline & ZARAGOZA & COOP VICTORL MURTINEZ & SANTA ISAEEL & 40 & 1905 \\
\hline & ZARACOZA & COOP VICTORK MKRTINEZ & ENTRE RIOS & 46 & 1206 \\
\hline & ZARAGOZA & COOP VICTORU MURTINEZ & PUEERAI & 48 & 1997 \\
\hline & ZARAGOZA & COOP VICTORU MURTINEZ & RUEERA II & 48 & 1999 \\
\hline & ZARAGOZA & COOP VICTORM MMRTINEZ & LAPAZ E & 25 & 1989 \\
\hline & ZARACOVA & COOP V'CTORИ MURTIMEZ & PAROUE GOYAI & 90 & 2000 \\
\hline & ZARACOZA & COOP. VICTORL MAPTINEZ & PAFOCUE GOYA.II & 70 & 2001 \\
\hline & ZARABOZA & COOP VCTORU MURTINEZ & PAFOCUE QOYA III & 243 & 2003 \\
\hline & HLESCA & COOP VICTORU MURTINEZ & POLKCONO 24 & 49 & 2005 \\
\hline & ZARACOZA & COOP VICTORM MHRTINEZ & MONTES DEL CANAL & 96 & 2005 \\
\hline & ZARAOOZA & COOP VCT MART. & WLLOESPARTERA P-21 & 48 & 2007 \\
\hline & ZARACOZA & COOP. VICT MART. & WALOESOARTERAP-52 & 60 & 20007 \\
\hline & & & & 2.620 & \\
\hline
\end{tabular}

\section{PROMOCIONES EN DESARROLLO}

\begin{tabular}{|c|c|c|c|c|c|}
\hline & LOCALIDAD & PROMOTORA & PROMOCION & N $\mathbf{N}^{2} \mathrm{VIV}$, & FECHA \\
\hline \multirow{3}{*}{ ARAGÓN } & TERLEL & COOP VCT MART. & FUENFRESCA & \$2 & 2000 \\
\hline & ZARABOZA & COOP VICT MART. & WLLEESPATERAP-12 & 164 & 2005 \\
\hline & ZARACOZA & | MCT. MART-NALLESP-OA & WMLLESSMATERA P.22 & 115 & 2008 \\
\hline & & & & 311 & \\
\hline
\end{tabular}

\section{\begin{tabular}{|l|l|}
\hline TOTAL VIVIENDAS & $\mathbf{2 . 9 3 1}$ \\
\hline
\end{tabular}}

Siendo coherentes con sus estatutos, nuestra cooperativa es una entidad sin ánimo de lucro que se creó con un objetivo de continuidad en el tiempo, concibiendo el proceso de sus promociones como una forma de participación social y cuyo fin no es solo la consecución de una vivienda para sus asociados, sino la promoción solidaria de un proyecto 
donde se potencien los valores sociales e individuales como son la participación, la solidaridad, el consenso y la tolerancia.

\section{Principio básico: participación democrática de los socios en las cooperativas de vivienda}

La exposición se centra en uno de los principios básicos del cooperativismo como es la participación democrática de los socios. La cooperativa Victoria Martínez constituye un claro ejemplo de participación y gestión a la vez, puesto que desde sus inicios se encuentra respaldada por una gestora que nació y se desarrolló con ella, dotada de una gran profesionalidad y experiencia (Creixeda, SAU).

Para centrar la participación democrática en el cooperativismo de viviendas, es necesario entender antes lo que es una cooperativa de viviendas.

\section{Qué es una cooperativa de viviendas}

La sociedad cooperativa de vivienda es una cooperativa de consumo especializada, las diversas leyes de cooperativas estatales la configuran como una categoría propia que nuestra legislación autonómica define (art. 84, Ley de Cooperativas de Aragón) así: «Son las que tienen por objeto procurar, exclusivamente para sus socios, viviendas, servicios o edificaciones complementarias, así como su rehabilitación, pudiendo organizar el uso y disfrute de los elementos comunes y regular la administración, conservación y mejora de los mismos en el modo que se establezca en los estatutos».

En otras palabras, se trata de una agrupación de personas que comparten la necesidad de una vivienda y se unen para acceder a ella mediante la autopromoción, en las mejores condiciones de calidad y precio posibles.

El carácter de autopromoción elimina el beneficio del promotor, lo que abarata el coste final del producto; de ahí que se consiga una vivienda de calidad y a precio de coste (que no de mercado).

Pero sobre todo la cooperativa es la empresa participativa por excelencia, hasta tal punto que, sin la participación del socio la sociedad se desnaturalizaría. 
Así, la cooperativa de viviendas es una sociedad personalista. El cooperativista es socio de la cooperativa y, como tal, copropietario de la misma; al mismo tiempo es adjudicatario y usuario de una vivienda, sea en régimen de acceso a la propiedad o en alquiler, de la que es copromotor. Ambas vertientes de la condición del socio (socio/copromotor/beneficiario) son inseparables. Para lograr este objetivo, el derecho otorga a la cooperativa personalidad jurídica propia, distinta de la de sus socios, como ocurre con las sociedades mercantiles, pero alejándose de este modelo.

Así, ser socio de una cooperativa de viviendas es algo más que comprarse una casa; significa participar en el desarrollo de la promoción, es decir, el socio cooperativista no está comprando una casa, sino que la está construyendo, es decir, que corre además con las ventajas y riesgos de ser el promotor de la vivienda, pero por otro lado se beneficia de obtenerla a precio de coste (que no de mercado) y en las mejores condiciones de calidad.

\section{Sociedad cooperativa de viviendas como empresa de participación}

Así, la sociedad cooperativa de viviendas actúa como empresa, ya que en ella acontecen interrelacionados los tres tipos de flujos que caracterizan toda actividad empresarial (García-Gutiérrez, 1999, 1988-1989; Gómez, 2001):
A) Los flujos de información-decisión.
B) Los flujos reales relativos a la prestación de un servicio: suminis- trar alojamiento.
C) Los flujos financieros asociados a los flujos reales.
Y asimismo, la sociedad cooperativa de viviendas es una empresa de participación, porque los socios intervienen activamente en esos tres tipos
A.1) Tomando las decisiones que como socios les corresponden. De acuerdo a las reglas o principios cooperativos, todos los socios han de participar democráticamente; de acuerdo con la regla de una persona un voto, independientemente de la participa- ción en el capital que posea, primacía de la persona sobre el capital. de flujos: 
B.1) Como "consumidores» o usuarios de las viviendas.

C.1) Financiando la promoción de las viviendas. Aportan el denominado capital social, la cuota de ingreso y/o periódica, y las aportaciones para financiar la vivienda y anejos:

1. Aportaciones al capital social.

2. Cuota de ingreso y /o periódicas. No integran el capital social ni son reintegrables. Su destino es sufragar los gastos generados por la actuación de la sociedad cooperativa y los servicios que esta realice, tanto en las primeras etapas de su funcionamiento, como posteriormente: constitución, mantenimiento, administración, etc.

3. Entrega o aportaciones para financiar la vivienda y anexos. Cuantitativamente son las más importantes. Lo socios deben pagar el coste de la actividad cooperativizada: la producción de la vivienda. Los socios aportan una cantidad inicial para los primeros costes de desarrollo, y luego el resto fraccionado hasta completar las cantidades no financiables por vía hipotecaria.

En el proceso de edificación y participación intervienen los socios mediante sus órganos de representación (consejo rector y asamblea) y casi siempre (por no decir siempre) interviene asimismo una entidad gestora; pero su intervención se basa única y exclusivamente en el asesoramiento, no en la decisión.

\section{Otros entes intervinientes en la participación (que no decisión): sociedades gestoras}

Es interesante hacer hincapié en la entidad gestora, al ser un ente que interviene en la participación del socio, asesorando y asistiéndolo, pero en ningún caso tomando decisiones, y que en la cooperativa Victoria Martínez tiene un peso importante.

La gestora es, normalmente, una sociedad mercantil que presta sus servicios de gestión y asesoramiento a la cooperativa, a cambio de un precio pactado entre ambas partes.

Estas empresas facilitan a las cooperativas un asesoramiento amplio que va desde la constitución de la sociedad cooperativa, guiando a los socios en los trámites necesarios para su correcta inscripción en el registro 
de cooperativas, y su asesoramiento en el cumplimiento de las obligaciones que como sociedad cooperativa deben cumplir hasta la coordinación de todos los trabajos, profesionales y empresas que participan en el cada día más complejo campo de la promoción de viviendas, hasta la entrega de las viviendas o liquidación de la cooperativa en su caso.

Se ha de tener en cuenta que la gestora no toma decisiones, sino que asesora y gestiona pero en ningún caso toma decisiones dentro del seno de la cooperativa, las decisiones las toman los órganos de gobierno de la cooperativa.

Es necesario delimitar la responsabilidad de la gestora como agente independiente con atribuciones propias, pero sin confundirlas con las de los órganos sociales. Las gestoras no deben tener poderes de las cooperativas, ni su representación, ni capacidad de decisión.

La relación contractual entre la cooperativa y la sociedad gestora se materializa en el contrato de gestión, que determina los derechos y obligaciones de la gestora y la cooperativa en cada promoción, y establece la contraprestación económica u honorarios que la cooperativa pagará por ellos, y que oscilan entre un 6\% y un $8 \%$.

En todo caso, el prestigio, la solvencia y la profesionalidad de la sociedad gestora se convierten en la máxima garantía para el éxito de cualquier promoción. Por esta razón es imprescindible tener en cuenta estos factores a la hora de contratar los servicios de una sociedad de este tipo.

\section{Labores}

- Constitución de la cooperativa.

- Adquisición y gestión de suelo. Asistencia en la selección del solar o solares donde se desarrollarán las promociones, especificando previsiones urbanísticas, económicas y financieras, sometiéndolas a la aprobación de los órganos correspondientes de la cooperativa. Estudio y seguimiento de la gestión de los procesos urbanísticos en los que se encuentren afectados los solares que adquiera la cooperativa.

- Financiación. Realización los estudios económico financieros de viabilidad de la cooperativa y sus promociones inmobiliarias, su seguimiento y control presupuestario. 
- Dirección facultativa. Selección y propuesta de los técnicos encargados de elaborar todos los proyectos técnicos necesarios para el desarrollo de la promoción y su dirección de obra.

- Administración pública. Realización de las gestiones para la obtención de las licencias y permisos requeridos para construir y entregar la promoción.

- Construcción. Selección de un conjunto de empresas constructoras para la realización de las obras de construcción de las promociones inmobiliarias, a promover por la cooperativa; gestión del concurso, adjudicación de las obras de construcción, recopilando ofertas, elaborando cuadros comparativos y análisis de las mismas y condiciones de cada oferente. Seguimiento y control de las certificaciones de obras y gestión de su liquidación.

- Socios de la cooperativa. Asistencia en la formalización de la admisión de socios, adopción de los acuerdos sociales y formalización de los contratos de adjudicación de los productos inmobiliarios. Preparación de la documentación necesaria para la adecuada información de los derechos y deberes y asistencia en la relación de los socios con la cooperativa.

- Órganos Sociales. Asistencia técnica y jurídica a los órganos sociales de la cooperativa para el adecuado desarrollo de sus funciones.

- Gestión Económica. Realización de la contabilidad de la cooperativa y sus promociones.

- Fiscalidad. Preparación y gestión de todas las declaraciones fiscales necesarias.

- Asistencia Jurídica.

- Administración.

En resumen de lo antedicho, en el caso concreto de las cooperativas de vivienda, y teniendo en cuenta el proceso edificatorio, la participación influye en los siguientes aspectos:

Participación social, ya que los socios eligen a los componentes del órgano de administración.

Participación en la obtención del producto, es decir, la vivienda; ya que los socios eligen a los técnicos redactores del proyecto, la gestora, la constructora mediante un concurso, y toman decisiones durante la ejecución de la construcción, modificación proyecto/calidades. 
Participación en el coste económico de su vivienda, puesto que con la adquisición del suelo y la elección de la constructora, ya se cubre el 85\% del coste de la vivienda, cubriendo cerca del $90 \%$ con la elección de la dirección facultativa, los demás costes suelen ser de índole fiscal que no dependen de los socios.

Participación en el control de la ejecución de sus decisiones, con el examen de la gestión social y aprobación o censura de las cuentas anuales, auditadas.

\section{Divergencias con legislación VPO. Contradicción del principio básico de participación}

Las sociedades cooperativas de vivienda sufren los problemas derivados de la dificultad de promover viviendas adecuadas a las necesidades de sus socios y soportan, por otro lado, las dificultades para promocionar la vivienda protegida, puesto que sufren incesantes trabas legislativas provocadas por el desconocimiento y la desconfianza en el sistema cooperativo que tienen los legisladores, y que son causa de disposiciones legales intervencionistas, que limitan en gran medida la participación del socio cooperativista.

A modo de ejemplo:

\section{Sobrecoste en el precio de la vivienda}

Ley 24/2003 de medidas urgentes

Artículo 9. Condiciones de protección.

«En las actuaciones protegidas de vivienda promovidas por cooperativas $[\ldots]$ el coste máximo de las viviendas protegidas para los mismos [socios] [...] no podrá superar el precio máximo establecido para las viviendas correspondientes».

Artículo 12. Mejoras.

«Con carácter general, no se autorizará la realización de mejoras que impliquen un sobrecoste para los destinatarios de la vivienda».

Artículo 44. Infracciones muy graves.

«Constituyen infracciones administrativas muy graves:

La gestión de las cooperativas de viviendas [...] que genere sobrecoste para los cooperativistas». 
Decreto 80/2004, Reglamento del Registro de solicitantes

Artículo 47.b) Control económico.

«[...] El coste máximo de las viviendas protegidas para los mismos, incluidos cualesquiera beneficios o gastos de las cooperativas o entidades o de sus gestores o apoderados, no podrá superar el precio máximo establecido para las viviendas correspondientes $[\ldots] »$.

Teniendo en cuenta, como ya se ha expuesto, que las sociedades cooperativas de viviendas no son más que un grupo de individuos reunidos en una sociedad cooperativa constituida al efecto de promover y construir unas viviendas para sí mismos y no para destinarlas al tráfico con terceros compradores para obtener beneficio económico, no se entiende que se aplique la presente prohibición, puesto que en cualquier momento y durante la construcción de la promoción, los socios cooperativistas pueden decidir por unanimidad en asamblea general la modificación de las calidades del proyecto o la aprobación de mejoras en la construcción de sus propias viviendas, sin que ese exceso suponga un sobrecoste del precio de la vivienda, máxime cuando tal exceso se satisface voluntariamente por los cooperativistas. O puede producirse incluso por encontrarse con imprevistos producidos por fuerza mayor.

Los gastos de construcción de las viviendas por la cooperativa, pagados por los cooperativistas adjudicatarios de las viviendas, no pueden ser incluidos dentro del concepto de «sobreprecio o prima» en la venta.

Estas disposiciones van en contra de la normativa en materia de cooperativas, la cual obliga a repercutir los costes de una promoción a los cooperativistas de la misma, independientemente del precio máximo fijado. Lo cual no solo es una obligación legal sino la única posible, ¿quién, que no sean los socios, debe sufragar los costes de sus viviendas?

\section{Responsabilidad del Gestor cooperativas}

Ley de medidas urgentes 24/2003

Artículo 46. Responsabilidad.

«Cuando las personas o entidades promotoras responsables hayan adquirido los terrenos destinados por el planeamiento a la promoción de vi- 
viendas protegidas por un precio superior al calculado conforme al método residual [...] serán igualmente responsables las personas o entidades que transmitieron dichos terrenos, así como, tratándose de comunidades de bienes, cooperativas de viviendas protegidas [...] sus respectivas entidades gestoras $[\ldots] »$.

Artículo 55. Reintegro del sobrecoste, sobreprecio o sobrerrenta percibidos.

«[...] Quienes hayan adquirido o arrendado viviendas protegidas por precios o rentas superiores a los legalmente aplicables en cada caso, podrán dirigirse a la administración de la Comunidad Autónoma a fin de que [...] exija del gestor de la comunidad de bienes, cooperativa [...] el reintegro, en concepto de beneficio ilegalmente obtenido, del sobrecoste, sobreprecio o sobrerrenta percibidos, que serán reembolsados al comunero, cooperativista, comprador $[\ldots] »$.

Decreto 80/2004, Reglamento del Registro de solicitantes

Artículo 48. Responsabilidad de los administradores o gestores.

«Los gestores contratados por cooperativas [...] serán responsables de los daños que causen a la entidad promotora o a sus miembros de conformidad con lo dispuesto en la legislación civil y mercantil».

Estas disposiciones cargan en el gestor de cooperativas responsabilidades obvias y otras que no tiene por qué asumir, olvidándose de que el gestor de una cooperativa no decide, sino que decide la cooperativa. Si la cooperativa ha adoptado mediante acuerdo de los órganos sociales correspondientes, asamblea general o consejo rector, las decisiones que corresponden a los elementos de coste que definen el coste total efectivo de las viviendas y por consiguiente del sobrecoste, no puede exigirse a la gestora ninguna responsabilidad.

Bajo el principio de que cada uno es responsable de sus propios actos, se pretende hacer responsable a la gestora de los actos de la cooperativa.

Por ello, los obligados al pago del sobrecoste son los socios copromotores de la cooperativa quienes deben asumir el coste real y efectivo de sus viviendas si la cooperativa ha adoptado sus decisiones con arreglo a derecho, la gestora no es responsable del sobrecoste. 
El sujeto responsable de la promoción es la cooperativa y en ningún caso la empresa con la que se contrata la gestión de la misma, puesto que son dos personas jurídicas diferentes.

\section{Retos relativos a su funcionamiento como empresa de participación}

El principal reto es conservar su esencia, es decir, la gestión democrática, tratando de conseguir una efectiva participación (y responsabilidad) de los socios, organizando un diálogo democrático sobre la consecución del objeto - la producción de las viviendas- que no la inviabilice, y conseguir involucrar a los socios consumidores en el proceso de desarrollo del producto, a través de los mecanismos adecuados (Blonquist y Böök, 1994, pág. 305).

En el modelo actual de sociedades cooperativas en España existen dos peligros; uno que se desvirtúe su funcionamiento democrático por desconocimiento del socio de la naturaleza de la sociedad, y otro, el abuso de los responsables de la entidad a la que se ha encargado la gestión dificultando la participación.

Pero, sin embargo, la intervención de la gestora no contradice la pureza de la participación democrática, ya que el binomio cooperativa y empresa gestora es la mejor alternativa para satisfacer la necesidad de vivienda a precio de coste y de gran calidad.

\section{Conclusión}

Las sociedades cooperativas han articulado un sistema genuino de promoción de vivienda que ha encontrado un hueco en la promoción inmobiliaria española.

Se ha manifestado que este sistema es altamente eficaz, no solo como forma de promoción inmobiliaria, sino en la medida en que ha hecho posible el acceso a la vivienda a precios asequibles a muchas familias (García-Gutiérrez et ál., 2002).

Y constituye un potencial instrumento para las administraciones públicas en la medida en que ha contribuido de forma importante a la promoción de vivienda protegida en España. 
Las sociedades cooperativas de vivienda contribuyen a una organización eficaz de los mercados, como agentes correctores y dinamizadores en el mercado inmobiliario. Es de destacar su contribución a regular los precios y las condiciones de las zonas en donde actúan.

Cuando las sociedades cooperativas funcionan adecuadamente, aportan ventajas de orden económico, financiero, técnico y social que pueden producir competencia significativa frente a otros modos de promoción de viviendas convencionales, sean cuales sean los tipos de vivienda y las características de los socios. 



\section{COOP57 (Cooperativa de servicios financieros éticos y solidarios)}

JAVIER ORTEGa Díaz

Presidente del Consejo de Sección COOP57 Aragón

(Red de Economía Alternativa y Solidaria Aragón, REAS-Aragón)

COOP57 es una cooperativa de servicios financieros al servicio de la Economía Social y solidaria que nace en 1995 en Cataluña de la confluencia de tres factores:

- Los fondos compensatorios recibidos por 57 ex trabajadores de la editorial Bruguera, tras una larga lucha sindical.

- La crisis industrial y la lucha del movimiento obrero para evitar la pérdida de puestos de trabajo a través del cooperativismo.

— La sensibilidad de la sociedad civil y los movimientos sociales.

Con escasa incidencia en los primeros años, es a partir del año 2000 cuando comienza a operar con mayor fluidez incrementando notablemente su número de socios entidades y socios colaboradores. El crecimiento orgánico en red de COOP57 hace que en el año 2005 se constituya la sección territorial de COOP57 Aragón y en el año 2007 la sección territorial de COOP Madrid. Para el año 2008 está prevista la constitución de las redes territoriales de Andalucía y Galicia.

COOP57 es propiedad colectiva de las propias entidades socias de la Economía Social

\section{Misión y objetivos}

COOP57 es una cooperativa de servicios que promueve el ahorro ético y que destina sus recursos a dar créditos a proyectos de economía so- 
cial y solidaria que promuevan la ocupación, fomenten el cooperativismo, el asociacionismo y la solidaridad en general, promoviendo la sostenibilidad sobre la base de los principios éticos y solidarios:

Principio de coherencia. Evitamos la contradicción de que nuestro dinero pueda estar financiando proyectos contradictorios con nuestros principios éticos y sociales (como por ejemplo, la industria armamentística, las centrales nucleares, el dumping social, la explotación infantil, los regímenes dictatoriales, la expoliación ambiental, etc.).

Principio de compatibilidad. Compatibilizamos el rendimiento financiero y el rendimiento social. Uno no puede ir disociado del otro. Los criterios de uso del dinero se basan en indicadores relativos de riesgo, pero no de máximo rendimiento para la entidad y sus socios en detrimento del rendimiento social.

Principio de participación. Fomentamos la responsabilidad de los inversores ahorradores, como ciudadanos y ciudadanas, en sus operaciones financieras.

Hacemos de la participación en la política de la entidad de las entidades socias y de los socios y socias colaboradores una de nuestras señas de identidad. En definitiva, pretendemos recuperar el control de nuestros ahorros y recursos económicos y promover la autogestión financiera.

Principio de transparencia. Aplicamos una absoluta transparencia en la gestión de la entidad, tanto en la concesión de los préstamos como en las inversiones. Toda entidad socia y todo socio y socia colaborador sabe perfectamente para qué sirven sus recursos. Publicamos dos veces al año un boletín informativo electrónico donde se incluye la lista de préstamos acordados con cada entidad beneficiada, así como el volumen y la duración de cada préstamo. La memoria anual culmina esta voluntad de transparencia.

Principio de solidaridad. Las entidades socias y los socios y socias colaboradores sabemos que nuestro dinero contribuye a construir una economía más humana y solidaria. Además, podemos manifestar nuestra solidaridad fijando, nosotros mismos en la asamblea, la tasa de remuneración de los ahorros.

Principio de reflexión. Reflexionamos continuamente sobre los principios que deben orientar nuestra acción. Entendemos el comportamiento 
ético como un proceso y repensamos racionalmente los valores que deben orientar nuestra acción, y nos adaptamos a los valores y principios que consideramos justos y prioritarios.

\section{Estructura de la organización}

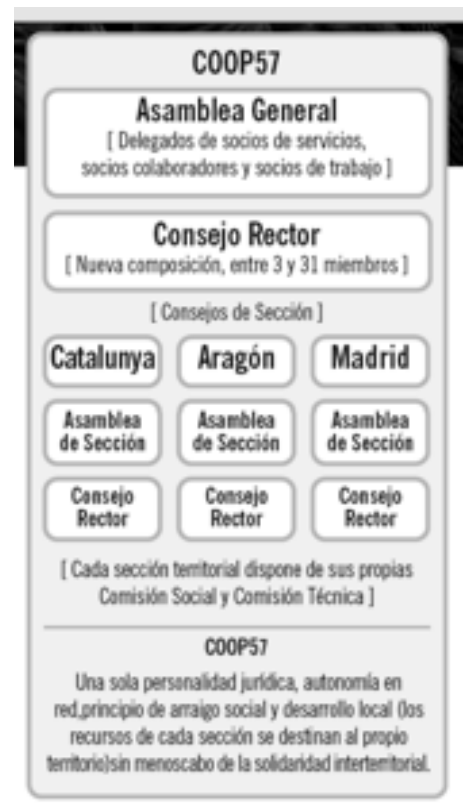

\section{Servicios y recursos de la entidad}

Principales servicios financieros que ofrece COOP57:

a) Préstamos a corto y largo plazo para financiar proyectos y/o inversiones en inmovilizado.

b) Productos de financiación de circulante.

c) Créditos puente para anticipar el importe de subvenciones de entidades y organismos públicos.

d) Préstamos de intercooperación orientados a facilitar operaciones entre entidades socias de COOP57. 
Recursos económicos de COOP57:

Pueden ahorrar a través de COOP57 las personas y las entidades de la Economía Social y solidaria que comparten los principios de las finanzas éticas y solidarias y sean socias. Las personas solo aportan ahorro, que se remunera anualmente al tipo de interés fijado en la propia asamblea general mientras que las entidades también pueden ser receptoras de los créditos.

COOP57 Aragón

C/ Mayoral 9, local 2, 50003 Zaragoza

COOP57 Cataluña

COOP57 Madrid

COOP57 SCCL (Servicios centrales)

Méndez Núñez, 1, pral., 2. ${ }^{a}, 08003$ Barcelona 


\section{Saldo de las aportaciones de socios y socias}

\begin{tabular}{|c|c|c|c|c|c|c|c|c|}
\hline Eneuros & 2000 & 2001 & 2002 & 2000 & 2004 & 2005 & 2006 & 2000 \\
\hline Apert dilikatrix & 200321 & 233957 & 239.604 & 20.375 & 27.72 & 285499 & 302085 & 34.238 \\
\hline Apert wluntarian & 90.976 & 156846 & 100.387 & 200250 & 245.59 & 264.833 & 338.192 & 434.06 \\
\hline Anet sais aditerables & 61.233 & 204616 & 345.903 & 533.694 & 898258 & 1.341 .632 & 1.817 .494 & 2.405 .20 \\
\hline Apstadine La Pasta & 0 & 0 & 0 & 0 & 0 & 0 & $A R 000$ & 245.000 \\
\hline Total & 3.590 & 507.420 & 767.85 & 081.761 & 1.343563 & $1.8 \mathrm{ng} .094$ & 284.711 & 200.10 \\
\hline
\end{tabular}

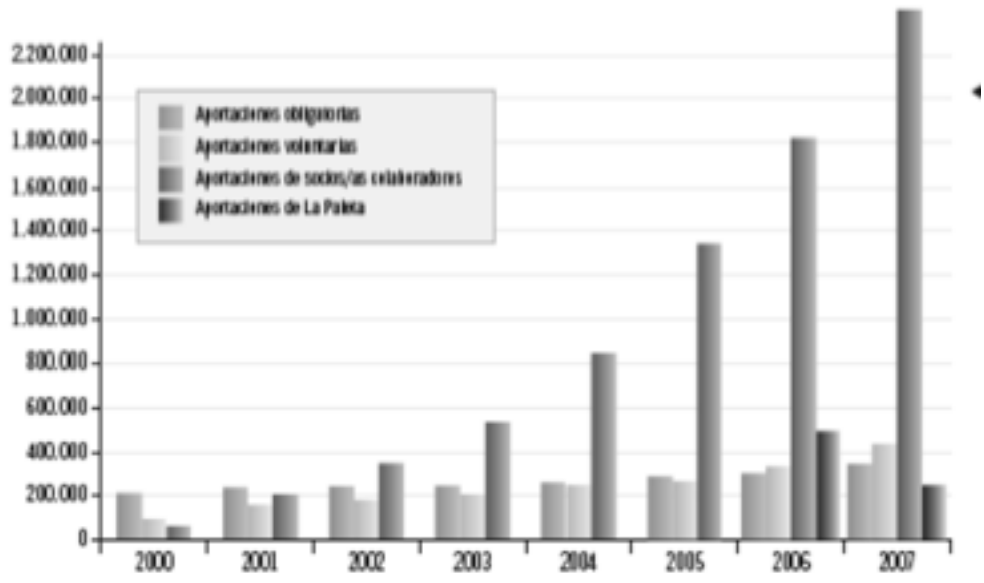

Evolución de los créditos concedidos

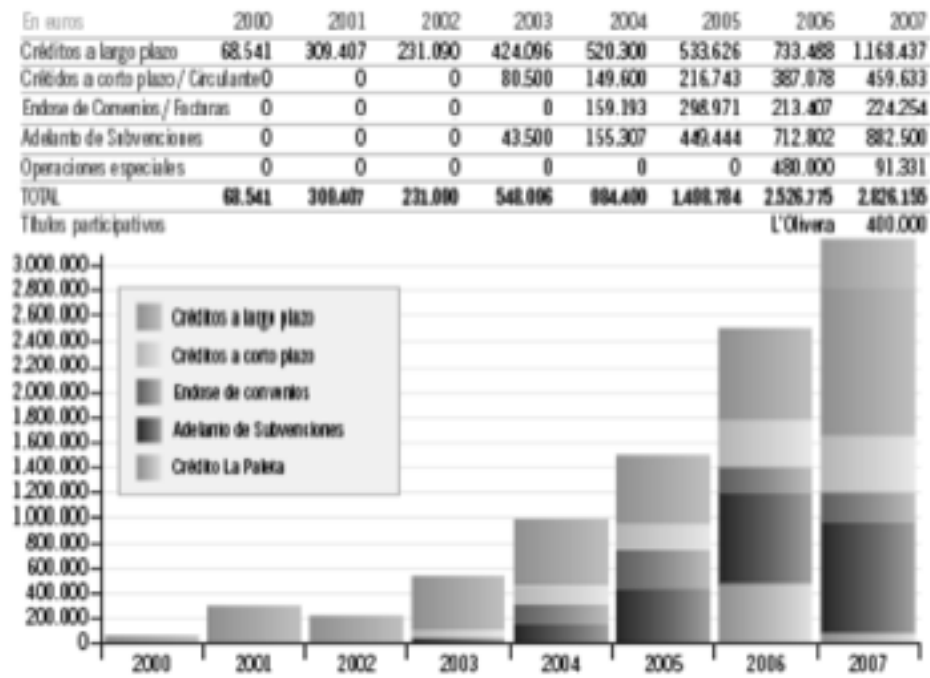





\section{Cooperativas de alumnos, UCEA-Aragón}

Pablo Herranz

Unión de Cooperativas de Enseñanza de Aragón (UCEA-Aragón)

\section{Presentación de UCEA}

Esta Unión de Cooperativas de Enseñanza de Aragón (UCEA) surge como consecuencia de la configuración de las autonomías. Desde la Unión de Cooperativas de España (UECoE) se insta a que se forme la Unión Autonómica correspondiente y con los representantes de las distintas uniones, conformar el consejo rector de la UECoE con sede en Madrid.

Formamos la UCEA, con las connotaciones propias de la tierra, pocos y dispersos y su evolución contiene las propiedades de Aragón. Nuestra estructura es muy sencilla puesto que solo existen 5 pequeñas cooperativas en Aragón. Nuestra sede está en uno de los centros, en el colegio don Bosco, donde se coordina y desarrolla su actividad, en comunión con UECoE, como en el tema de formación, cambio de experiencias, etc.

Es precisamente en el colegio don Bosco donde se realiza la experiencia que presentamos.

Este centro inició sus actividades como cooperativa de enseñanza en 1984 con ocho cooperativistas, para continuar la actividad tras un cese del anterior titular. Inició un proceso en el que se estudió el cambio de localización, adecuación de un nuevo edificio. En la actualidad atiende a 325 niños de 3 a 16 años, alumnos de $2 .^{\circ}$ ciclo de educación infantil, primaria y ESO, con un total de treinta trabajadores, de los que catorce son cooperativistas 
Don Bosco tiene un doble objetivo, como empresa, al ser cooperativa, se rige por los principios cooperativos y, como centro escolar, ofrece un servicio público, desde una empresa privada, procurando que los principios cooperativos transmitan una especificidad en la que estos principios mejoren la calidad de enseñanza.

\section{Experiencia a presentar}

Don Bosco realizó, con alumnos de $4 .^{\circ}$ de ESO, la experiencia que se presenta de una cooperativa escolar en un centro educativo.

Esta experiencia se expuso en el congreso de UECoE, en Cáceres en 2006, junto con experiencias escolares de otras comunidades autónomas.

Sabemos que hay experiencias muy interesantes, que han mejorado la metodología y que sigue ampliándose con alumnos de otras edades con resultados muy interesantes.

\subsection{Objetivos}

- Trasmitir los principios cooperativos de la empresa a los alumnos que conviven en una de ellas parte de su vida.

- Desarrollar el método cooperativo en la preparación de un intercambio con alumnos europeos para mejorar el idioma.

Algunas de las razones por las que este método favorece el aprendizaje son las siguientes:

- Utiliza el entorno próximo como fuente de aprendizaje.

- Motiva el esfuerzo por aprender, valorando más el proceso que el producto, y consigue una fuerte implicación del alumno en su proceso de aprendizaje.

- Posibilita la construcción individual y colectiva del conocimiento.

- Emplea una metodología activa.

- Utiliza un método inductivo-deductivo; por una parte, se induce el aprendizaje a partir de la experiencia directa y, por otra, se utilizan recursos para permitir la reflexión y el análisis.

- Utiliza como recurso el aprendizaje entre iguales.

- El aprendizaje se construye a partir de las propias motivaciones de los alumnos. 
- Se favorecen situaciones didácticas donde el alumno realiza con facilidad aprendizajes significativos.

- El aprendizaje se construye a partir de las propias motivaciones de los alumnos.

- Los alumnos aprenden la cooperación económica.

- Las cooperativas escolares, persiguiendo un fin educativo, logran múltiples ventajas económicas.

\section{Desarrollo}

\subsection{Fase de motivación con el grupo de alumnos}

Es importante que el grupo de alumnos sea consciente de los objetivos y necesidades que comparten (colaborar en la organización del intercambio con Francia), porque será este el punto de inicio para el desarrollo de este método. Deben analizar las dificultades que tienen a la hora de organizarse como grupo para iniciar acciones que les permitan conseguir sus objetivos, los pasos que se requieren para conseguir las metas formuladas, generar estrategias para su funcionamiento como grupo, etc. Tras realizar todas estas reflexiones, el autor propondrá constituir la cooperativa del grupo como posible fórmula de organización.

\subsection{Fase de conocimiento del funcionamiento de una cooperativa}

Asamblea general: compuesta por todos los miembros de la cooperativa. Es la que decide quién gobierna la vida de la cooperativa.

Asamblea constituyente: es la primera reunión formal que celebran los socios con el fin de constituirse como tal cooperativa.

Asamblea ordinaria: se realiza por lo menos una vez al año. En ella se tratan los siguientes asuntos: designación de los miembros del consejo rector, de los interventores de cuentas y examen de la gestión y aprobación, si procede, de las cuentas y balances.

Asamblea extraordinaria: se celebra en cualquier momento, sobre todo cuando hay problemas importantes, cambio de estatutos, aprobar inversiones, etc. 


\subsection{Recursos}

Tiempos: Este trabajo estuvo programado como práctica del área de iniciación a la vida activa de $4 .^{\circ}$ de la ESO y se realizó también fuera del horario escolar.

Fuente de ingresos:

- Aportación inicial de los miembros.

- La explotación de las máquinas de bebidas y aperitivos que hay en el centro.

- Aportación de minibocadillos para vender en los recreos.

\subsection{Obligaciones}

Responsables del encargo, revisión de buen uso de estas máquinas (cumpliendo la normativa correspondiente), distribución, contabilidad, publicidad, y todas aquellas actividades que la asamblea proponga.

\section{Conclusiones}

Comprobamos que, además de los objetivos propuestos, mejoramos la participación de la comunidad escolar, padres, alumnos, trabajadores, incluso la comunicación entre los alumnos y sus familias respectivas, en la valoración del intercambio evitando que sea, como ocurría en otras actividades, en las que los padres ponen una cantidad de dinero y dejaban de valorarse otros aspectos colaterales, muy importantes dentro de la formación del alumno, como la participación, valoración del trabajo necesario para que la actividad funcione, participación, capacidad de análisis y valoración. 


\title{
GRUPOS DE TRABAJO
}

Experiencias de buenas prácticas en la Economía Social aragonesa

\author{
GRUPOS 2 Y 3 \\ «Retos y oportunidades \\ de la Economía Social aragonesa»
}





\title{
Retos y oportunidades de la Economía Social aragonesa
}

\author{
MARISA EsteVE \\ Asociación Aragonesa de Empresas de Inserción (AREI) \\ ÁNGEL GUTIÉRREZ \\ Instituto Aragonés de Empleo (INAEM)
}

Los grupos de trabajo 2 y 3 , si bien celebraron sus exposiciones de buenas prácticas de forma separada, expusieron y debatieron las conclusiones de forma conjunta, que es como las recoge este documento.

Estas conclusiones se agrupan en cinco grandes apartados.

\section{Visibilidad y comunicación de las Organizaciones}

Importancia de las cifras. Tras las exposiciones efectuadas, relativas a volumen de actividad de nuestras organizaciones, así como de las experiencias y buenas prácticas puestas de manifiesto, se puede comprobar que las cifras que ofrecen las entidades y organizaciones de Economía Social en Aragón son objetivamente importantes, no solo en números absolutos, sino también en incidencia social. Además, cuanto más tamaño tiene una organización o un sector, más visible es en el entorno que desarrolla su actividad.

En Aragón tenemos grandes empresas y entidades de Economía Social que desarrollan un papel esencial en determinados sectores sociales y económicos, como pueden ser, a modo de ejemplo, el agropecuario, o el de los servicios y asistencia social

Capacidad de comunicar. Pese a la importancia de determinadas cifras y de la función desarrollada, las entidades de Economía Social debemos 
tener capacidad de comunicar y difundir de nuestra labor a la sociedad. Se constata que existen carencias en nuestra cultura de comunicación y en la elaboración de un discurso positivo de nosotros mismos. Ello da lugar a que nuestro peso específico y nuestra relevancia real no sea apreciada de forma adecuada por la sociedad. Es necesario el diseño de unas estrategias y mecanismos de comunicación que nos den a conocer de forma efectiva y en la dimensión que tenemos.

Importancia del trabajo bien hecho. Tan fundamental como saber comunicar la importancia cuantitativa es el trabajo bien hecho. Detrás de las cifras aportadas por la Economía Social, debe haber un trabajo de calidad que les dé soporte ante la sociedad. Las cifras por sí mismas no aportan nada si no se tienen buenos resultados que ofrecer. A fin de cuentas, una buena imagen se crea a partir de un buen trabajo y muchas de nuestras organizaciones poseen valores añadidos de los que carecen otro tipo de organizaciones que no pertenecen a la Economía Social y que nos pueden ayudar a la hora de ofrecer excelencia en nuestro trabajo y nuestros resultados.

Complejo de inferioridad. Existe cierto complejo de inferioridad en las organizaciones de Economía Social. En demasiadas ocasiones existe la sensación de que otras entidades que no pertenecen a la Economía Social saben vender mejor sus iniciativas de carácter social o filantrópico, aunque no constituya precisamente el eje de su labor. Por el contrario, en nuestro ámbito existe demasiadas veces una tendencia excesiva a la autocrítica que minimiza nuestros logros. Otros sectores económicos distintos al nuestro alientan muchas veces la idea de que la empresa u organización de corte tradicional y puramente mercantilista es la única que ofrece buenos resultados, lo que además trasladan por extensión a las iniciativas de carácter social que ponen en marcha, muchas de las cuales se ponen en funcionamiento con el objetivo principal de ofrecer buena imagen ante la sociedad. Sin embargo, la dedicación y desarrollo social es precisamente la razón de ser de nuestra actuación como organizaciones que pertenecemos a la Economía Social y, además, hemos demostrado sobradamente a lo largo del tiempo que nuestros objetivos los cumplimos con eficacia. Este principio y estos hechos constatables son los que deben primar, sin perjuicio de llevar a cabo las oportunas reflexiones que nos permitan mejorar día a día. 
Desconocimiento a nivel empresarial. A la falta de conocimiento y difusión de la Economía Social en nuestra sociedad, se suma el desconocimiento de la misma que también existe en el mundo empresarial y profesional. La forma de configuración, la organización y el régimen interno de nuestras entidades son ignoradas por muchas empresas, profesionales y agentes del mundo social y económico, con las dificultades que ello plantea para la puesta en marcha de nuevas iniciativas en el sector y el buen desarrollo de las ya existentes. Nuestras fórmulas jurídicas más comunes, como las cooperativas, las sociedades laborales, las fundaciones, etc., son vistas en muchos casos como elementos atípicos y extraños del mundo socioeconómico, lo que en demasiadas ocasiones trae como consecuencia el desvío de estas iniciativas hacia otras fórmulas jurídicas y organizativas que no guardan relación directa con nuestro sector. Al mismo tiempo, es necesario adaptar mejor la normativa para que nuestras organizaciones, sin perder su carácter, puedan utilizar fórmulas empresariales instrumentales propias del sector de la Economía Social, sin que tengan la necesidad de emplear otro tipo de configuración jurídica distinta para llevar a cabo determinadas funciones que forman parte de su actividad ordinaria.

Base educativa. La visibilidad del sector debería comenzar desde la fase educativa. La Economía Social está ausente de las escuelas y solo se enseña de forma limitada o bajo mínimos en la universidad. No podemos tener buenos profesionales o una sociedad concienciada si no creamos desde el principio una cultura de la Economía Social y un buen sistema de formación enfocado hacia sus valores y procedimientos. Se dice que lo que no se conoce es casi como si no existiera y en nuestro caso es así en gran medida, lo que nos acarrea graves consecuencias.

Definición de límites. No se conocen suficientemente los principios y valores que definen la Economía Social y su delimitación, que se configura bajo unas fórmulas organizativas y normativas propias y concretas. Se confunde este concepto con el de responsabilidad social, que es claramente distinto. El que una entidad lleve a cabo determinadas actuaciones en este ámbito, no quiere decir que por ese motivo ya forme parte de la Economía Social. Es necesario evitar esta confusión que por desgracia se da de forma bastante generalizada y que nos acarrea graves problemas de identificación ante la sociedad en general y en muchos casos ante los po- 
deres sociales y económicos. Para ello tenemos que reivindicar nuestro espacio y nuestras fórmulas de organización como garantes de una actividad que se desarrolla bajo unos principios y objetivos bien definidos, distintos a los que son propios de otras organizaciones o entes constituidos de acuerdo a valores distintos, aunque de forma accesoria este tipo de empresas $u$ organizaciones realicen actuaciones que incidan en el ámbito que nos es propio, sin que ello constituya su objetivo principal.

\section{Trabajo en red}

Conocimiento mutuo. Aunque se aprecian avances significativos en el conocimiento mutuo entre las diferentes plataformas que configuran la Economía Social en Aragón, aún queda mucho camino por recorrer. Es necesario articular sistemas que lo faciliten. Estas jornadas han contribuido a fortalecer este conocimiento, pero son necesarios más mecanismos que lo refuercen de forma permanente, en el ámbito de la diversidad de nuestras organizaciones.

Importancia de la intercooperación. También queda camino por recorrer en este aspecto. La intercooperación entre plataformas y entidades facilita y abre nuevas posibilidades de desarrollo empresarial. Además de formar una red de proveedores y clientes entre las propias organizaciones, se produce la apertura a un sistema de intercambios de clientes potenciales. Tenemos que ser proveedores y clientes preferenciales entre nosotros mismos, lo que redundará también en una intercomunicación de valores y formas de actuación, que serán muy valiosas para nuestra actividad cotidiana.

Ventajas de las sinergias. La interrelación entre organizaciones permite crecer y adaptarse mejor al entorno socioeconómico. Es bueno y necesario que se den estas colaboraciones y por tanto aprovechar las sinergias que el mutuo intercambio de conocimientos pueden propiciar a las actuaciones de las organizaciones. Agrupándonos y sumando esfuerzos, incluso formando redes cuando ello sea posible, conseguiremos entrar y avanzar en sectores de actividad en los que hasta ahora no nos veíamos capaces y, al mismo tiempo, optimizaremos resultados en los que estamos presentes. Del mismo modo, pondremos de manifiesto a la sociedad que la Economía Social es capaz de estar presente en cualquier ámbito socioeconómico, con independencia de sus características o del tamaño requerido. 
Importancia de la $I+D$. Es fundamental para el crecimiento de las organizaciones. En muchos casos constituye el hecho diferencial que permite una mayor competitividad y penetración en el mercado, como se ha podido constatar en la presentación de las buenas prácticas. Las entidades de Economía Social deben prestar especial atención a este aspecto. $\mathrm{Mu}-$ chas veces nuestra labor cotidiana hace que descuidemos este apartado, que constituye en muchas ocasiones la mejor garantía de desarrollo y avances posteriores.

Equidad en los esfuerzos. La colaboración e intercooperación requiere un esfuerzo equitativo entre todos los participantes. Para que los resultados sean realmente positivos, todas las organizaciones han de implicarse de forma efectiva. El desequilibrio en los esfuerzos de los distintos participantes puede hacer fracasar muchas iniciativas adoptadas en esta materia, por lo que es preciso cuidar especialmente este aspecto. Para ello debe llevarse a cabo una adecuada programación y definición de las tareas, cometidos y medios puestos a disposición por parte de cada una de las entidades implicadas.

\section{Participación}

El crecimiento no debe ser un obstáculo para mantener los valores. El crecimiento interno en su actividad, medios y participantes, que experimentan numerosas entidades y empresas de Economía Social, no debe dificultar la aplicación de los valores y mecanismos propios del sector. Crecimiento no debe ser incompatible con participación de los socios y trabajadores en la vida social interna o con la aplicación del derecho a la información. La participación es un valor consultancial y definitorio de la Economía Social. Un fracaso en los sistemas y mecanismos de participación puede llevar al fracaso de una entidad constituida bajo sus normas y principios. En las distintas exposiciones de buenas prácticas que se han realizado, se ha podido comprobar que grandes empresas y organizaciones aragonesas de la Economía Social han tenido que encarar directamente este problema para evitar que el crecimiento experimentado afectase a su propia esencia y principios de actuación. En primer lugar, ha existido un convencimiento de la necesidad de preservar este carácter. A continuación se han buscado los mecanismos necesarios, según cada caso, para preservar la existencia de 
unos adecuados cauces de participación de todos los integrantes en la toma de decisiones, sin que por ello se viesen afectadas la seguridad y agilidad necesarias para la toma de decisiones.

Definición de los sistemas de participación. A través de las distintas normas que regulan las entidades del sector, existen mecanismos adecuados para garantizar una adecuada participación de los integrantes de la Economía Social en la vida de las entidades. El intercambio de experiencias en este aspecto entre las diversas entidades debe servir para conocer las distintas soluciones adoptadas para garantizar la participación.

Desde otros sectores y organizaciones se ha acusado a las empresas y entidades de la Economía Social de falta de agilidad y operatividad en la toma de sus decisiones, precisamente por la necesaria observancia de los mecanismos de participación a que están obligadas. Ello no debe ser así y se ha podido constatar en las jornadas. Un adecuado funcionamiento de los sistemas participativos de gestión, diseñados de acuerdo con las características de la organización en la que se enmarcan y de conformidad con sus normas reguladoras, ha de redundar por el contrario en una mayor riqueza de ideas a la hora de afrontar las decisiones a tomar. Para ello es necesario establecer y configurar inicialmente y de forma precisa dichos mecanismos, así como los distintos niveles de toma de decisión y sus prioridades, para evitar conflictos posteriores.

\section{El papel de las entidades asociativas}

Identificación de los puntos de mejora. Se constata que a nivel de las entidades y empresas concretas que forman parte de la Economía Social, existe un nivel adecuado de identificación de los aspectos organizativos que son susceptibles de mejora. Sin embargo, esto no se da con la suficiente intensidad a un nivel superior, en el seno de las propias organizaciones asociativas, por lo que es necesario que estas tomen conciencia de ello y adopten las soluciones necesarias.

En muchos casos, el papel de las organizaciones se centra fundamentalmente en tareas de representatividad de los distintos sectores que configuran la Economía Social ante las distintas instancias sociales y económicas. Es necesario que, sin descuidar este cometido, se aproveche 
también la capacidad de las organizaciones asociativas para buscar mecanismos de mejora de gestión y funcionamiento de las propias entidades asociadas. Para ello, es necesario mejorar la comunicación y participación en el seno de las entidades, configurando esta tarea como un objetivo fundamental y básico de las propias organizaciones.

Equilibrio en los beneficios obtenidos a través de las entidades asociativas. En el seno de las organizaciones debe encontrarse el punto de equilibrio tendente a que se beneficien por igual todos los asociados. En ocasiones se tiene la sensación de que unos miembros sacan más partido que otros por su pertenencia a ellas. Recíprocamente, debe buscarse también la implicación en la organización asociativa de todos sus integrantes. Para ello es necesario, una vez más, profundizar en la mejora de los sistemas de participación e información en el seno de las propias organizaciones asociativas.

\section{Relaciones con la Administración}

Interlocución a través las entidades asociativas. Se constata la importancia de las organizaciones asociativas como vehículos adecuados e imprescindibles para establecer una interlocución directa, inmediata y eficaz con las administraciones públicas en el ámbito de la Economía Social. En consecuencia, es necesario asociarse para que las entidades y empresas del sector lleven a cabo un intercambio eficaz de iniciativas y propuestas con los poderes públicos.

Mecanismos de relación con la Administración Pública. Si bien en los últimos años se han mejorado los mecanismos de relación entre organizaciones representativas de la Economía Social y las administraciones públicas, aún queda camino por recorrer. Es importante que los sistemas de relación e intercomunicación se hallen bien definidos en su estructura y competencias y, sobre todo, sean útiles para ambas partes. Es necesario crear una cultura de confianza y colaboración estrecha entre la administración pública y las entidades y organizaciones de Economía Social.A fin de cuentas, ambas tienen en común el objetivo principal de conseguir, a través de la implicación y participación social, la mejora de las condiciones de vida y desarrollo de las personas y sectores a los que se extiende su ámbito de actuación. 
Mejora en los sistemas de comunicación. Desde las organizaciones representativas de la Economía Social se tiene en ocasiones la sensación de que estas y la Administración Pública utilizan lenguajes o visiones distintas. Hay que procurar avanzar también en este aspecto. Es necesario acercar los objetivos y métodos de actuación utilizados entre ambas instancias, para conseguir mayor eficacia en los resultados por ambas partes. Para ello es imprescindible articular unos mecanismos de intercomunicación que sean adecuados y utilizables por ambas partes.

Necesidad de evaluar el impacto social. La administración, en sus relaciones con las entidades y empresas de la Economía Social, actúa en bastantes ocasiones como mero fiscalizador de resultados numéricos o estadísticos, sin valorar el impacto social obtenido. Es fundamental concienciar a los poderes públicos para que estos, en colaboración con las organizaciones del sector, articulen sistemas adecuados de evaluación de los resultados obtenidos a nivel social, la denominada «rentabilidad social».

Esta es quizás una de las grandes asignaturas pendientes. Es muy frecuente dar a los ciudadanos resultados globales, sin distinguir y analizar adecuadamente su eficacia real. Unos resultados de calidad, sin cifras espectaculares, consiguen mejor sus objetivos en muchas ocasiones y es necesario que la sociedad tome conciencia de ello.

Adaptación de la Administración a la realidad cambiante. Es necesaria una adaptación más ágil de la Administración a la realidad y necesidades sociales cambiantes. Las entidades que trabajan en este área, por su contacto diario con esta realidad social, ofrecen respuestas adecuadas a las necesidades concretas de cada momento.

Deben articularse los cauces idóneos para que esta experiencia e información llegue a los órganos de la Administración Pública y que, a su vez, esta incremente sus esfuerzos por adecuar sus políticas y medidas a la misma. Ello debe encontrar reflejo en sus presupuestos anuales y en la delimitación de sus programas y líneas de actuación, recogiendo nuevas partidas y programas económicos mejor adaptados y actualizados a la realidad cambiante.

Coordinación interdepartamental. Es necesario una mejor intercomunicación y planificación entre los distintos departamentos de la Administración Pública y de las distintas administraciones entre sí. 
En muchos casos, una misma necesidad está cubierta simultáneamente por varios departamentos, sin que exista coordinación entre ellos para diversificar mejor las medidas de apoyo o buscar una complementariedad en las políticas a aplicar. Ello da lugar a que determinadas necesidades tengan un exceso de protección desde los distintos departamentos de las diferentes administraciones públicas, mientras que para otras exista déficit.

Simplificación de los trámites con la Administración. Es necesario que la Administración Pública avance en el camino de la simplificación de los trámites. La agilización de los procedimientos y el aligeramiento de la documentación a presentar es algo necesario. En muchas ocasiones se piden reiteradamente documentos que ya se hallan en poder de la propia Administración. Esta mejora debería producirse tanto en lo que se refiere a la fase inicial de los procedimientos — solicitudes - como en el momento de justificar las distintas acciones. 



\title{
Participación democrática en las entidades de Economía Social
}

\author{
Chaime Marcuello Servós \\ GESES-Universidad de Zaragoza
}

En la segunda sesión del grupo 3, Participación democrática, seguimos la estela trazada por la sesión previa moderada por Fernando Pérez (FAS), donde habían intervenido los representantes de la Asociación Voluntariado de Geriatría, por la Coordinadora Aragonesa de Voluntariado, de Victoria Martínez Coop., por FACOVI, de COOP57, por REAS Aragón y de Cooperativa de alumnos, por UCEA Aragón. Los cuatro se incorporaron al diálogo y participaron del debate.

En el grupo contamos con la presencia de diecinueve personas, de las cuales ocho éramos varones y once, mujeres, con una gran heterogeneidad de edades y de experiencias en el ámbito de la Economía Social. Desde quienes era la primera vez que tomaban contacto con las ideas y organizaciones, hasta quienes llevan toda su vida dedicada a la gestión y promoción de actividades en el sector.

Nos propusimos como objetivo de la sesión recorrer el «camino» que va del diagnóstico a las propuestas. Para ello utilizamos una dinámica de intervenciones, donde todas las personas aportaron sus opiniones sobre los elementos que surgían en el debate. Con diferentes grados de intervención todo el mundo colaboró y aportó al grupo.

La primera cuestión que se introdujo en la discusión fue el problema de los significados de las palabras, pues se decía que muchos de los conceptos centrales en la Economía Social — cooperación, solidaridad, participación social...- están «manoseados» y cargados de connotaciones y de sentidos. Por ejemplo, las formas de participación en las entidades y las 
visiones al respecto de los propios actores sociales, las cuales son muy diversas. Una tarea que muestra esa diversidad es preguntar qué entiende cada uno cuando hablamos de esto.Y de hecho, lo contrastamos con las propias experiencias de quienes estábamos en el grupo.

En un segundo paso, se formuló una propuesta para caracterizar el contexto social actual aportando cuatro aspectos. Uno, la idea de «trabajo» se ha devaluado como valor, como asunto importante para los sujetos. Dos, los riesgos en el día a día de las empresas de las organizaciones se han trasladado a los individuos, de tal modo que proliferan los contratos a autónomos con la clara intención de reducir costes. Tres, «las obligaciones son voluntarias», con toda la carga de significado que esto tiene en la concepción de los compromisos personales e institucionales. Cuatro, la igualdad se confunde con la no discriminación, que deja sobre la mesa una serie de contradicciones y dificultades.

A esto se añadió el convencimiento general de la importancia de reafirmar lo público. Pero se constataban varias posiciones; quienes asimilaban lo público al estado confundiendo la mayor amplitud del primero.Y quienes enfatizaban el carácter común y compartido de lo público como responsabilidad de todos sin ser patrimonio de nadie. El consenso se recogía diciendo que lo público no es solo atribución del Estado, pero no menos. No se trataba de hablar de más o menos Estado, sino de hacer cada vez mejor las cosas comunes, la res publica.

Respecto de las formas de participación planteamos tres ejes para el análisis. Estos los entendimos, a su vez, como ejes en "correlación» con los momentos históricos, con el contexto social y con el tiempo personal. Sin llegar a ser muy rigurosos con las definiciones, los momentos históricos se entendían como el peldaño al que se llegaba tras una serie de pasos anteriores, en un proceso. En el caso del contexto social, se incorporaban los elementos más generales del sistema, de la sociedad como algo donde lo económico y lo político también contaban.Y en el caso del tiempo personal, como es evidente, la referencia era cada uno de los individuos que percibía su propia identidad y situación desde una perspectiva intransferible y particular.

Así, pasamos a revisar las formas de participación en las organizaciones de la Economía Social. En esto detectamos un gradiente en los modos 
de participar, en los tiempos y en las maneras de entenderse. Para los más jóvenes, estudiantes universitarios, la pregunta retórica que daba pie a la reflexión posterior fue: ¿soy un recurso?

Tenían la impresión de que las personas más implicadas en la gestión de las entidades veían a sus partícipes como recursos de la organización. Por eso, otra pregunta que se planteaba era sobre el valor añadido que genera la participación individual, como si este fuera el criterio para medir, si merece la pena implicarse o no. Frente a lo cual también aparecía la duda o crítica — según cómo se mire — sobre si el voluntariado es mera mano de obra o qué es. Las conversaciones y experiencias al respecto fueron muy enriquecedoras porque muestran la diversidad de posiciones y de «matices de color» en la concepción de la participación en las entidades. El contrapunto venía dado por quienes enfatizaban la idea de "autogestión», de autonomía en la toma de decisiones para llevar la propia vida. Una visión de lo propio y de lo ajeno que dejaba las preguntas anteriores en otro nivel. Por eso, la pregunta o duda — que no se resolvió- es si todos los caminos son igualmente válidos. Obviamente, el mero hecho de preguntar ya sugiere que no está claro.

Sin embargo, las organizaciones de la Economía Social se caracterizan, desde sus orígenes y desde los conceptos teóricos más consolidados, como aquellas donde «la puerta está abierta». Es decir, tienen que darse los mecanismos necesarios para la incorporación de personas, sabiendo también que estos han de ir acompañados de criterios de coherencia y compromiso. Por eso, como característica general del sector, la conclusión fue que son espacios de posibilidad para intervenir en la vida social, cada una en el ámbito específico que después les puede interesar a distintas personas.

No obstante, una crítica planteada desde una de las jóvenes estudiantes - en este caso, de Derecho - es la idea de las entidades como «burbujas». Es decir organizaciones que ya tienen un recorrido tras de sí, con unas dinámicas establecidas que dejan pocos poros abiertos para ser permeables ante la sociedad en general y ante los sujetos particulares que se interesan por sus actividades. En esto se constató que hay grandes diferencias en función de los tamaños de las entidades, de sus «maquinarias» de gestión y también de la propaganda que las más grandes tienden a difundir. 
Por eso, la siguiente cuestión trabajada en el grupo fue cómo promover la participación en las entidades y en la vida cotidiana. Para algunos esto no dejaba de ser una nueva forma de «tiranía» casi religiosa, en tanto que mandamiento axiomático que no se puede discutir porque forma parte esencial del sistema. Más allá de esas disquisiciones, lo que entendimos es que una persona tiene una inquietud en un momento dado y esto le lleva a establecer contacto con una organización donde, tanto la información, como la formación van a ser piezas clave para su posterior implicación en la entidad. Esto es lo que intenta representar el siguiente gráfico:

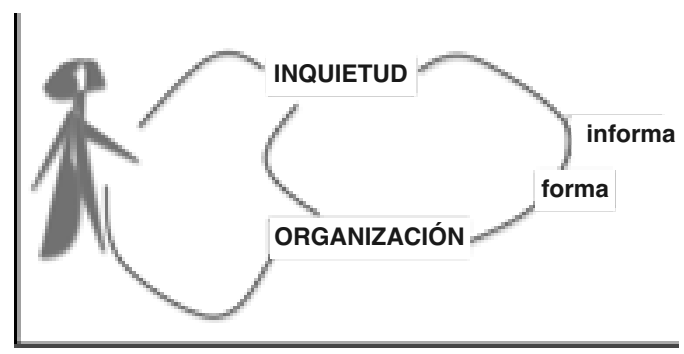

Es un proceso que establece una relación de simbiosis y realimentación de ambas partes. Las personas traducen sus inquietudes en organizaciones que son capaces de dar sentido al sujeto y nutrirse, por su parte, de las inquietudes y energías que estas aportan. Como teoría parecía evidente, pero resultaba contradictoria o, si no, al menos, paradójica respecto de las circunstancias actuales. Parece que no hay una renovación generacional en el sector. Quienes están son los que ya llevan tiempo en el sector y parece que para la gente más joven es un campo donde, si llega, quizá interese en otro momento.

De hecho, una de las frases que dio pie a un debate más apasionado fue la afirmación — también de una estudiante- donde decía «no tengo nada que me interese...», se entiende respecto del sector de la Economía Social y de las numerosas entidades que forman el sector no lucrativo.Y resultó evidente que no era una frase aislada de una joven particular que pasaba por ahí. Se constató lo obvio: que cada generación tiene sus «intereses», que hay una primacía de asuntos en la vida cotidiana y estos estaban en la parte más alejada de la jerarquía de preferencias. Por eso, el «más 
viejo» del lugar se preguntaba qué gen hemos perdido. Es decir, al echar la vista atrás miraba la evolución de la sociedad española, de cómo a su generación las luchas por transformar la sociedad les habían llevado a movilizarse y a no parar hasta la fecha... y toparse de frente con una juventud que ve sus intereses en otro lugar. Quizá haya que pasar del lamento a la revisión, porque de aquellas ansias de participación parece que se ha pasado a las ausencias generalizadas. Quizá sea el efecto de haber dejado atrás una sociedad cerrada y estar en una abierta y opulenta.

Cuando intentamos pasar de «los diagnósticos» —en plural, porque así fue- - a las propuestas, llegamos a la conclusión — quizá obvia desde el comienzo - de que la respuesta al participar tiene una carga inevitable de identidad personal y de concepción de lo que uno es en sociedad. Es decir, la mirada del gestor que cuenta con recursos puede ser que se quede en aquello de "cuántos voluntarios tienes y cuántas horas dedica/s/n». Pero si se cambia la perspectiva y se lleva al terreno personal, se produce un cambio de conciencia. Cada segundo de nuestra vida irremediablemente colabora a que el sistema social se oriente en una dirección. Por esa misma razón es fundamental caer en la cuenta de que la participación es permanente, aunque no la veamos. Por eso es crucial pasar a la conciencia activa que sabe que cada segundo cuenta, que cuando compramos estamos dando nuestros voto, nuestra confianza a una cadena de procesos que modelan nuestro vivir presente y el futuro.

Por eso, la capacidad de intervenir que tenemos delante es mucho mayor de la que solemos pensar. De ahí que la encomienda realizada desde los más activistas del grupo fuese el pasar de la protesta a la propuesta, basada en esa conciencia de quien interpreta un cambio de rol ante los procesos sociales, entre ellos los que trabamos en el mercado más próximo.

Terminamos nuestro trabajo con dos aportaciones en clave de ironía. La primera recordando que la solidaridad hoy se ha divorciado por aburrimiento del voluntariado. Habrá que pensar en toda la carga de sentido que esto supone. La segunda, recordando el desayuno inglés de huevos con bacon: la gallina participa, el cerdo se implica.

Hubo mucho más, esto es lo que he sabido sintetizar. 



\title{
MESA 3
}

\author{
Retos y futuro \\ de la Economía Social
}





\section{Retos y futuro de la Economía Social}

Miguel Ángel Cabra de luna

Consejero del Comité Económico y Social Europeo, en representación de la Confederación Empresarial Española para la Economía Social (CEPES)

\section{Introducción}

Estimados amigos:

Permitidme comenzar mi intervención agradeciendo al comité organizador de las jornadas por la iniciativa de este foro y por haberme invitado a contribuir al mismo. Ya os avanzo que será modestamente. Hablar de los retos y del futuro siempre resulta más complicado que hacerlo del pasado y del presente.Y lo que es peor, el riesgo de equivocación es mayor.

Más aún cuando se trata de hablar del futuro de una realidad tan rica y diversa como la Economía Social y cuando se quiere hacer desde una perspectiva europea, que es lo que voy a intentar hacer yo en esta media hora que me han otorgado los organizadores. Y más aún en la situación de crisis e incertidumbre en la que vivimos. En cualquier caso, espero no aburriros. Para hacerlo más entretenido no dudéis en interrumpirme durante mi intervención, ya sea para interrogarme o para rebatir alguno de mis argumentos.

En efecto, si la Economía Social (ES) ya es de por sí un sector diverso en nuestro país, en el que conviven formas de empresa tan variadas como las cooperativas, las mutualidades, las asociaciones, las fundaciones, las empresas de inserción, los centros de especiales de empleo (personas con discapacidad) o las sociedades laborales, dicha diversidad es aún más pronunciada cuando el horizonte se amplía al contexto europeo. 
Intentaré, pues, explorar la realidad y problemática común a todas esas formas de emprender de otra manera (entreprendre autrement, como dirían los franceses), las cuales, no olvidemos, más allá de sus diferencias y especificidades comparten un denominador común que se declina a varios niveles, a saber:

- primacía de la persona y del objeto social sobre el capital;

- control democrático por sus miembros, defensa del interés general;

- aplicación de los principios de solidaridad y responsabilidad;

- reinversión del beneficio o excedentes en la propia empresa o en objetivos de interés general.

En mi opinión, dichas características convierten a la ES en una institución necesaria para la estabilidad y sostenibilidad del crecimiento económico (particularmente en momentos de crisis e inestabilidad como el actual), la corrección de desequilibrios en el acceso al mercado de trabajo (a través, por ejemplo, de la integración de grupos desfavorecidos como las mujeres, las personas con discapacidad o los emigrantes), la lucha contra la precariedad en el empleo (nuestras empresas generan empleo estable y de calidad, y no recortan plantilla cuando llegan las "vacas flacas»), la revalorización de la actividad económica al servicio de las necesidades sociales y la profundización de la democracia económica

Por todo ello, debemos afirmar, sin tapujos ni complejos, que las empresas de ES son aliados importantes, si no imprescindibles, tanto de la UE como de los estados miembros, para alcanzar sus objetivos económicos y sociales. No olvidemos que, en términos cuantitativos, representan el 10\% del empleo (20 millones de trabajadores) y de las empresas europeas (2 millones de empresas). Sin embargo, por desgracia, esta importancia cuantitativa y cualitativa no se ve acompañada de un reconocimiento proporcional por parte de las instituciones públicas. En efecto, mientras que las empresas de ES en Europa están en pleno desarrollo y crecimiento y actúan en un número creciente de sectores (bancario, agricultura, seguros, distribución, transporte, sanidad, educación, manufacturas, bienes de equipo, nuevas tecnologías, etc.), paradójicamente, las mismas no reciben por parte de las instituciones públicas un reconocimiento proporcional a su contribución económica y social.Y ello tanto a nivel nacional como europeo. 
Os facilito a continuación otras cifras a nivel europeo que creo ilustrativas y que dan una idea de la importancia de nuestro sector:

- Por ejemplo, existen 240.000 cooperativas activas económicamente que emplean 3,7 millones de personas y tiene 143 millones de miembros.

- Las mutuas proporcionan asistencia y cobertura a 120 millones de personas, esto es, uno de cada cuatro ciudadanos.

- Las asociaciones emplean a 4 millones de personas y suponen ellas solas el 4\% del producto nacional bruto y cuentan con $250 \mathrm{mi}-$ llones de socios, esto es el 50\% de los ciudadanos europeos.

- Las empresas de Economía Social están presentes en casi todos los sectores económicos, y en muchos de ellos con una importante cuota de mercado (sector bancario, seguros, agricultura, distribución, transporte, sanidad, educación, servicios sociales, sector manufacturero, bienes de equipo, etc.). Por poner un ejemplo, las mutuas de seguros tienen una cuota de mercado de casi el 24\%, un dato que a pesar de llevar muchos años en este sector yo desconocía.

\section{Desafíos de la economía social a nivel europeo}

En concreto, a nivel europeo esa falta de reconocimiento se refleja en varios frentes.

1. Por un lado, la falta de unos estatutos europeos para las distintas formas jurídicas que adoptan las empresas de la ES que permitan a las mismas operar libremente a lo largo y ancho de la UE y las pongan en pie de igualdad con las otras formas de empresa tradicionales que ya cuentan con tal figura (sociedades anónimas), o que están en proceso de adopción (sociedad limitada). La aprobación en 2003 del estatuto de la sociedad cooperativa europea fue un avance importante. Sin embargo, desde entonces los estatutos de las mutualidades, asociaciones y fundaciones, por razones de distinta índole, permanecen bloqueados en el complejo proceso legislativo comunitario. Cabe señalar que las cooperativas se hallan reconocidas explícitamente en el artículo 48 del Tratado de Roma como una forma empresarial específica y en el articulado de las constituciones 
de varios Estados, como Grecia, Italia, Portugal y España. Desafortunadamente, no es el caso, al menos su consagración en el tratado, de las otras formas de empresa de Economía Social.

A nivel de reconocimiento jurídico, cabe señalar, que pueden identificarse tres grupos de países dentro de la UE: un primer grupo se caracteriza por disponer de legislación específica para las formas de Economía Social (ese sería, por ejemplo, el caso de España y Bélgica); un segundo grupo de países dispone de algunos elementos normativos dispersos en diferentes leyes que regulan las entidades de Economía Social; finalmente otro grupo de países carece de cualquier resquicio normativo que regule ciertas formas de ES (por ejemplo, varios de los nuevos estados miembros, en parte debido a las connotaciones negativas asociadas al sector cooperativo, heredadas del régimen comunista).

2. En segundo lugar, las empresas de ES, a pesar de avances aislados en algunos estados miembros (por ejemplo, el pacto Andaluz por la Economía Social de 2002, posteriormente renovado en 2006) y en algunos sectores en los que han sido invitadas al diálogo sectorial (agrícola, seguros, bancario), continúan estando casi ausentes de la mesa del diálogo social; no por voluntad propia, sino porque no nos han invitado. Y ello a pesar de su gran peso como empleador. Como organización paraguas, considero que Social Economy Europe (SEE) debe ser invitada a la mesa del diálogo social intersectorial a escala europea, ya que representa a empresas que emplean muchos millones de trabajos. Su ausencia no deja de ser un anacronismo que debe ser prontamente superado, uniéndose así a las otras organizaciones que ya están presentes en el diálogo sectorial, tal como es el caso de ACME (Asociación de Mutuas y Cooperativas Aseguradoras), COGECA (Comité General para la Cooperación Agrícola en la Unión Europea) o EACB (Asociación Europea de Bancos Cooperativos).

3. Por otro lado, la ES, en tanto que sector, sigue ausente de las cuentas y estadísticas nacionales y europeas. Y ello porque la metodología de los actuales sistemas de contabilidad nacional, cimentada a mediados del siglo $\mathrm{XX}$, ha desarrollado instrumentos para captar los grandes agregados económicos nacionales en un contexto de economía mixta con un fuerte sector privado capitalista y un sector público complementario y frecuen- 
temente intervencionista. Como resultado, en un sistema de cuentas nacionales articulado en torno a una realidad institucional bipolar, dificilmente podría caber un tercer polo diferente del público o del capitalista. Lo que ocurre entonces es que la Economía Social acaba siendo sumergida en el polo del sector privado tradicional. Esta invisibilidad estadística (recordemos el clásico precepto "lo que no puede ser medido no existe») es una de las principales causas de la ignorancia reinante entre una gran parte de las autoridades públicas en relación con nuestro sector y, a su vez, uno de los mayores obstáculos para su reconocimiento. Afortunadamente, en los últimos años ha confluido una serie de iniciativas que, potenciadas debidamente, pueden contribuir a darle la vuelta a la tortilla. Me refiero, por ejemplo, al estudio sobre las cuentas satélites de las cooperativas y mutualidades promovido por la Comisión Europea, el cual permitirá obtener datos homogéneos, precisos y fiables sobre una parte muy significativa de la ES; al estudio sobre las cuentas de la ES en España promovido por la Fundación ONCE con el objetivo de que seamos tenidos en cuenta por la contabilidad nacional (el más exhaustivo de este tipo realizado hasta el momento en Europa); o al reciente anuncio del gobierno británico sobre la creación de un "nuevo sistema estadístico» que permita valorar tanto cuantitativamente, como cualitativamente los servicios prestados por las empresas del «Tercer Sector». Esperemos que todas estas iniciativas sirvan para convencer a Eurostat (Oficina Estadística de la Unión Europea) de la necesidad de un esquema de este tipo a nivel paneuropeo y, a su vez, a las oficinas estadísticas nacionales sobre la importancia del reconocimiento de la ES en los sistemas de contabilidad nacional.

En cualquier caso, creemos que todas estas iniciativas, aunque positivas, son insuficientes y que se necesita un mayor compromiso de los gobiernos y de las instituciones europeas para avanzar más rápidamente en este ámbito. Eurostat (la Oficina Estadística de la UE) debe jugar un papel fundamental en este sentido.

4. Otro desafio al que nos enfrentamos a nivel europeo es el terminológico. En efecto, la propia riqueza lingüística (no olvidemos que en la UE existen 23 lenguas oficiales) hace que en cada país se utilice a menudo terminología diferente para nombrar a una misma realidad. Este fenómeno lo sufre particularmente nuestro sector, en algunos países es llamada 
Economía Social, en otros Tercer Sector, en otros Economía Solidaria... Pues bien, dicha diversidad, que es más terminológica que conceptual, está impidiendo que avancemos adecuadamente en el reconocimiento de nuestro sector. Unas veces porque es utilizada como excusa por nuestros interlocutores para la inacción y otras porque es explotada como arma arrojadiza por nuestros «enemigos». El reciente estudio del Comité Económico y Social Europeo, elaborado por CIRIEC ${ }^{1}$, es una contribución positiva en la medida en que proporciona un marco conceptual claro más allá de discusiones terminológicas. Sin embargo, de nada servirá si no llevamos a cabo una importante labor pedagógica y de comunicación.

Concretamente, el estudio de CIRIEC para el CESE propone una definición de trabajo de la Economía Social que me parece acertada y que debemos explotar y esgrimir cuando se nos acuse de falta de definición. Según CIRIEC, la Economía Social es:

[El] conjunto de empresas privadas organizadas formalmente, con autonomía de decisión y libertad de adhesión, creadas para satisfacer las necesidades de sus socios a través del mercado, produciendo bienes y servicios, asegurando o financiando y en las que la eventual distribución entre los socios de beneficios o excedentes así como la toma de decisiones no están ligadas directamente con el capital o cotizaciones aportados por cada socio, correspondiendo un voto a cada uno de ellos. La Economía Social - continúa la definición de CIRIEC - también agrupa a aquellas entidades privadas organizadas formalmente con autonomía de decisión y libertad de adhesión que producen servicios de no mercado a favor de familias, cuyos excedentes, si los hubiera, no pueden ser apropiados por los agentes económicos que las crean, controlan o financian.

Es imprescindible transmitir adecuada y ampliamente que el que la Economía Social sea un sector plural no significa que sea también un totum revolutum carente de identidad o de valor interpretativo. Al contrario, tenemos que transmitir a los políticos, medios de comunicación y al público en general, que el núcleo identitario común de la Economía Social se afirma a partir de un amplio y diverso conjunto de entidades micro y macroeconómicas, de carácter libre y voluntario, creadas desde la sociedad civil para satisfacer y resolver las necesidades de los individuos,

1 CIRIEC: Centro Internacional de Investigación e Información sobre la Economía Pública, Social y Cooperativa: <http://www.ciriec.es/>. 
hogares o familias; esto es, para luchar por el interés general, y no para retribuir o dar cobertura a inversores o a empresas capitalistas que a menudo únicamente buscan el beneficio a corto plazo y/o a cualquier precio.

5.Volviendo al ámbito legislativo, también parece necesaria la clarificación de la aplicación del derecho de la competencia y del mercado interior a nuestro sector, sobre todo en lo que se refiere a los servicios sociales de interés general (en un gran número de casos proporcionados por la propia ES). En la actualidad, nuestras empresas se enfrentan a una gran incertidumbre jurídica a la hora de la aplicación del derecho comunitario en dichos ámbitos, la cual permite que continuamente su actividad sea puesta en cuestión por nuestros «enemigos» (ahí están las distintas investigaciones que está llevando a cabo la Comisión Europea en relación con las cooperativas, que están poniendo en cuestión el propio modelo cooperativo y que han sido provocadas por empresas competidoras) y, por ende, actúa como freno al desarrollo del sector de la ES en su conjunto. Para los que no estéis familiarizados con los casos que acabo de mencionar, la Comisión Europea, provocada por partes no precisamente amigas de nuestro sector, tiene actualmente abiertas tres investigaciones que afectan a las cooperativas agrícolas españolas, a las cooperativas de distribución italianas y a las cooperativas bancarias francesas. En los tres casos la cuestión de fondo es si el régimen fiscal de las mismas las coloca en una situación de ventaja competitiva con respecto a sus competidoras capitalistas. Nosotros estamos convencidos de que no y de que la fiscalidad específica de las cooperativas se justifica por su propia especificidad. Como decía anteriormente, lo que es desigual se ha de tratar desigualmente o, lo que es lo mismo, lo que no es igual no se puede tratar de igual manera. Y en este sentido, las cooperativas tienen determinadas obligaciones legales onerosas a las que no están sujetas otras formas de empresa. Por lo tanto, su especificidad fiscal debe quedar justificada y no debe ser considerada como una ayuda de estado, al menos como una ayuda de estado ilegal. Más aún cuando en las últimas semanas hemos visto como aquellos que llevan especulando durante más de una década están beneficiándose de ayudas de estado indiscriminadas. Me refiero concretamente al sector financiero. 
A la Comisión Europea le está costando entender todo esto, pero yo confio en que lo acabe entendiendo y que las cooperativas puedan continuar haciendo, como dirían los ingleses, business as usual. Para ello estamos trabajando y para evitar que la Comisión, empujada por nuestros «enemigos», quiera demonizar a las grandes empresas de la Economía Social y acepte solo a las pequeñas. Obviamente esto es inadmisible e injustificable.

Se puede decir que en cierta manera existe un trecho importante y una falta de coherencia entre la idea del mercado interior y la igualdad de formas de empresa, por un lado, y la aplicación en la práctica del derecho de la competencia, que a menudo se lleva a cabo en clara contradicción con los anteriores.

En efecto, desde la perspectiva de garantizar una igualdad de oportunidades entre las diferentes formas organizativas y de empresas, y dado que se ha de realizar un tratamiento desigual ante situaciones desiguales, es imprescindible que el marco legal europeo establezca medidas dirigidas a compensar las dificultades de operar de las empresas de Economía Social que se encuentran en situación de inferioridad de oportunidades en relación con las otras formas de empresas. Estas medidas pueden ser ayudas directas, pero también pueden ser medidas de tipo fiscal o ciertas bonificaciones en el ámbito de la seguridad social. Esto es algo que a la Comisión Europea le está costando entender, quizás por falta de familiaridad con la realidad de nuestro sector, pero también por la presión ejercida por otros actores. Ello no quiere decir que el legislador no deba establecer los mecanismos adecuados para evitar que ciertos agentes económicos desarrollen comportamientos oportunistas, beneficiándose de las compensaciones por tener los estatutos correspondientes a las empresas de Economía Social, sin cargar con sus correspondientes costes.

6. En materia de ayudas de estado, yo creo que los acontecimientos de las últimas semanas y lo que queda por venir, debe hacernos cambiar el «chip» y ser más valientes en nuestras demandas. Yo abogaría para que de cara a la próxima revisión del reglamento de exenciones en bloque que regulará las ayudas de estado a partir de 2013 exijamos un tratamiento especial y beneficioso para nuestro sector. Sé que 2013 queda aún muy lejos, pero los que trabajamos en asuntos europeos sabemos bien que en Bruselas hay que empezar a trabajar y a moverse con mucha más antela- 
ción que a nivel nacional. Típicamente, un instrumento legislativo de este tipo se empieza a discutir en grupos de expertos al menos tres años antes de que sea adoptado o entre en vigor en los estados miembros. Por lo tanto, no debemos dormirnos en los laureles sino adoptar una actitud preactiva. Obviamente, para ello se necesitan medios. De ello hablaré más adelante.

7. Igualmente importante es trabajar para el mainstreaming de la Economía Social en las distintas políticas europeas, principalmente las públicas. Aunque a lo largo del último cuarto de siglo ha habido distintos gobiernos nacionales y regionales de la UE que han desplegado políticas públicas con referencias explícitas a la Economía Social, bien en su conjunto o bien a sus componentes, aún queda un largo camino por recorrer hasta que la Economía Social salga de su madriguera y sea debidamente tenida en cuenta en las distintas políticas. Hasta el momento, se han articulado sobre todo políticas sectoriales que han incluido referencias explícitas a las formas institucionales que integran la Economía Social, aunque con plasmación fragementaria e inconexa. Son, por ejemplo, los casos de las políticas activas de empleo en las que han sido involucradas sobre todo las cooperativas de trabajadores, las empresas de inserción o los centros especiales de empleo; de las políticas de servicios sociales, donde las asociaciones, fundaciones y otras entidades sin ánimo de lucro han desempeñado un papel clave; de las políticas agrarias y de desarrollo rural, en las que las cooperativas agrarias han sido implicadas; o la referencia a las mutualidades de previsión social en el marco de los sistemas de previsión social. Más recientemente, y singularmente, han emergido en algunos países políticas específicas de Economía Social, unas centradas en las empresas que operan en el mercado y otras dirigidas a las entidades sin fines de lucro, que operan fuera del mercado, pocas veces de modo transversal. En cualquier caso el despliegue de estas políticas ha sido irregular tanto en amplitud como en contenido en los países de la UE. Nuestro desafio es luchar porque ello se haga de forma más consistente y cubriendo todo el espectro de políticas.

8. Un aspecto fundamental para ello es conseguir que exista en todos los gobiernos, tanto a nivel local, como regional o nacional, un órgano de alto rango que tenga competencias reconocidas y explícitas en materia 
de Economía Social. Es por ejemplo el caso de la Dirección General de Economía Social existente en el Ministerio de Trabajo español; de la Secretaria de Estado de Desarrollo Sostenible y de Economía Social belga; de la Unidad de Economía Social irlandesa; de la Dirección General para las Entidades Cooperativas italiana o la Unidad de Empresas Sociales del Reino Unido. Las mismas juegan, o al menos pueden jugar, un papel fundamental en la promoción, el reconocimiento y el mainstreaming de la Economía Social, aunque su impacto depende obviamente de sus recursos y también de quién dependen orgánicamente, así como de sus ámbitos competenciales y de la voluntad política. En cualquier caso, una de nuestras prioridades debe ser que se creen organismos similares en los estados miembros que no cuenten con ellos, así como garantizar el mantenimiento en aquellos en los que ya existan, ya que desgraciadamente su existencia no está blindada. Un buen ejemplo es el desmantelamiento progresivo de la Delegación Interministerial francesa de la Economía Social francesa, por parte de Nicolas Sarkozy y su equipo. El hecho de que esto pase en el país considerado como la cuna de la Economía Social es ilustrativo de la falta de apoyo y los ataques a los que está sometido nuestro sector, no solamente por parte de ciertos actores económicos, sino también por parte de ciertos políticos.

\section{Respuestas a los desafíos en el marco europeo}

Una vez esbozados, cabe preguntarse cómo estos grandes desafios que, con más o menos suerte, acabo de intentar detallar, pueden ser abordados de manera eficaz y exitosa por nuestro sector. Por el momento, no se esperan cambios radicales en la actitud de los políticos europeos, ni tampoco se conocen pócimas mágicas que puedan resolver de la noche a la mañana los problemas a los que se enfrenta nuestro sector. No es dificil, pues, anticipar que se tratará de una carrera de fondo, de una «batalla» que se librará a medio y largo plazo y para la que debemos estar bien preparados.

1. En este sentido se me antoja necesario recordar el viejo adagio de la «unión hace la fuerza». Mientras que a nivel nacional, a través de CEPES (Confederación Empresarial Española de la Economía Social) creo que estamos haciendo honor al mismo casi a rajatabla (con algunas excepciones) a nivel europeo aún nos queda un buen trecho por recorrer.Y ello a pesar 
de los avances importantes alcanzados en los últimos años. En efecto, a pesar de dichos esfuerzos, Social Economy Europe (el equivalente a CEPES a nivel europeo y antiguamente denominada CEP-CMAF, esto es Confederación Europea de Cooperativas, Mutualidades, Asociaciones y Fundaciones) todavía no ha conseguido integrar plenamente las distintas realidades y sensibilidades existentes en la UE a 27 . Ni tampoco se ha dotado de los recursos (humanos y económicos) necesarios para abordar con éxito dichos desafios. En cuanto a lo primero, esto es, a las sensibilidades, se han dado últimamente algunos pasos positivos, como la reciente incorporación de la Federación de Empleadores Sociales Europeos, la Red Europea de Empresas de Inserción (ENISE) o de la Red Europea de Ciudades y Regiones para la Economía Social (REVES). No obstante, aún debemos ir más allá e incorporar a más organizaciones representativas del sector, sobre todo que tengan presencia en los nuevos estados miembros. Y no solo incorporarlas sino también asegurar que sean activas. El hecho de que a menudo los cargos representativos de SEE y de otras organizaciones representativas de las otras familias estén dominados por francófonos o mediterráneos hace que seamos percibidos por algunos como un fenómeno limitado a ciertos países (Francia, España, Italia, Bélgica, etc.) y no al conjunto de la Unión.

Por otro lado, la falta de recursos es también un punto fundamental. No me refiero a falta de recursos en términos absolutos, ya que contamos en nuestro sector con entidades con una facturación y unos activos que no tienen nada que envidiar a cualquier multinacional. Me refiero a la falta de presupuesto de las organizaciones representativas y que defienden los intereses del sector en Bruselas, donde, recordemos, tiene su origen entre el 70 y el $80 \%$ de la normativa que se aplica en los estados miembros, nuestro país incluido. En efecto, las mismas cuentan con unos medios muy limitados; en algunos casos, con todo el debido respeto, rozando el amateurismo. Esto nos coloca en una situación de desequilibrio y desventajas con otros sectores con los que competimos y con las empresas de capital tradicionales, las cuales, como estamos viendo en el caso de las investigaciones que afectan a las cooperativas y que mencionaba anteriormente, están actuando como nuestros «enemigos». En resumen, uno de los aspectos fundamentales a mejorar es la dotación presupuestaria de 
las organizaciones representativas del sector. Las mismas deben contar con un presupuesto que les permita luchar en igualdad de condiciones, cuando menos, con los otros actores. Para ello se me antoja necesaria una mayor corresponsabilidad de las grandes empresas del sector, que en la práctica son las que tienen más que perder y también que ganar.

2. Igualmente creo necesario fortalecer la coordinación entre las distintas organizaciones para optimizar y maximizar el impacto, aprovechando al máximo las sinergias. Lo mismo ocurre con los actores de la Economía Social que podríamos denominar como institucionales. Me refiero en concreto al intergrupo de Economía Social del Parlamento Europeo, a la unidad de Economía Social de la DG Empresa de la Comisión Europea y a la Categoría de Economía Social del Comité Económico y Social Europeo.

2.1. El primero de ellos, el intergrupo de Economía Social, reúne a distintos eurodiputados procedentes de Comisiones y países diferentes, pero a los que les une un elemento común, su sensibilidad hacia la Economía Social. Los mismos se reúnen aproximadamente una vez al mes, normalmente en la sede del Parlamento Europeo en Bruselas, para abordar iniciativas políticas y legislativas que afectan a nuestro sector. Aunque no cabe duda de que tanto su composición como su impacto pueden y deben ser potenciados, creo que en la última legislatura, y particularmente en los dos últimos años, tras la asunción de la presidencia por la eurodiputada francesa del grupo socialista Anne Ferreira, el intergrupo ha evolucionado favorablemente y está creándose un espacio y proporcionando un valor añadido que está siendo claramente beneficioso para nuestro sector. Prueba de ello, por ejemplo, es la celebración de las jornadas de la Economía Social en el Parlamento Europeo el mes de mayo de 2008, la conferencia sobre Economía Social organizada por el grupo parlamentario socialista europeo en esas mismas fechas o la inclusión de la promoción de la Economía Social en el proyecto de programa político del mismo grupo de cara a las elecciones al Parlamento Europeo que tendrán lugar antes de finalizar el primer semestre de 2009. Igualmente, el intergrupo ha jugado un papel importante en la obtención del Informe sobre la Economía Social que está siendo elaborado actualmente y que se espera sea aprobado en forma de resolución a principios de 2009. Su po- 
nente es la eurodiputada liberal italiana Patrizia Toia, con la que me voy a reunir próximamente en calidad de ponente del próximo dictamen del CESE en materia de Economía Social del que hablaré en un momento.

2.2. En segundo lugar, a nivel institucional, aunque a veces resulta un hueso duro de roer, también debemos colaborar con la Unidad de Economía Social de la DG Empresa de la Comisión Europea, la cual stricto sensu solamente es responsable de las cooperativas, de las PYMES y del artesanado, pero que indirectamente actúa también en el ámbito más amplio de la Economía Social. Nos está costando que entiendan de verdad la diversidad, complejidad y especificidad, pero también la unicidad, de nuestro sector, pero creo que poco a poco vamos sensibilizándolos. El desafio es que esa sensibilización se transmita al más alto nivel, no solo a nivel técnico sino también político (comisarios y sus gabinetes, directores generales, etc.). Poco a poco también vamos avanzando en ese frente. Por ejemplo, hace unos meses tuvimos al comisario Verheugen, responsable de Empresa e Industria, y uno de los comisarios más influyentes, en un seminario en el CESE organizado por la categoría de Economía Social y se comprometió a trabajar por la promoción de la Economía Social. Nuestro reto ahora es que ahora pase de las palabras a los hechos. El hecho de que el próximo año 2009 cambie la comisión no ayuda, al menos a corto plazo. A largo plazo podría ser beneficioso.

2.3. En tercer lugar, permitidme que diga unas breves palabras sobre la categoría de Economía Social del CESE, de la cual soy presidente y de la que nuestro buen amigo Jan es uno de los consejeros más destacados y principal ideólogo. Pues bien, salvando las distancias, se podría decir que la Categoría de Economía Social es al CESE lo que el Intergrupo de Economía Social es al Parlamento Europeo. La misma reúne a una cuarentena de consejeros procedentes de distintas secciones (equivalente a las Comisiones en el Parlamento) y de una veintena de países, todos ellos con un denominador común: el representar a organizaciones de Economía Social, en sus distintas formas: cooperativas, mutualidades, asociaciones, fundaciones, sin olvidar las nuevas formas de empresa.

El objetivo principal de la Categoría es velar por el mainstreaming de la Economía Social en los dictámenes del CESE. En otras palabras, que en los dictámenes del CESE se tengan debidamente en cuenta las especifici- 
dades y los intereses de las empresas de Economía Social. No hay que olvidar que según cálculos de la comisión, alrededor del 60\% de las propuestas del CESE son incorporadas por la comisión y el Parlamento en sus iniciativas políticas y legislativas, por lo que no se debe infravalorar su importancia como órgano generador de ideas y propuestas. Igualmente también intentamos promover dictámenes específicos sobre Economía Social. Por ejemplo hemos conseguido que en enero de 2009 se cree un grupo de estudio que trabajará sobre un dictamen sobre «Economía Social y la diversidad de formas de empresa».

Aparte de ello y a nivel externo, también intentamos explotar sinergias con los otros actores claves que ya he mencionado, esto es, el intergrupo de Economía Social del Parlamento Europeo, la DG Empresa en la Comisión Europea o Social Economy Europe, en tanto que plataforma unitaria representativa de nuestro sector a nivel europeo. Para ello invitamos a representantes de alto nivel de estas instituciones a nuestras reuniones y procuramos definir acciones conjuntas. También colaboramos con los Estados miembros, particularmente con aquellos que van a ocupar la presidencia rotatoria de la UE. Por ejemplo, en la última reunión de la categoría, que tuvo lugar a principios de este mes, tuvimos a la ministra de Asuntos Sociales de la República Checa, así como a la embajadora permanente ante la UE de dicho país, que ostentará la presidencia el primer semestre de 2009. El objetivo es obviamente adelantarnos a los acontecimientos. De hecho, les pedimos que la Economía Social ocupe el lugar que se merece en la agenda de la presidencia. Nos dieron buenas palabras. A ver si se cumplen.

Finalmente, en la categoría intentamos actuar como think-tank generando nuevas ideas e iniciativas que redunden en beneficio y en la promoción de la Economía Social a nivel europeo. Un buen ejemplo es el reciente estudio sobre la Economía Social en la UE que encargamos a CIRIEC, el cual ofrece una fotografia completa de la presencia y la importancia de la Economía Social en toda la UE, tanto a nivel cuantitativo como cualitativo. Para los que no lo conocéis, CIRIEC (Centro Internacional de Investigación e Información sobre la Economía Pública, Social y Cooperativa) es el instituto de investigación más prestigioso en nuestro ámbito. Os animo a leer dicho estudio, el cual está disponible en todos los idiomas oficiales de la UE en la página web del CESE. 
3. La Economía Social y el Empleo. Mientras tanto permitidme que os lea literalmente un párrafo del estudio que creo que recoge muy bien el mensaje y conclusiones del mismo y que creo que es particularmente relevante en los tiempos de crisis y convulsiones económicas en las que vivimos actualmente. La Economía Social contribuye, cito textualmente, a "crear nuevos empleos, a mantener puestos de trabajo en sectores de actividad y en empresas en crisis y/o amenazadas de cierre, a incrementar el nivel de estabilidad del empleo, a emerger empleos desde la economía informal hacia la oficial, a mantener oficios y explorar nuevas profesiones y a desarrollar trayectorias de inserción laboral de colectivos especialmente desfavorecidos y ubicados en procesos de exclusión social». En efecto, concluye el estudio, «en los últimos decenios los datos estadísticos han demostrado que se trata de un potente sector generador de empleo en Europa, con mayor sensibilidad al empleo que los otros sectores de la economía».

4. Es esta última carta, la del empleo, una de las cartas que en mi opinión debemos jugar con más fuerza, particularmente en épocas de crisis e incertidumbre como la que vivimos en estos momentos. Está demostrado que generamos puestos de trabajo de mayor estabilidad y calidad, con más alto crecimiento, contribuyendo a fijar la población en áreas geográficas donde la economía tradicional está ausente o en crisis. Además, a través del fomento de la capacidad emprendedora y empresarial, ofrecemos fórmulas adecuadas para el desarrollo del espíritu y la capacidad del emprendedor, y para la implicación personal en la construcción social. Igualmente, mediante el trabajo asociativo o cooperativo, contribuimos a la cohesión e inserción social, a través de la integración laboral y social de las personas y grupos en riesgo de exclusión (como es el caso de mi organización, «la ONCE y su fundación», que trabaja en la integración social y laboral de las personas con discapacidad) o donde convenga el enraizamiento territorial de la población, evitando migraciones internas o impulsando la integración social de inmigrantes.

5. Antes de finalizar permitidme una última reflexión. Al haberme centrado tanto en Europa algunos estaréis pensando que todo esto queda muy lejos. Sin embargo, nada más lejos de la realidad. El trabajo de concienciación de nuestros políticos y de lobbying que hagamos día a día a nivel local y regional puede marcar las diferencias. Ahí está el caso de An- 
dalucía, que es puesto como ejemplo a nivel europeo y en el que se están inspirando otras regiones europeas. Aunque a los que estamos en Bruselas nos corresponde presionar a nivel europeo (utilizando lo que los anglosajones denominarían un top-down approach), el enfoque desde abajo, esto es desde las regiones (o bottom-up approach), puede ser tanto o más efectivo. En cualquier caso, ambos son complementarios. El hecho de que España vaya a asumir la presidencia de la UE en el primer semestre de 2010 hace este enfoque aún más necesario. Si convencemos al gobierno español de hacer de la Economía Social una de sus prioridades habremos conseguido un gran avance. Desde CEPES ya lo estamos intentando con el gobierno central. Toda la presión que se pueda añadir desde las comunidades autónomas es un plus. Por lo tanto, yo os animo a que desde Aragón contribuyáis con vuestro granito de arena a que así sea. Muchas gracias. 



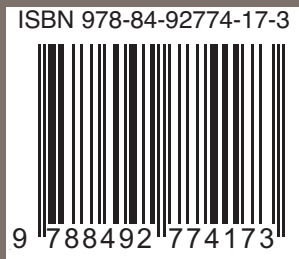

\section{Organizan}

\section{einaem}

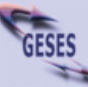

\section{CGOBIERNO}

\section{Departamento de Presidencia}

Universidad de
Zaragozo

A arei

Coordinadora

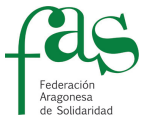

Colabora 300e?

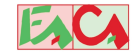

FEDERACIÓN ARAGONESA
DE COOPERATIVAS AGRARIAS

Red aragonesa de inclusion

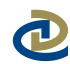

Asociación Española de Fundaciones

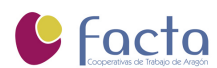
reac

RED DE ECONOMIA ALTERNATIVA Y SOLIDARIA
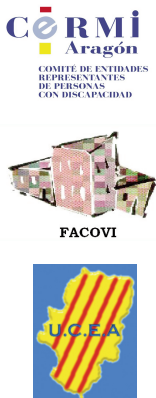